University of Tennessee Health Science Center

UTHSC Digital Commons

\title{
Self-Efficacy, Physical Activity, and Aerobic Fitness in Middle School Children: Examination of a Pedometer Intervention Program
}

Dana M. Manley

University of Tennessee Health Science Center

Follow this and additional works at: https://dc.uthsc.edu/dissertations

Part of the Health Services Research Commons, and the Pediatric Nursing Commons

\section{Recommended Citation}

Manley, Dana M. , "Self-Efficacy, Physical Activity, and Aerobic Fitness in Middle School Children: Examination of a Pedometer Intervention Program" (2008). Theses and Dissertations (ETD). Paper 164. http://dx.doi.org/10.21007/etd.cghs.2008.0198. 


\title{
Self-Efficacy, Physical Activity, and Aerobic Fitness in Middle School Children: Examination of a Pedometer Intervention Program
}

\begin{abstract}
The purpose of this study was to examine the relationships among self-efficacy levels, physical activity, aerobic fitness, and body composition (relative body mass index; RBMI) and to determine whether a school-based pedometer intervention program would improve those variables and prevent weight gain in sixth and seventh graders in rural mid-South middle schools. Bandura's Social Cognitive Theory served as the theoretical basis for the study.Methods: A quasi-experimental pre-test, post-test design was used. The sample, recruited from two rural middle schools in Kentucky, consisted of 116 sixth and seventh grade students ( $98 \%$ Caucasian, $51 \%$ male, age $=11.65 \pm 0.71)$. Anthropometric assessment of height, weight, body mass index (BMI), BMI percentile ranges, and RBMI were conducted. Physical activity levels were assessed using Digiwalker 200 pedometers and aerobic fitness levels were assessed using the one mile walk test. The Physical Activity Self-Efficacy scale was used to measure self-efficacy levels in participants and parental support of physical activity was assessed using the Amherst Health and Activity Survey. The intervention program consisted of students wearing a pedometer during the school day and participating in 10 minutes of physical activity beyond their usual activities at school. Data were analyzed using descriptive statistics, Pearson's correlation coefficient, and repeated measures ANOVA. Results: Aggregate baseline data revealed a mean self-efficacy score of 14.9; physical activity level of 10181.41 steps/day; aerobic fitness level (VO2max) of $49.4 \mathrm{ml} / \mathrm{kg} / \mathrm{min}$, BMl of 21.84 , with $56.9 \%$ of students classified in the healthy weight range, $13.8 \%$ as overweight, and $29.3 \%$ as obese. Only $19 \%$ of students meet recommended physical activity levels. Weakly positive correlations between self-efficacy and physical activity $(r=0.269, p=0.004)$ and self-efficacy and aerobic fitness $(r=0.236, p=0.013)$ were found. A weakly correlated inverse relationship was revealed between self-efficacy and RBMI $(r=-0.243, p$ $=0.009)$. Physical activity was weakly correlated with aerobic fitness $(r=0.309, p=0.001)$, while a weak, negative correlation was found between physical activity and RBMI $(r=-0.361, p=0.000)$. Finally, aerobic fitness was weakly, inversely correlated with RBMI $(r=-0.493, p=0.000)$. Students in the intervention school $(n=55)$ were similar in ethnicity, gender, and age to the control group $(n=61)$. Physical education (PE) class participation was found to be a confounding variable in the study resulting in subgroup analysis of pre-post differences in outcome measures based on concomitant PE. There were no statistical differences between the intervention and control groups and between subjects within groups when analyzing outcome variables. Both groups exhibited a non-significant decrease in physical activity over the course of the study. Although not statistically significant, the intervention group had greater improvements in self-efficacy, aerobic fitness levels, and RBMI than the control group. Conclusion: These study results support the findings from other research regarding the high prevalence of overweight and low levels of physical activity in rural children. The use of the pedometers to promote physical activity, fitness, and self-efficacy proved to be a cost effective, easy to implement method. Additional research focusing on increasing diversity and sample size is warranted.
\end{abstract}

\section{Document Type}

Dissertation

\section{Degree Name}

Doctor of Philosophy (PhD)

\section{Program}

Nursing 
Research Advisor

Patricia Cowan, $\mathrm{PhD}$

\section{Keywords}

Self-efficacy; physical activity; aerobic fitness; body composition; middle school children; pedometer

\section{Subject Categories}

Health Services Research | Medicine and Health Sciences | Nursing | Pediatric Nursing 
SELF-EFFICACY, PHYSICAL ACTIVITY, AND AEROBIC FITNESS IN MIDDLE SCHOOL CHILDREN: EXAMINATION OF A PEDOMETER INTERVENTION PROGRAM

\author{
A Dissertation \\ Presented for \\ The Graduate Studies Council \\ The University of Tennessee \\ Health Science Center
}

In Partial Fulfillment

Of the Requirements for the Degree

Doctor of Philosophy

From The University of Tennessee

By

Dana Manley

May 2008 
Copyright (C) 2008 by Dana Manley

All rights reserved 


\section{DEDICATION PAGE}

This dissertation is dedicated to my husband, Christopher T. Manley

and my children,

Kyle and Michaela Manley

for their continuous support, encouragement, and unconditional love.

1 Timothy 1:17 


\section{ACKNOWLEDGEMENT}

The author would like to express sincere appreciation and gratitude to Dr. Patricia A. Cowan for serving as mentor and for providing continuous direction, guidance, and encouragement throughout the process. Her expertise and assistance has been fundamental to the completion of this project and to the professional growth of this author. The author also acknowledges the valuable contributions and support provided by committee members; Dr. Carolyn Graff, Dr. Michael Perlow, Dr. Pamela Rice, Dr. Phyllis Richey, and Dr. Zoila Sanchez.

Additionally, the author would like to express appreciation to her family for their encouragement and tolerance throughout the process. Also, thanks to her parents for serving as wonderful role models and encouragers of education.

The author wishes to express appreciation to her fellow classmates for their unconditional support and encouragement and a special thanks to Dr. Dina Byers and Mrs. Katy Garth. In addition, appreciation is extended to Mrs. Geneva Cooper, Dr. Marcia Hobbs, Dr. Elizabeth Blodgett, and to fellow faculty at Murray State University Department of Nursing for the words of encouragement, support, and friendship. Also, a special thanks to the principals, teachers, and students that assisted and participated in the project. All of these listed have been instrumental in achieving this accomplishment and the author extends the utmost appreciation.

Finally, the author would like to acknowledge grant support from the Nurses' Educational Funds, Margaret G. Tyson Scholarship, as this scholarship supported the implementation of the pedometer intervention. Also, the author would like to express appreciation to Murray State University Department of Nursing for travel support and to the College of Health Science and Human Services for purchasing technology to support the continuing education process. 


\begin{abstract}
The purpose of this study was to examine the relationships among self-efficacy levels, physical activity, aerobic fitness, and body composition (relative body mass index; RBMI) and to determine whether a school-based pedometer intervention program would improve those variables and prevent weight gain in sixth and seventh graders in rural mid-South middle schools. Bandura's Social Cognitive Theory served as the theoretical basis for the study. Methods: A quasi-experimental pre-test, post-test design was used. The sample, recruited from two rural middle schools in Kentucky, consisted of 116 sixth and seventh grade students $(98 \%$ Caucasian, $51 \%$ male, age $=11.65 \pm 0.71)$. Anthropometric assessment of height, weight, body mass index (BMI), BMI percentile ranges, and RBMI were conducted. Physical activity levels were assessed using Digiwalker 200 pedometers and aerobic fitness levels were assessed using the one mile walk test. The Physical Activity Self-Efficacy scale was used to measure self-efficacy levels in participants and parental support of physical activity was assessed using the Amherst Health and Activity Survey. The intervention program consisted of students wearing a pedometer during the school day and participating in 10 minutes of physical activity beyond their usual activities at school. Data were analyzed using descriptive statistics, Pearson's correlation coefficient, and repeated measures ANOVA. Results: Aggregate baseline data revealed a mean self-efficacy score of 14.9; physical activity level of $10181.41 \mathrm{steps} /$ day; aerobic fitness level (VO2max) of $49.4 \mathrm{ml} / \mathrm{kg} / \mathrm{min}$, BMI of 21.84 , with $56.9 \%$ of students classified in the healthy weight range, $13.8 \%$ as overweight, and $29.3 \%$ as obese. Only $19 \%$ of students meet recommended physical activity levels. Weakly positive correlations between self-efficacy and physical activity ( $\mathrm{r}$ $=0.269, p=0.004)$ and self-efficacy and aerobic fitness $(r=0.236, p=0.013)$ were found. A weakly correlated inverse relationship was revealed between self-efficacy and RBMI $(r=-0.243, p=0.009)$. Physical activity was weakly correlated with aerobic fitness $(\mathrm{r}=0.309, \mathrm{p}=0.001)$, while a weak, negative correlation was found between physical activity and RBMI $(r=-0.361, p=0.000)$. Finally, aerobic fitness was weakly, inversely correlated with RBMI $(r=-0.493, p=0.000)$. Students in the intervention school $(n=55)$ were similar in ethnicity, gender, and age to the control group $(n=61)$. Physical education (PE) class participation was found to be a confounding variable in the study resulting in subgroup analysis of pre-post differences in outcome measures based on concomitant PE. There were no statistical differences between the intervention and control groups and between subjects within groups when analyzing outcome variables. Both groups exhibited a non-significant decrease in physical activity over the course of the study. Although not statistically significant, the intervention group had greater improvements in self-efficacy, aerobic fitness levels, and RBMI than the control group. Conclusion: These study results support the findings from other research regarding the high prevalence of overweight and low levels of physical activity in rural children. The use of the pedometers to promote physical activity, fitness, and self-efficacy proved to be a cost effective, easy to implement method. Additional research focusing on increasing diversity and sample size is warranted.
\end{abstract}




\section{TABLE OF CONTENTS}

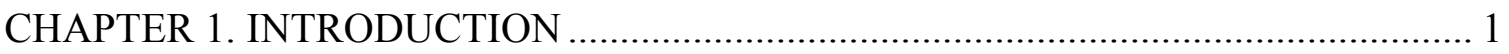

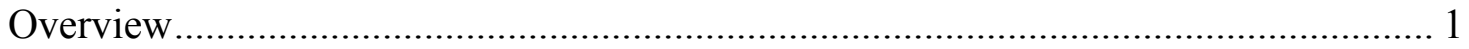

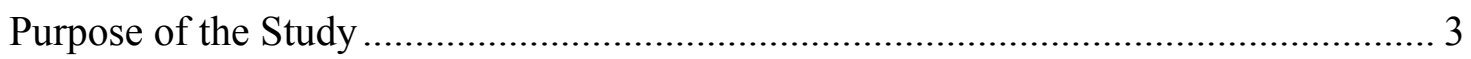

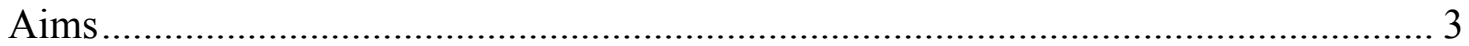

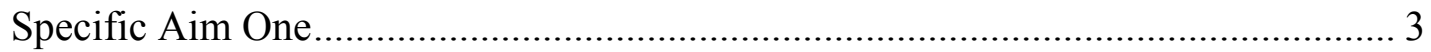

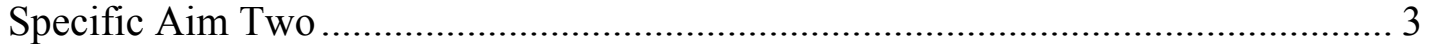

Significance of the Study ....................................................................................... 3

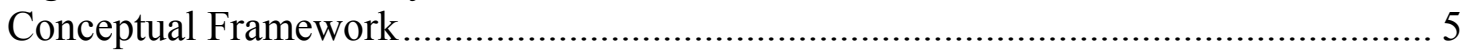

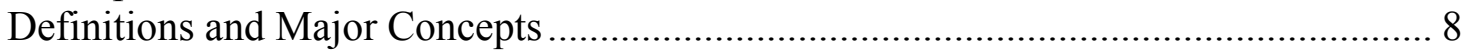

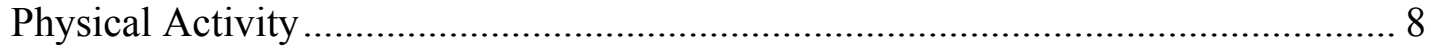

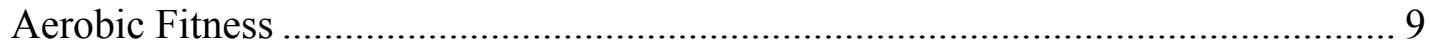

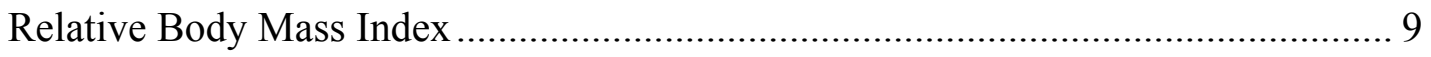

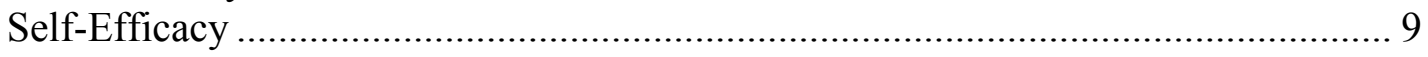

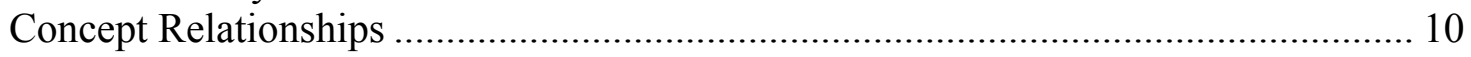

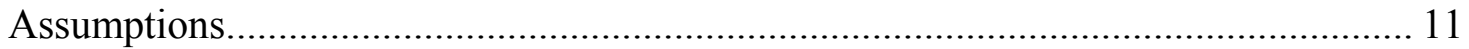

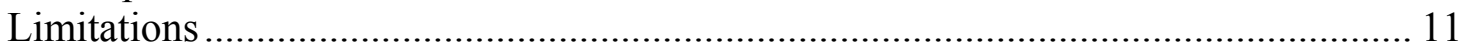



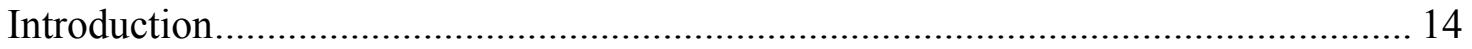

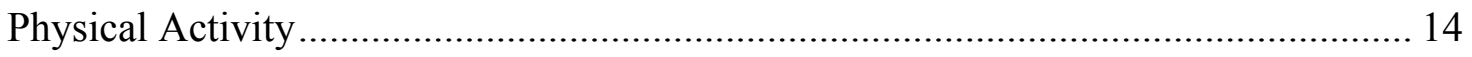

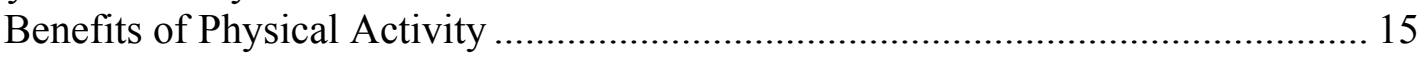

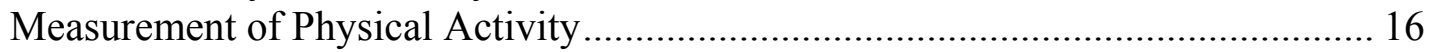

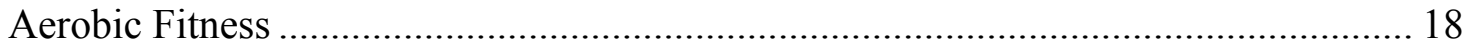

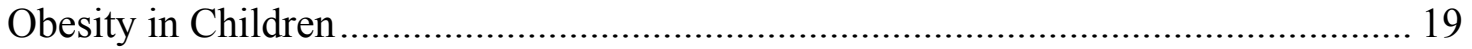

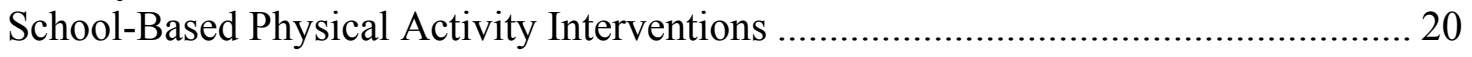

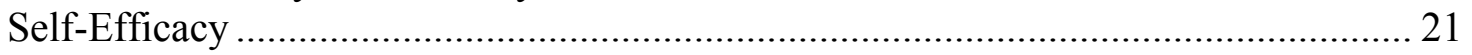

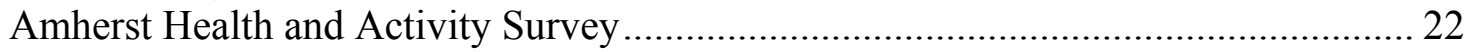

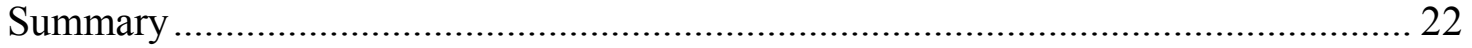

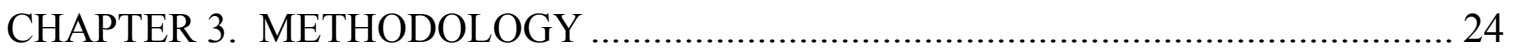

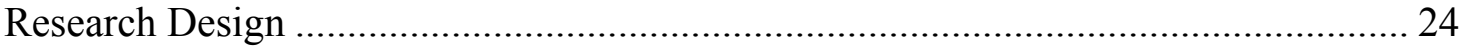

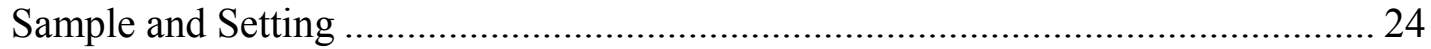

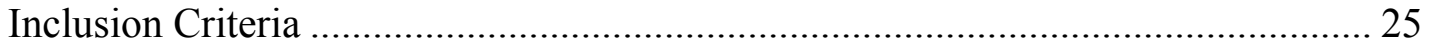

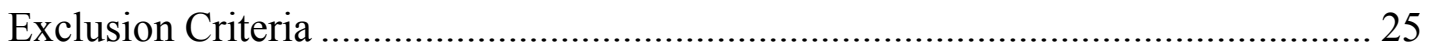

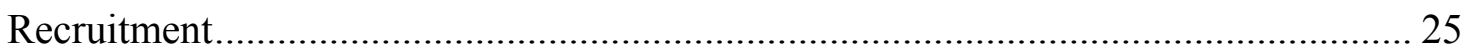

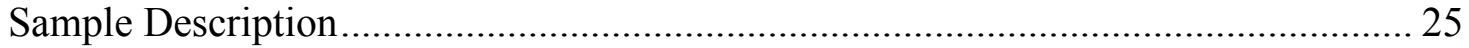

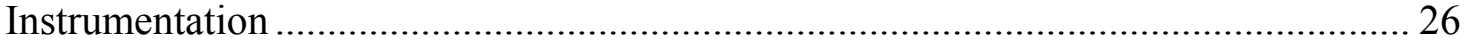

Anthropometric Assessment ......................................................................... 26

Relative Body Mass Index (RBMI) ............................................................... 26

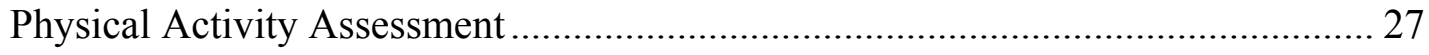

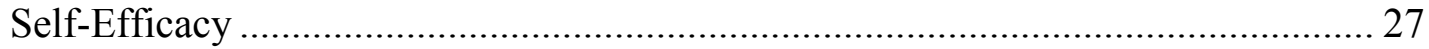


Aerobic Fitness Assessment ………………………….................................... 27

Amherst Health and Activity Survey ……………….......................................... 28



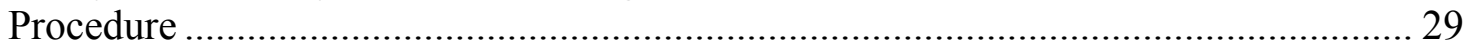

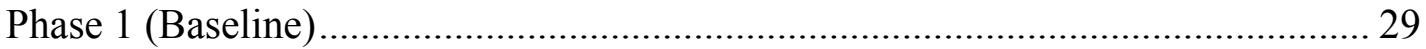

Anthropometric Measurement ……………………......................................... 29

Physical Activity Levels ................................................................................ 29

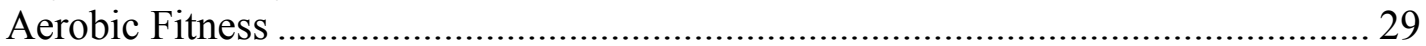

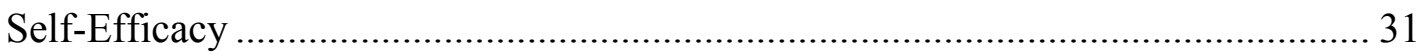

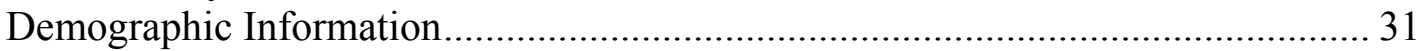

Amherst Health and Activity Survey .................................................................. 31

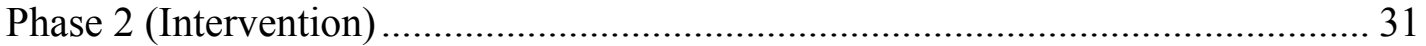

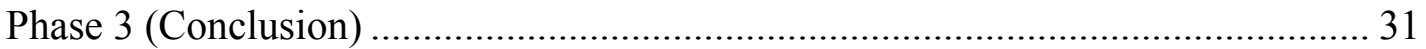

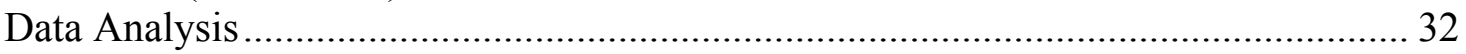

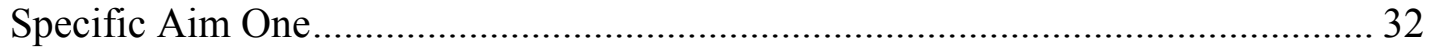

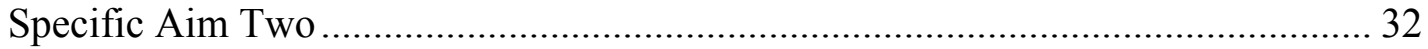

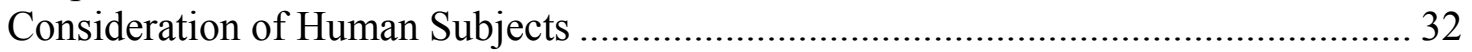

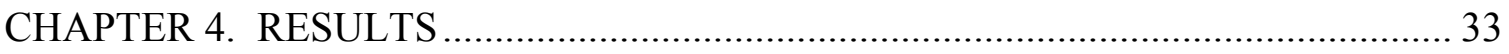

General Sample Description ..................................................................................... 33

Specific Aim One-Correlations Among Self-Efficacy Levels,

Physical Activity, Aerobic Fitness, and Body Composition ......................................... 33

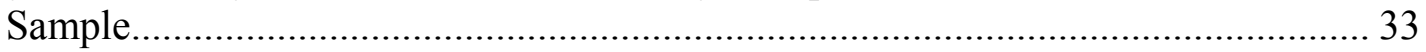

Description of the Total Group's Self-Efficacy, Physical Activity,

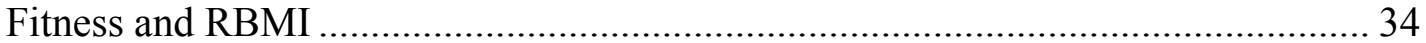

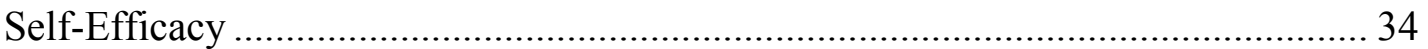

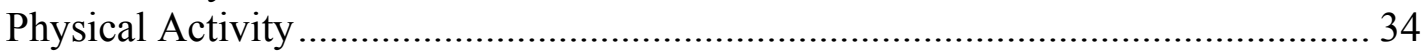

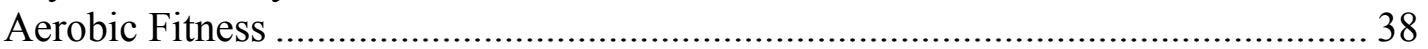

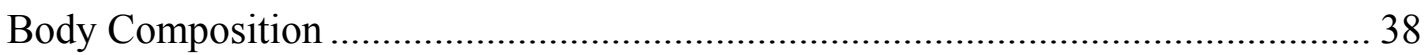

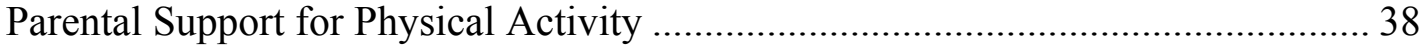

Results of Correlational Analysis ............................................................................. 39

Specific Aim Two-Effect of the Pedometer Intervention Program on Outcomes ..... 39

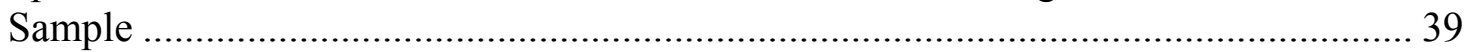

CHAPTER 5. DISCUSSION, IMPLICATIONS, AND CONCLUSIONS ..................... 51

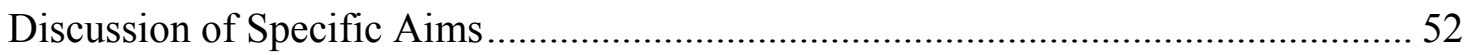

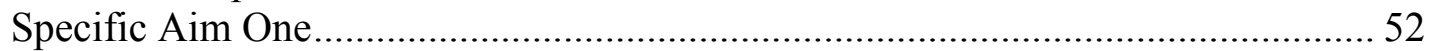

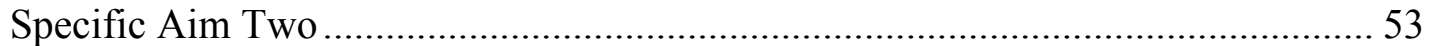

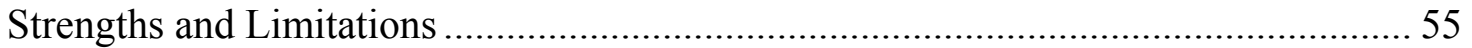

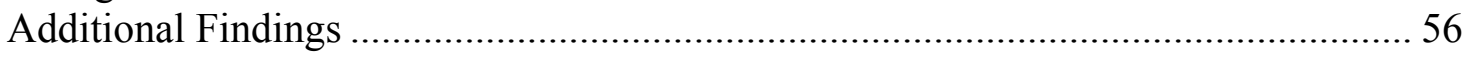

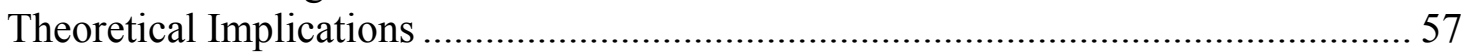

Clinical Practice Implications ................................................................................... 57

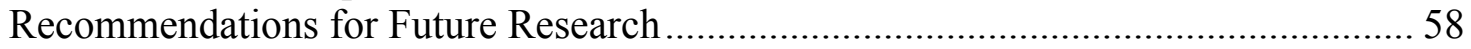

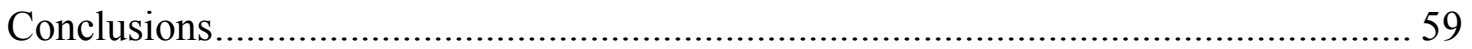




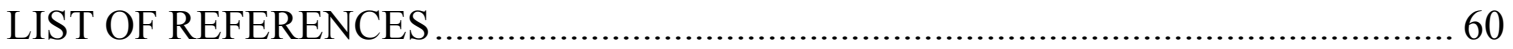

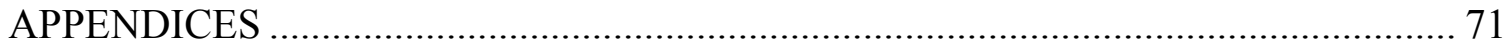

Appendix A. Amherst Health and Activity Survey .............................................. 72

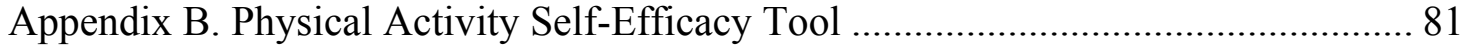

Appendix C. Institutional Review Board Approval Letter .................................... 83

Appendix D. Informed Consent Form ..................................................................... 84

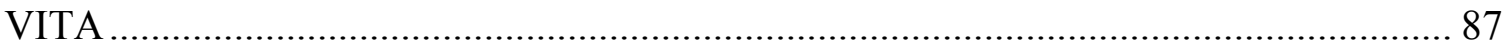




\section{LIST OF TABLES}

Table 3-1. Variables and Measurement Tools or Source Used for Data

Collection.

Table 4-1. Demographic Characteristics of Total Study Participants................35

Table 4-2. Baseline Measures of Self-Efficacy, Physical Activity, Aerobic Fitness and Body Composition in Middle School Children......................36

Table 4-3. Baseline Measures of Self-Efficacy, Physical Activity, Aerobic Fitness and Body Composition by Gender in Middle School Children............37

Table 4-4. Correlational Analysis Among Self-Efficacy, Physical Activity, Aerobic Fitness and RBMI.

Table 4-5. Demographic Characteristics of Control School Participants by PE Group.

Table 4-6. Demographic Characteristics of Intervention School Participants by PE Group.

Table 4-7. Summary of ANOVA Findings between Groups........................44

Table 4-8. Mean Results of Outcome Variables...............................45

Table 4-9. Demographic Characteristics of Control School and Intervention School Participants Who Were Not Enrolled in Concomitant PE Class.

Table 4-10. Results of Repeated Measure-ANOVA for Study Outcomes Following Completion of the 12 Week Intervention.

Table 4-11. Mean Results of Outcome Variables in Participants Who Were Not Enrolled in Concomitant PE Class 


\section{CHAPTER 1. INTRODUCTION}

\section{Overview}

Physical inactivity has been identified by the American Heart Association as one of the five leading risk factors for cardiovascular disease (Cardinal, 1999). Decreased physical activity levels are associated with increased adiposity, which in turn, increases the risks for cardiovascular disease and metabolic disorders (Aggoun, 2007). These conditions once seen primarily in adults are now affecting children and adolescents.

Lifestyle and behavioral factors, such as daily physical activity, play a role in the etiology and prevention of chronic disease, including cardiovascular disease, diabetes, and obesity (Hardin, Hebert, Bayden, Dehart, \& Mazur, 1997; Rowlands, Eston, \& Ingledew, 1999; Strong, et al., 2005). Unfortunately, since 1999 the prevalence of physical inactivity among youth has risen from $30.5 \%$ to $33.4 \%$ in 2003 (Grunbaum et al., 2004.). In fact, it is estimated that 20 to $50 \%$ of adolescents do not participate in adequate amounts of physical activity (Grunbaum et al., 2004). Vincent, Pangrazzi, and Raustorp report that United States children age 6-12 years old were less physically active and had higher body mass index (BMI) compared to Swedish and Australian children (2003).

Physical inactivity has been found to be more prevalent among certain population groups. These groups include: females, ethnic minorities, low income children, children living in rural areas, children with disabilities, and those children living in public housing or environments lacking safe play areas (Centers for Disease Control, 2003; Hoos, Gerver, Kester, \& Westerterp, 2003; Pratt, Macera, Blanton, 1999; Sallis, Prochaska, \& Taylor, 2000; United States Department of Health and Human Services, 2001). Evidence suggests that physical activity begins to decrease in early adolescence and progressively declines as students enter high school and the pattern continues into adulthood (Grunbaum et al., 2004). For these reasons, increasing physical activity levels in youth is a Healthy People 2010 priority (U.S. Department of Health and Human Services, 2004). Interventions that increase physical activity in the early adolescent population are essential to improve the health status of young Americans.

A major concern of diminished physical activity levels in children is the associated increased BMI (Berkey, Rockett, Gillman, \& Colditz, 2003). In the United States obesity has been shown to be a leading contributing factor of a multitude of health problems. Although the causes of obesity are multifaceted, a strong association has been found between decreased physical activity levels and increased BMI in children and adolescents (Roberts, 2000). Findings from recent studies suggest that the prevalence of obesity in school children aged 6-11 has doubled and the prevalence in adolescents aged 12-19 has tripled in the last thirty years (National Center for Health Statistics, 2000). More recent data support these findings and conclude the prevalence of obesity in female children and adolescents has increased from $13.8 \%$ in $1999-2000$ to $16.0 \%$ in $2003-2004$ 
(Ogden et al., 2006). In male children and adolescents the prevalence has also increased from $14.0 \%$ to $18.2 \%$ (Ogden et al., 2006).

Increasing physical activity in this population has been associated with a variety of positive outcomes. Overweight adolescents participating in physical activity have demonstrated reductions in triglyceride and glucose levels, decreased insulin resistance, and reduction of blood pressure in those with mild essential hypertension (Hardin et al., 1997). Children participating in regular physical activity have lower adiposity; thus, reducing the risks of cardiovascular disease (Rowlands et al., 1999). Furthermore, physical activity in healthy weight and obese school-age youth is associated with lower rates of depression, anxiety, and improved self-concept (Strong et al., 2005). Improved self-concept leads to improved self-efficacy. Mauriello, Driskell, Sherman, et al. define self-efficacy as "the degree to which an individual believes he or she has the ability to perform the behavior change in various tempting situations" (2006, p. 271). Research reveals physical self-efficacy or physical activity confidence as being one of the most influential correlates of physical activity in the adolescent population (Dishman, Motl, Saunders, et al., 2004, 2005; Sallis, Prochaska, \& Taylor, 2000). Improving self-efficacy has the potential to positively influence change and improve physical activity in this population.

An effectively designed intervention program is essential for successful outcomes. The majority of an adolescent's time is spent in the school setting; therefore, school based programs facilitate inclusion of a large proportion of this population. Studies support the efficacy of school based intervention programs to increase physical activity during structured physical education classes and improve fitness in children (Carrel et al., 2005; Luepker et al., 1996; Sallis et al., 2003).

Pedometers have been utilized in several school based intervention programs. The programs using pedometers in school aged children have primarily focused on using them as a measurement tool of physical activity and not as an intervention (Oliver, 2006; Pangrazi et al., 2003; Scruggs et al., 2003). One study conducted in Australia examined the effectiveness of using pedometers to increase physical activity in inactive Australian, high school girls (Schofield, Mummery, \& Schofield, 2005). Findings from the 12 week intervention study revealed increased step counts in both pedometer and minute groups (Schofield et al.). Conclusions from this study suggest that the use of a pedometer may be motivational in increasing moderate and vigorous physical activity levels (Schofield et al.). A recent study examined the impact of pedometer use on daily step counts in elementary school children (Butcher, Fairclough, Stratton, \& Richardson, 2007). The study concluded that short term daily pedometer step counts increased in a group receiving physical activity information and step-count feedback (Butcher et al.) Additional research in this area is warranted, as cost-effective interventions that promote physical activity both in the school setting and community are needed. 


\section{Purpose of the Study}

The purpose of this study was to determine whether a school-based pedometer intervention program would improve self-efficacy levels, physical activity, aerobic fitness, and prevent weight gain in sixth and seventh graders of a rural Kentucky middle school. The central hypothesis of this proposal is that a 12 -week pedometer intervention program will increase self-efficacy, physical activity, aerobic fitness, and maintain relative body mass index (RBMI) in the middle school children of the treatment group, receiving the physical activity intervention versus the control group not receiving the intervention.

\section{Aims}

\section{Specific Aim One}

The relationships among self-efficacy levels, physical activity, aerobic fitness, and body composition, expressed as relative body mass index (RBMI) in Kentucky middle school children were examined. It was hypothesized that:

1a. Self-efficacy levels would be positively associated with physical activity and aerobic fitness.

1b. Self-efficacy, physical activity, and aerobic fitness would be inversely associated with body composition (RBMI).

\section{Specific Aim Two}

The effect of a 12 week intervention program on self-efficacy, physical activity levels, aerobic fitness, and RBMI in the intervention group (School 1) compared the control group (School 2) was evaluated. It was hypothesized that:

2a. Self-efficacy, physical activity levels, and aerobic fitness would increase in middle school children who participate in the treatment compared to the control group.

2b. RBMI would decrease or be maintained in the treatment compared to the control group.

\section{Significance of the Study}

Presently, national objectives are focusing on improving the amount of youth physical activity (United States Department of Health and Human Services, 2000). The 
first is to increase the proportion of adolescents to $35 \%$ or greater that participate in moderate physical activity at least 30 minutes for 5 out of 7 days (objective number 22-6) and the second is to increase the proportion of adolescents that engage in vigorous physical activity that promotes cardio-respiratory health for at least 20 minutes three times a week to $85 \%$ or greater (objective number 22-7) (United States Department of Health and Human Services, 2004). With only two years left to achieve these objectives, the United States is falling short. A recent study conducted by the Centers for Disease Control (CDC), revealed that $61.5 \%$ of children aged $9-13$ years of age do not participate in any structured physical activity outside of school hours (2003). Physical activity begins to decline in early adolescence and often continues into adulthood (Sallis et al., 2000). Schools offer an excellent environment for targeting physical activity intervention programs, as children spend a majority of their weekday time in the school setting (Hills, King, \& Armstrong, 2007). Therefore, intervention programs that are aimed at maintaining or increasing physical activity in middle school children are important.

The prevalence of overweight and obese children and adolescents continues to increase. The prevalence of obese female children and adolescents has increased from $13.8 \%$ in $1999-2000$ to $16.0 \%$ in 2003-2004 (Ogden, 2006). Male children and adolescents have also seen an increase in obesity statistics from 14.0\% in 1999-2000 to $18.2 \%$ in 2003-2004 (Ogden). Kentucky statistics are staggering with averages above those of national averages. It is estimated that $20.6 \%$ of Kentucky children aged $10-11$ are classified as obese compared to the national average of $14.8 \%$ (United States Department of Health and Human Services, 2005). The rate of obesity in Kentucky adolescents aged $12-14$ is $29.7 \%$ compared to the national average of $21.9 \%$ (United States Department of Health and Human Services). Physical inactivity and diminished aerobic fitness has been directly linked to obesity in children (Rowlands et al., 1999). Pedometer studies used in school aged children have primarily focused on the measurement of physical activity (Oliver, 2006; Pangrazi et al., 2003; Scruggs et al., 2003). A study conducted in the United Kingdom used pedometers to assess step counts and provided feedback of those steps with physical activity information to elementary aged school children (Butcher, 2007). Children were divided into an information and feedback group, a feedback only group, and a control group. The study concluded that pedometer step counts increased the most in the feedback and information group (Butcher et al.) To the knowledge of this author, there have been no studies conducted in the United States focusing on evaluating the pedometer as an intervention tool in school aged children.

The proposed study will make a significant contribution to the body of knowledge regarding school-based interventions using pedometers as a tool to improve self-efficacy, physical activity, aerobic fitness, and prevent weight gain in middle school students. Minimal research examining the use of pedometers as an intervention tool in school-aged children exists. The proposed program provides a cost effective intervention that is easy to implement. Highly trained personnel are not required to implement the program. The program has the potential to be adapted to all middle school children and has broad applicability. Evidence based intervention programs are necessary to improve the health of this population. 
The study will also provide additional information regarding the physical activity and aerobic fitness levels of middle school children and will examine the relationship between these variables. Present research, has revealed weak to moderate positive relationships between physical activity and aerobic fitness in children (Dencker, Thorsson, Karlsson, 2006; Rowlands et al., 1999). Additional research is necessary to better understand this association.

\section{Conceptual Framework}

Lifestyle and behavioral factors, such as daily physical activity, play a role in the etiology and prevention of chronic disease, including cardiovascular disease, diabetes, and obesity (Hardin et al., 1997; Rowlands et al., 1999; Strong et al., 2005). Unfortunately, since 1999 the prevalence of physical inactivity among youth has risen from $30.5 \%$ to $33.4 \%$ in 2003 (Grunbaum, et al., 2004). Identifying effective interventions that are theoretically based are essential to create change in this disastrous trend. Human behavior is complex, making change complicated. Effective interventions must incorporate strategies that address educational and behavioral perspectives (Allen, 2004). The proposed study investigates the effect of a pedometer and physical activity intervention on self-efficacy, physical activity, aerobic fitness, and RBMI in middle school children. The Social Cognitive Theory provided the conceptual framework for this intervention study.

The Social Cognitive Theory exists to describe behavior in human beings. The relationship between environment, behavior, and personal factors are used to define the interaction of the phenomenon (Bandura, 1986). The theory consists of a reciprocal triad consisting of person-behavior, environment-behavior, and environment-person (Pajares, 2002). The interaction between behavior, personal factors, consisting of thoughts, feelings, and biologic characteristics, and both physical and social environment are key components of the theory.

Other constructs inherent to this theory consists of the ideas that human beings are equipped with specific capabilities (Pajares, 2002). These capabilities are described by Bandura as symbolizing, vicarious forethought, self-regulatory, and self-reflection systems (1986). The early capabilities are basic skills of language, communication, and observation. The key concept meshed in the later capabilities is self-efficacy. Bandura defines self-efficacy as "people's judgments of their capabilities to organize and execute courses of action required to attain designated types of performances" (1986, p.391). Self-efficacy strongly influences self-motivation and self-reflection; thus, influencing behavioral changes (Pajares).

The Social Cognitive Theory has been used in a variety of behavioral science research. Cole, Waldrop, D’Auria, and Garner (2006) reviewed ten school-based intervention studies and concluded that eight of the ten studies used the Social Cognitive Theory as a conceptual guide. Furthermore, they concluded that the Social Cognitive successful interventions with children" (Cole et al., 2006, p. 175). 
Social Cognitive Theory incorporates the concept of modeling as an important tool for behavior change (Cole et al., 2006). For the purposes of this study, modeling is achieved through the practice of physical activity and daily pedometer use. The underlying premise of this study incorporated the concept of modeling combined with positive peer influences to help increase self-efficacy levels in this population.

Self-regulation is an important concept used in the Social Cognitive Theory "that incorporates self-reflection and self-evaluation of behaviors" (Cole et al., 2006, p. 176). The use of the pedometer provided the children an opportunity to monitor physical activity levels. Generalized goals were given to the children based on literature findings in an attempt to increase physical activity levels. Monitoring physical activity levels provided an evaluation tool and opportunity for children to examine and reflect on their individual outcomes.

This study incorporated the components of the Social Cognitive Theory and applied them to study variables. Each student participant had their own unique cognitive abilities and their attitudes and feelings about physical activity. Inclusion criteria included children with the cognitive ability to understand and follow directions. The Physical Activity Self-Efficacy Scale was used to assess the attitude and feelings each participant possessed regarding physical activity. Biological factors of gender and age were assessed.

The study utilized the school gym and the use of pedometers to be physical environmental factors influencing physical activity in this population. Furthermore, the use of an extra ten minute physical activity time was an environmental piece influencing outcomes. Finally, teachers and peers were social environmental factors that had the potential to influence the behavior of these student participants.

The behavior consisted of the physical activity intervention combined with personal and environmental factors. Collectively, these factors influence one another. This concept enhances the understanding that physical activity behavior is a complex triad and that participation in it is influenced by a variety of factors. The conceptualization of the study variables applied to the theory concepts is displayed in Figure 1-1.

In summary, the Social Cognitive Theory provided the conceptual framework for this study. Behavior, personal factors, and environmental factors were relevant key constructs of the theory that provided direction for this study. Furthermore, the use of modeling and self-regulation provided the participants the opportunity to practice a skill and evaluate the outcomes of the activity. 
Person

Cognition

Affect

(Self-Efficacy)

Biological factors

(Age, gender)
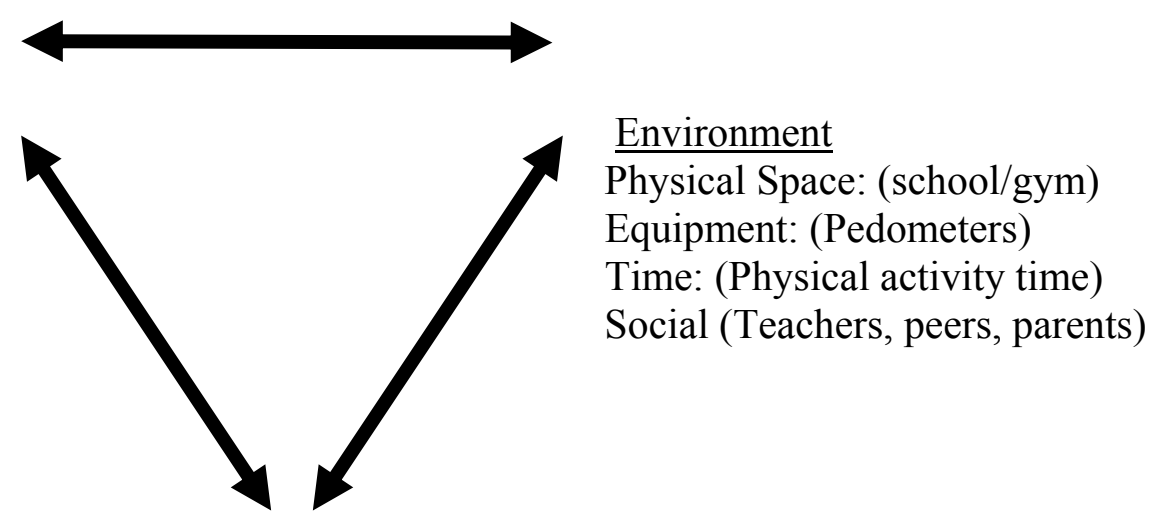

Physical Activity Behavior

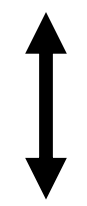

Aerobic Fitness and Relative Body Mass Index

Figure 1-1. Application of the Social Cognitive Theory to Physical Activity, Aerobic Fitness and RBMI in Middle School Children. Source: From Pajares, F. (2002). Overview of social cognitive theory and of self-efficacy. Retrieved October 28, 2006 from http://www.emory.edu/EDUCATION/mfp/eff.html. Modified with permission. 


\section{Definitions and Major Concepts}

\section{Physical Activity}

Physical activity consists of any movement of the body that results in energy expenditure (Caspersen, Powell, \& Christenson, 1985). Physical activity can be defined by types; including, mechanical classifications of isometric, static, isotonic, or dynamic movement and metabolic classifications of aerobic or anaerobic processes (Haskell \& Kiernan, 2000). Energy expenditure is a result of physical activity and correlates closely with physical fitness levels that may vary from low to high levels (Caspersen et al).

Doubly labeled water method is the gold standard to measure energy expenditure; however, the method is expensive and requires a minimum of 3 days to receive results (Zhang, Pi-Sunyer, \& Boozer, 2004). Other methods include heart rate monitors, accelerometers, self-reports, and pedometers. Heart rate monitors provide direct measurement of cardiovascular effect and have established reliability for long term use (Bjornson, 2005). Disadvantages to the use of heart rate monitoring include the expense and time associated with the method. Other disadvantages include the physiological changes of the heart rate in children, as children tend to have bursts of activity and heart rate monitors may mask the response. Heart rate monitoring in children, especially young children, is not a good indicator of physical activity (Rowlands, Eston, \& Ingledew, 1997).

Self-reports are associated with low cost and decreased participant burden; however, there is a major potential for errors in recall time or intensity of physical activity or misinterpretation and/or deliberate misinformation (Welk, Corbin, \& Dale, 2000). Accelerometers are advantageous as measurements of activity and intensity can be measured; however, the instruments require specific computer software packages and the expense of the unit is often not practical for use in large groups (Tudor-Locke, 2002).

Pedometers have the benefit of being cost effective, easy to use, and outcomes may be defined in steps, distance, and/or calories. Positive correlations have been established between heart rate and oxygen consumption in children wearing pedometers (Eston, Rowlands, \& Ingledew, 1998). Disadvantages include the inability to measure physical intensity levels and incorrect placement of the pedometer can result in inaccurate outcomes (Trost, 2001).

All physical activity measurements have pros and cons. Although pedometers do not have the ability to measure intensity, they have been found to be appropriate tools to measure physical activity in children (Rowlands, Eston, \& Ingledew, 1997). For that reason, pedometers have been chosen for use in this study. The Digiwalker 200 pedometer is reliable and valid for step measurement in school age populations (Beets \& Pitetti, 2004). Positive correlations $(\mathrm{r}=0.78)$ have been established between pedometer steps and oxygen uptake with treadmill walking using the Digiwalker 200 (Eston, Rowlands, \& Ingledew 1998.). 


\section{Aerobic Fitness}

Physical fitness consists of an array of characteristics that deal with skill and health (Molnar \& Livingstone, 2000). Physical fitness measures are defined often in terms used to define health related fitness, such as aerobic fitness, strength, endurance, flexibility, and body composition. All aspects of fitness are important; however, aerobic fitness assessments provide information directly related to cardiovascular health. For this reason, the measurement of aerobic fitness is the primary assessment tool used when conducting research of both adults and children (Haskell \& Kiernan, 2000).

There are a variety of aerobic fitness measurements. Maximal oxygen uptake $\left(\mathrm{VO}_{2} \max \right)$ is the gold standard measurement of aerobic fitness. Although a thorough measurement tool, the procedure requires special equipment and trained personnel in a controlled setting. This test is not practical for use in large settings related to the time consuming nature and expense involved with the testing. An alternative method that was utilized in this study is the one-mile walk test. The one-mile walk test has been identified as an appropriate assessment of aerobic fitness in children. Studies using this test in children age 8 and older have revealed reliability coefficients averaging above .80 (Cureton \& Plowman, 2001; McSwegin, Plowman, Wolff, and Guttenberg, 1998). An equation using the one-mile walk time, heart rate, gender, age, and weight was used to calculate an estimated maximal oxygen consumption $\left(\mathrm{VO}_{2} \max \right)$ (Kline, et al., 1987).

\section{Relative Body Mass Index}

Definitions of overweight and obesity in children have been debated over the years. Body mass index (BMI) is an adequate measure to assess the amount of body fat in children and adolescents (Dietz \& Bellizzi, 1999). Tracking BMI on age and genderspecific growth charts provides a practical method of assessing changes in adiposity over time relative to normative values. Overweight in children is defined as a BMI between the 85-95 percentile on age and sex specific growth charts, while a BMI greater than the 95 percentile on growth charts constitutes obesity (Anderson \& Butcher, 2006). Relative BMI, calculated as BMI divided by $50^{\text {th }}$ percentile on the BMI charts, provides a measure of overweight severity in children, facilitates longitudinal follow-up of overweight in youth, and allows comparisons across gender and age groups (Velasquez-Mieyer, PerezFaustillin, \& Cowan, 2005).

\section{Self-Efficacy}

Self efficacy is defined by Bandura, as "people's judgments of their capabilities to organize and execute courses of action required to attain designated types of performances" (1986, p.391). Research reveals self-efficacy or physical activity confidence as being one of the most influential correlates of physical activity in this population group (Dishman et al., 2004, 2005; Sallis, Prochaska, \& Taylor, 2000). Middle school students are viewed as being proactively engaged in their own 
development and exerting control over their thoughts, feelings, and actions. Behavior is shaped by the cognitive, affective, and biological factors of the person. The students' beliefs and feelings about themselves influence their physical activity behavior. Reciprocally, the students' physical activity behaviors influence their self-efficacy.

The Physical Activity Self-Efficacy scale has been shown to be valid and reliable for use in children (Saunders et al., 1997). This scale consisted of 17 dichotomous items that assessed factors of support seeking, barriers, and positive alternatives (Saunders et al.). Reliability results reveal: (1) support seeking (Cronbach's alpha $=0.52$, test-retest reliability $=0.76)$; $(2)$ barriers (Cronbach's alpha $=0.55$, test-retest reliability $=0.82$ ); and $(3)$ positive alternatives $($ Cronbach's alpha $=0.62$, test-retest reliability $=0.61$ ) (Saunders et al.).

\section{Concept Relationships}

The Social Cognitive Theory provides a triad of reciprocal interactions consisting of personal, behavioral, and environmental factors (Bandura, 1986). The social cognitive theory provides a conceptual framework for changing physical activity (behavior) in middle school students. Behavior change results from the dynamic interplay of the person, behavior, and the environment (Bandura). Interactions between the variables; physical activity behavior, environment, and person explain the theory outcomes (Pajares, 2002).

Behavior involves the actions of the individual. The environment includes physical and social factors. Person encompasses cognitive, affective, and biological factors. One measure of affect is self-efficacy. Self-efficacy refers to the belief in one's ability to undertake actions required to achieve a goal. Self-efficacy strongly influences self-motivation and self-reflection; thus, influencing behavioral changes (Pajares, 2002). Research reveals physical self-efficacy or physical activity confidence as being one of the most influential correlates of physical activity in the adolescent population (Dishman, Motl, Saunders, Felton, Ward, \& Dowda, 2004, 2005; Sallis, Prochaska, \& Taylor, 2000).

Increasing physical activity in middle school children is essential. Evidence suggests that physical activity begins to decrease in early adolescence and progressively declines as students enter into high school and the pattern continues into adulthood (Grunbaum et al., 2004). The Social Cognitive Theory provides a holistic approach when applied to this population. Middle school students are viewed as being proactively engaged in their own development and exerting control over their thoughts, feelings, and actions. Behavior is shaped by the personal factors of cognition, affective, and biological characteristics of the student. The students' beliefs and feelings about themselves influence their physical activity behavior. Reciprocally, the students' physical activity behaviors influence that student.

The environment includes physical and social factors that can affect physical activity behavior. The physical environment includes equipment, and time and space to 
engage in physical activity in the school, home, and community. Schools provide an environment that can promote healthful behavior for children and can reach a large population (Hayman, et al., 2004). Teachers, classmates, and family are aspects of the social environment that influence physical activity participation. Peers and teachers participating in the program have the potential to positively impact the program and influence others. Additionally, parents or other caregivers will be assessed regarding their involvement and encouragement of physical activity with study participants through the Amherst Health and Activity Survey. Thus, the environment may serve as source of support for physical activity by providing opportunity and resources for the behavior, models for the behavior, and social support. Additionally, students' behavior determines aspects of their environment and the person contribute to the development of new expectations and beliefs (self-efficacy), cognitive competencies of the person, evoke reactions within the environment.

\section{Assumptions}

The following assumptions were made for the purpose of the study:

1. Increases in physical activity over a 12 -week period improve physical fitness in children.

2. Self-efficacy is a construct that can be quantified using self-report instruments.

3. Participants honestly and conscientiously complete self-report questionnaires.

4. Participants actively participate and put forth their best effort in the intervention program.

5. Participants use the pedometer appropriately and maintain correct placement.

6. Teachers will assist with program implementation.

\section{Limitations}

There are a few potential limitations that can be identified in this study. Potential threats to the internal validity of this study include; the lack of randomization, history, maturation, attrition, instrumentation, and mortality. Threats to the external validity of this study consisted of novelty effects and interaction of history and treatment effect.

1. The lack of randomization is the first limitation to be addressed. Convenience sampling will result in a more homogenous sample that will lack randomization. The sample will consist predominately of Caucasian students from a rural area; therefore, the results may not be able to be generalized to all populations. However, the project has potential to be easily adapted to other populations. The 
ease of the project provides broad applicability of the intervention. Replication of this study in a more ethnically diverse school is a goal for future research.

2. History refers to the events that occur during a study that may influence the dependent variable (Polit \& Beck, 2004). Data collected in this study consisted of beginning and ending anthropometric, physical activity, aerobic fitness, and selfefficacy levels in participating students. The findings have the potential to be influenced by an array of other factors. The students will be wearing the pedometers for three days when baseline and conclusion physical activity levels are being assessed. There are a variety of factors that may influence the number of step counts that the pedometers will be measuring. Failure to wear the pedometer in the proper position or participation in activities that result in bouncing of the body (i.e. horseback riding, jumping rope, etc.) may result in inaccurate step counts. Students found to have a significant increase or decrease in the step count results will be questioned regarding their participation in activities. Inconsistent data will be excluded from data analysis.

It is recognized that history is major threat to internal validity in this study. There are a variety of external events that may occur along with the independent variable that could affect the dependent variables. It is impossible to control for these confounding variables; thus, this will serve as a limitation of the study.

3. Maturation is another threat to internal validity affecting this study. This study will collect beginning and ending anthropometric measurements in participating students. Maturation is naturally occurring in adolescent children; therefore, body mass index (BMI) changes may be related to normal physiologic growth and development. To account for this, relative body mass index (RBMI) which adjusts of BMI based on the $50^{\text {th }}$ percentile for age and gender will be used to address this threat.

4. Attrition poses a major limitation to the study as students may be absent or may fail to wear the pedometer during the data collection phase. If this occurs during the baseline data collection phase, students will be allowed to make-up the days during that week. If the absence extends over the scheduled baseline data collection week, the student will be eliminated from the study. Faculty and parents of participating students will encourage students to wear their pedometer appropriately.

5. The threat of instrumentation is another potential threat to internal validity. This threat is being addressed by administering the same pre and post test anthropometric, aerobic fitness, and self- efficacy measurements at the same time of the day in the same environment at both schools.

6. Mortality is another threat to internal validity related to this study. Absences from school and incorrect or inappropriate wearing of the pedometer may affect attrition of the study. For that reason, specific guidelines have been established to 
control for mortality. These guidelines include students being able to make-up baseline measurements during that week.

7. The novelty effect may occur when new situations are presented to the study population (Polit \& Beck, 2004). The study participants will be given a pedometer for use in the collection period. This could result in the participants increasing their number of daily steps. To account for the novelty effect, physical activity step counts were collected for four consecutive days with the initial day being excluded from step averages. This procedure was followed in both pre and post data collection periods.

8. An interaction of history and treatment effect may occur. As the study was conducted in a small, rural community, there was potential for cross contamination of subjects. Upon completion of the study, the control school will participate in the intervention program. This will be explained to faculty and students in the control school during the baseline data collection process. Thus, allowing for the control schools future participation in the intervention will minimize contamination.

9. A potential threat was related to the relatively short time frame of the study. The intervention period consisted of a minimum of 12 weeks combined with one week each of baseline and conclusion data; thus, the study was relatively short in duration. Given the short duration of the study, relatively small changes in anthropometric measures are likely and may not be detected. A goal of future research is to replicate the study using a longer intervention period.

10. Another limitation of the study is the concomitant physical activity that may occur during the course of the study. This physical activity may include outside sport participation, physical education class, and other community activities. A questionnaire will be utilized to identify those students participating in concomitant physical activity during the study. Statistical analysis will be used as a method to control for this confounding variable.

11. A final limitation of the study is the exclusion of the control school from a beneficial intervention. Upon the completion of this study, the control school will participate in the intervention. This will allow both schools to receive benefit from the pedometer intervention program. Goals of future research are aimed at replicating the intervention in the control school and examining the use of the pedometer post-intervention in the original intervention school. 


\section{CHAPTER 2. REVIEW OF LITERATURE}

\section{Introduction}

Obesity among children in the United States has reached epidemic proportions. Despite the growing data base that concludes the extreme risks associated with obesity in childhood, the problem continues to explode. There are several factors contributing to this epidemic with physical inactivity being an influencing variable. A substantial body of literature documents the benefits of physical activity and effective school-based intervention programs that have been successful in increasing physical activity in youth. The focus of this chapter will consist of describing the risks associated with obesity in children and benefits of physical activity. School-based intervention programs and concepts addressed within the conceptual framework will be addressed in this chapter.

\section{Physical Activity}

Physical activity is an important component in the maintenance of a healthy lifestyle. Physical activity involves movement of any skeletal muscle (Caspersen, Powell, \& Christenson, 1985). Guidelines associated with physical activity for adults have been known for some time. Healthy People 2010 goals are to increase the proportion of youth engaged in 30 minutes of moderate physical activity 5 or more times per week and vigorous activity 3 times weekly (United States Department of Health and Human Services, 2004). More recently, guidelines from the National Association for Sport and Physical Education (NASPE) have been released for children ages 5-12. These guidelines recommend children participate in a variety of physical activities totaling a minimum of 60 minutes or more on all or most days; 15 minutes of physical activity several times a day; and discourages inactivity lasting 2 hours or more during the day (National Association for Sport and Physical Education, 2004). Unfortunately, research suggests that physical inactivity is a major concern for the United States.

Physical inactivity remained consistent until 2003 when statistics revealed an increase in the prevalence from $30.5 \%$ to $33.4 \%$ (Grunbaum et al., 2004). In the same survey, it is important to note that $38 \%$ of $9^{\text {th }}$ graders compared to $18 \%$ of $12^{\text {th }}$ graders participated in daily physical education classes (Grunbaum et al.). Furthermore, it is estimated that $20 \%$ to $50 \%$ of adolescents do not participate in adequate amounts of physical activity (Grunbaum et al.). When compared to other countries, children of the United States ages 6-12 were less physically active and had higher BMI when compared to Swedish and Australian children (Vincent, Pangrazi, \& Raustorp, 2003). Decreased physical activity levels are associated with certain population characteristics.

Pratt, Macera, and Blanton (1999) report physical activity decreases with age and boys have the tendency to being more physically active than girls. Additional studies associate decreased physical activity levels with females, ethnic minorities, low income children, children living in rural areas, children with disabilities, and those children living in public housing or environments lacking safe play areas (Centers for Disease Control and 
Prevention, 2003; Hoos, Gerver, Kester, \& Westerterp, 2003; Pratt, Macera, \& Blanton, 1999; Sallis, Prochaska, \& Taylor, 2000; United States Department of Health and Human Services, 2001). Evidence suggests that physical activity begins to decrease in early adolescence and progressively declines as students enter into high school and the pattern continues into adulthood (Grunbaum et al., 2004). For these reasons, increasing physical activity levels in youth is a Healthy People 2010 priority (U.S. Department of Health and Human Services, 2004). Interventions that increase physical activity in the early adolescent population are essential to improve the health status of young Americans. Thus, incorporating physical activity into lifestyles at an early age may reverse the trends that are being reported in research.

Intensity levels of physical activity can be measured by metabolic equivalent levels. One metabolic equivalent (MET) is equal to the energy utilized while sitting quietly (Centers for Disease Control and Prevention, 2006). Vigorous intensity activities are classified as greater than 6 METs. Examples of vigorous intensity activities include jogging, aerobic dancing, and most competitive sports (Centers for Disease Control and Prevention, 1999). Moderate intensity activities are classified as 3-6 METs. Examples of moderate intensity activities are brisk walking, yoga, and recreational swimming (Centers for Disease Control and Prevention, 1999). Current physical activity recommendations for children include at least 60 minutes of moderate to vigorous physical activity 5 or more days of the week. This equates to walking briskly approximately 12,000-16,000 steps per day (Tudor-Locke, 2002).

\section{Benefits of Physical Activity}

The benefits of physical activity in youth have been well established. Children participating in regular physical activity have lower adiposity and improvements in cognition and classroom behavior (Ekeland et al., 2004; Shephard, 1996; Rowlands, Eston, and Ingledew, 1999). Studies have documented the benefit of weight bearing physical activity on bone mineral density and muscle development in pre-pubertal boys and girls (Centers for Disease Control, 1996; Strong et al., 2005). Physical activity in healthy weight and obese school-age youth is associated with lower rates of depression, anxiety, and improved self-concept (Strong et al.). Further benefits of physical activity include the reduction of triglyceride and insulin levels in overweight children (Hardin, Hebert, Bayden, Dehart, \& Mazur, 1997). There are few studies existing that reveal strong, positive correlations between physical activity and the reduction of blood pressure in children (Strong et al.). However, it has been suggested that regular physical activity (3 times per week) with duration of 30 minute increments in sufficient intensity can reduce blood pressure in children with mild essential hypertension (Strong et al.).

A major benefit of physical activity is decreased adiposity levels. A recent study concluded a weak association between moderate to vigorous physical activity as it related to the amount of body fat in children aged 9-10 (Ekelund et al., 2004). Unfortunately, those children with higher levels of adiposity are at greater risk for health consequences. Aggoun (2007) reports that atherosclerotic changes in the arteries of children and young 
adults are seen long before clinical symptoms of the disease appear. The sequela of obesity in children is associated with the increased incidence of conditions, including dyslipidemia, hypertension, type 2 diabetes, nonalcoholic fatty liver disease, sleep apnea, and depression (Daniels, 2006; Muntner, He, Cutler, Wildman, \& Whelton, 2004). Therefore, it is essential that children incorporate physical activity habits early into their lifestyle.

Another benefit associated with regular physical activity is the improvement of aerobic fitness. Research examining the relationship between physical activity and aerobic fitness in children has revealed a genre of mixed results. Dencker et al. (2006) report a weak but positive relationship between daily vigorous physical activity and aerobic fitness in children aged 8-11. An earlier study utilized Tritrac activity monitors and pedometers to assess physical activity (Rowlands et al., 1999). Results from this study revealed a positive correlation between aerobic fitness and physical activity with Tritrac, $r=0.66$ and pedometers, $r=0.59$, respectively (Rowlands et al.). Le Masurier and Corbin (2006) examined the relationship between pedometer step counts and aerobic fitness in middle school students. These results revealed a moderate relationship $(\mathrm{r}=$ 0.35) between the variables (Le Masurier \& Corbin, 2006). The moderate to weak correlations that have been found between physical activity and aerobic fitness levels in children can be attributed to the variety of fitness tests and difficulty in measuring physical activity in this population (Dencker et al., 2007). Additional research in this area is essential to help enhance the findings supporting the relationship between physical activity and aerobic fitness in children.

Early research has determined an association between physical activity and aerobic levels in youth determining future adult levels. Youth Fitness Test scores reveal that those boys scoring low on the fitness test as children were classified as being less physically active as young men (Dennison, Straus, Mellits, \& Charney, 1988).

Furthermore, research has shown the connection that overweight children tend to become overweight or obese adults; thus, contributing to the increased incidence of cardiovascular disease (Whitaker, Wright, Pepe, Seidel, \& Dietz, 1997).

\section{Measurement of Physical Activity}

There are a variety of measurement techniques of physical activity that can be utilized in adolescent populations. The gold standard for measurement is the doublelabeled water technique. This involves the oral administration of water containing oxygen and hydrogen isotopes with subsequent collection of urine specimens for analysis of energy expenditure and metabolic rate using special equipment called a spectrometer (Haskell \& Kiernan, 2000). Unfortunately, this technique is expensive for use with large population groups and provides only short-term evaluation. Self-report questionnaires, direct observation, heart rate monitoring, pedometers, and accelerometers are tools that can be used to measure physical activity in children (Bjornson, 2005). Unfortunately, double-labeled water technique, direct observation, and heart rate monitoring are expensive methods for large group sampling. 
Accelerometers are reliable and valid for measuring physical activity with this population; however, when compared to pedometers are more expensive (Bjornson, 2005). Pedometers have been found to be a cost effective and easy to use tool that provide a reliable measurement of physical activity in children (Bjornson, 2005; Haskell and Kiernan, 2000; Le Masurier \& Corbin, 2006). Beets, Patton, and Edwards (2005) present findings of the accuracy among a variety of pedometer brands measuring steps in children. The results revealed "high levels of agreement for steps for the Digiwalker 200 and the Walk4Life 2505" (Beets, et al., p. 518). Positive correlations $(r=0.78)$ have been established between pedometer steps and oxygen uptake with treadmill walking using the Digiwalker 200 (Eston, Rowlands, \& Ingledew, 1998). Pedometers also provide an opportunity for children to learn techniques of goal setting (i.e., steps per day) and through attainment of those goals increase self-efficacy and personal satisfaction (National Association of Sport and Physical Education, 2003). Thus, pedometers have proven to be a valid, economical tool to measure physical activity in children.

Several research studies have utilized pedometers as tools to measure physical activity in children. Scruggs and associates have determined that pedometers combined with direct observation are accurate measures of time spent engaged in physical activity in physical education classes (Scruggs et al., 2003; Scruggs et al., 2005; Scruggs, 2007a, 2007b). Research has recommended daily step counts for girls at 12,000 and boys at 15,000 per day (Tudor-Locke et al., 2004).

Recent intervention research has focused on combining physical activity with school day activities (Mahar et al., 2006; Oliver, Schofield, \& McEvoy, 2006). Pedometers were used to measure physical activity levels in third and fourth graders participating in a classroom-based program compared to a control group (Mahar et al.). Results revealed a statistically significant increase in the number of steps in the students participating in the intervention program $(5587 \pm 1633)$ compared to the control group (4805 + 1543) (Mahar et al.). Oliver, Schofield, and McEvoy (2006) evaluated physical activity levels and implemented a "virtual walk around the country" program to elementary school students. The study concluded that approximately $50 \%$ of the children were averaging greater than 15,000 steps per day with boys achieving more steps that girls. Although differences between program beginning and ending steps were not significant, findings revealed that step counts increased in students with decreased physical activity levels, especially female students (Oliver, Scholfield, \& McEvoy).

LeMasurier and Corbin (2006) examined the number of steps taken per day and aerobic fitness levels. The study confirmed existing research regarding a higher step count among boys with no differences in step counts between grade levels (LeMasurier \& Corbin). Those students participating in physical education classes and extracurricular sports had a higher number of step counts (LeMasurier \& Corbin). Findings revealed only a moderate relationship $(\mathrm{r}=0.35 ; \mathrm{p}<0.01)$ between physical activity and aerobic fitness levels in the middle school participants. However, the findings did reveal that those middle school students with higher step counts were more aerobically fit (LeMasurier \& Corbin). A final study examined the feasibility of pedometer use in a school setting in New Zealand (Bocquier et al., 2006). The study findings reveal that more children were 
active during the week and over half the students averaged over 15,000 steps per day. The study substantiates the feasibility of pedometer use in a school setting (Bocquier et al.).

\section{Aerobic Fitness}

Aerobic fitness provides information directly related to cardiovascular function. As previously mentioned, maximal oxygen uptake $\left(\mathrm{VO}_{2}\right.$ max $)$ is the gold standard measurement of aerobic fitness. Although a thorough measurement tool, the procedure requires special equipment and trained personnel in a controlled setting. This test is not practical for use in large settings related to the time consuming nature and expense involved with the testing. Alternate methods to estimate aerobic capacity in children through field tests consist of run tests, walk tests, shuttle run tests, and step tests (Ohtake, 2005). The most common tests used in children are the PACER, the one-mile run test, and the one-mile walk test (Cureton \& Plowman, 2001). "The reliability of the three field tests of aerobic capacity is, for the most part, high" (Cureton \& Plowman, p. 4). Although reliability coefficients have been high in all three tests, PACER and the one-mile run tests are better suited with higher reliability results in older children (Cureton \& Plowman). The one-mile walk test has been identified as an appropriate assessment of aerobic fitness in both younger and older children. Studies using this test in children age 8 and older have revealed reliability coefficients averaging above .80 (Cureton \& Plowman; McSwegin, Plowman, Wolff, \& Guttenberg, 1998).

The data from the one mile walk test can then be used to calculate estimated maximal oxygen consumption $\left(\mathrm{VO}_{2}\right.$ max). A regression equation using the one-mile walk time, heart rate, gender, age, and weight are used to estimate $\mathrm{VO}_{2}$ max (Kline et al., 1987). Cureton and Plowman (2001) report the one mile walk test prediction equation as: " $\mathrm{VO}_{2}$ max $=-0.3877$ (Age to the nearest year) +6.315 (Gender, $\left.\mathrm{F}=0, \mathrm{M}=1\right)-0.0769$ (Weight in pounds) -3.2649 (Time) -0.1565 (bpm) $+132.853 "$ (p. 15). Using this equation, various studies have reported a reliability coefficient of $>0.80$ in youth and young adults. (Cureton, Sloniger, O’Bannon, Black, \& McCormack, 1995; McSwegin, Plowman, Wolff, \& Guttenberg, 1998).

Maximum oxygen uptake measurements increase throughout childhood and adolescence; however, values tend to be higher in males throughout the lifespan (Brown, Miller, \& Eason, 2006). A recent study found that the mean $\mathrm{VO}_{2} \max$ was $17 \%$ lower in girls than boys, in particular, older females (aged 18-19) had significantly lower $\mathrm{VO}_{2}$ max levels when compared to younger females (aged 12-13) (Pate, Wang, Dowda, Farrell, \& O'Neill, 2006). Furthermore, the study concluded that regardless of age, male and females of normal weight had higher $\mathrm{VO}_{2}$ max levels compared to those overweight groups (Pate, Wang, Dowda, Farrell, \& O’Neill, 2006).

Children participating in maximal exercise have been found to have increased $\mathrm{VO}^{2}$ max (Obert et al., 2003). However, Brown et al. (2006) reports that $\mathrm{VO}^{2}$ max levels plateau in girls at around age 14 and in boys at age 18. Since $\mathrm{VO}_{2}$ max plateau is often not 
reached in children, peak observed oxygen uptake is an alternative measure to assess aerobic fitness in children (Washington et al., 1994). Research has confirmed that $\mathrm{VO}_{2}$ peak levels were higher in children participating in daily physical activity and in those children with more lean body mass (Dencker et al., 2007; Dencker, 2006).

\section{Obesity in Children}

Due to the fact that youth are growing, definitions of overweight and obesity in children have been debated over the years. Body mass index (BMI) is an adequate measure to assess the amount of body fat in children and adolescents (Dietz \& Bellizzi, 1999). Overweight in children is defined as a BMI between the 85-95 percentile on age and sex specific growth charts, while a BMI greater than the 95 percentile on growth charts constitutes obesity (Anderson \& Butcher, 2006).

In the United States, the prevalence of obese school aged children aged 6-11 has doubled and the prevalence of obese adolescents aged 12-19 has tripled in the last thirty years (National Center for Health and Statistics, 2000). Goran (2001) reports the greatest increases of overweight and obese school aged children occurring in rural areas and in minority populations. In rural Kentucky, the childhood obesity rates exceed national averages (29.7\% vs. $21.9 \%$ ) for ages $12-14$ (United States Department of Health and Human Services, 2005).

Research reveals that a majority of childhood obesity trends continue into adulthood. In children six years and older, the probability of obesity in adulthood exceeded $50 \%$ if the child was obese as compared to $10 \%$ for non-obese children (Whitaker, Wright, Pepe, Seidel, \& Dietz, 1997). Multiple studies link childhood obesity to subsequent morbidity and mortality in adulthood (DiPietro, Mossberg, \& Stunkard, 1994; Must, Jacques, Dallal, Bajema, \& Dietz, 1992; Nieto, Szkol, \& Comstock, 1992).

The sequela of obesity are not limited to adulthood, as evidenced by the increased incidence of concomitant conditions, including dyslipidemia, hypertension, type 2 diabetes, nonalcoholic fatty liver disease, sleep apnea, and depression, seen in overweight youth (Daniels, 2006; Muntner, He, Cutler, Wildman, \& Whelton, 2004). The increased incidence of obesity is associated with the increased incidence of metabolic syndrome or insulin resistance syndrome in children (Steinberger \& Daniels, 2003). Scott (2006) defines insulin resistance syndrome as the clustering of "...overweight, hypertension, hyperlipidemia, cardiovascular disease, acanthosis nigricans, and type 2 diabetes" ( $\mathrm{p}$. 119). The prevalence of insulin resistance syndrome is low in the general children and adolescent population at approximately $4 \%$ (Ornstein \& Jacobson, 2006). However, in overweight and obese youth populations, insulin resistance syndrome has been found to be prevalent in $30-50 \%$ of these children (Ornstein \& Jacobson; Weiss et al., 2004).

The negative health consequences of obesity in children also have a negative economic impact on healthcare costs. It is estimated that annual hospital costs rose threefold as a result of obesity (Wang \& Dietz, 2002). Therefore, effective interventions 
aimed at reducing childhood obesity will improve health, quality of life, and decrease healthcare expenses.

\section{School-Based Physical Activity Interventions}

Initiatives to improve student academic success and funding cuts have contributed to fewer opportunities for physical activity during recess or structured physical education classes. The School Health Policies and Programs Study (SHPPS) found that only 6.4\% of middle school children had daily physical education for the entire year (Burgeson, Wechsler, Brener, Young, \& Spain, 2001). Even students who have physical education classes typically spend less time engaged in moderate-to-vigorous physical activity than is recommended by the Healthy People 2010 objectives. The Youth Risk Behavior Surveillance System (YRBSS) documented inadequate levels of physical activity among high school-age youth with less than $89 \%$ meeting recommended activity levels of 60 minutes of moderate or more intense exercise five days per week, despite the opportunity to participate in extra-curricular sports (Grunbaum et al., 2004).

School based intervention programs have effectively increased student physical activity levels during physical education classes (Luepker et al., 1996; Sallis et al., 2003). The Child and Adolescent Trial for Cardiovascular Health (CATCH) and the Sports, Play, and Active Recreation for Kids (SPARK) intervention studies revealed an approximate increase of 7-12 minutes in physical activity among students participating during physical education classes (Hortz \& Petosa, 2006). A six month physical activity intervention used in children aged 6-10 years resulted in improved body composition in obese children (Lazaar et al., 2007). Furthermore, this study concluded the importance of 60 minutes of moderate to vigorous physical activity each day for school aged children (Lazaar et al.).

The Cardiovascular Health in Children Study (CHICS) compared intervention among at-risk children groups and children in the classroom setting. At-risk groups received the health education intervention from registered nurses while the classroombased group received the health education intervention from their classroom teachers. Outcomes revealed improvements in physical activity and cardiovascular risk knowledge between both groups. However, greater improvements in physical activity and cardiovascular risk knowledge were found in the classroom setting group when compared to the at-risk group. Also, the classroom-based group proved to provide an environment that was easier to implement the program in when compared to the at-risk group (Harrell, 1999).

The Take 10 ! program is a school-based curriculum intervention that combines classroom lessons with physical activity. Physical activity was measured using accelerometers. Classes participated in the program 8-9 times per week for approximately 10 minutes and reached moderate to vigorous physical activity levels during each session (Stewart, 2004). Two similar school-base curriculum intervention programs were designed using pedometers and classroom activities to increase physical activity. 
Running and Reading Across America program which began in 1997 in Alabama and Move Across America Program initiated in Kansas in 2001 (Oliver, 2006), both used pedometers to record numbers of steps traveled and then steps were calculated as miles and tracked across a map of the state or nation. Program effectiveness was not researched in these programs. Overall, schools provide an environment that is ideal for the implementation of physical activity programs for youth (Cole, 2006).

Research using pedometers in school aged children have primarily focused on using the pedometers as measurement tools of physical activity and not as an intervention (Oliver, 2006; Pangrazi et al., 2003; Scruggs et al., 2003). However, research in this area is moving to the examination of pedometers as motivational tools at increasing physical activity. One study conducted in Australia examined the effectiveness of using pedometers to increase physical activity in inactive Australian, high school girls (Schofield et al., 2005). Findings from the 12 week intervention study revealed increased step counts in both pedometer and minute groups (Schofield et al., 2005). Conclusions from this study suggest that the use of a pedometer may be motivational in increasing moderate and vigorous physical activity levels (Schofield et al.). Butcher, Fairclough, Stratton, and Richardson (2007) investigated the impact of pedometer step feedback combined with health education compared to a group with no health education and another group without feedback and without health education. The study revealed that students in the group receiving pedometer feedback and health education had significantly more pedometer steps when compared to those receiving only feedback and those receiving neither (Butcher, et al.).

\section{Self-Efficacy}

Bandura (1986) has defined self efficacy as "people's judgments of their capabilities to organize and execute courses of action required to attain designated types of performances" (p.391). According to Bandura (1977), self efficacy correlates to the level of confidence or efficiency one feels regarding a situation or skill. Research reveals self-efficacy or physical activity confidence as being one of the most influential correlates of physical activity (Dishman et al., 2004, 2005; Sallis, Prochaska, \& Taylor, 2000). Furthermore, high levels of physical activity have been associated with increased levels of self-efficacy in children aged 10 to 16 years (Strauss, Rodzilsky, Burack, \& Colin, 2001). Conversely, lower levels of self efficacy and confidence have been associated with lower levels of physical activity in overweight adolescents (Melnyk et al., 2006).

Effective physical activity intervention programs have utilized the self efficacy concept in improving physical activity levels. One study examined the impact of Lifestyle Education for Activity Program (LEAP) on self efficacy in African American and Caucasian adolescent females (Dishman et al., 2004). This school based intervention study concluded that increased self efficacy levels were correlated with increased physical activity levels in adolescent females (Dishman et al.). Another school based intervention program "aimed to test the relations of physical self-concept and self- 
efficacy with voluntary physical activity..." (Annesi, 2006, p. 515). Results revealed that improvements in voluntary physical activity were seen at the end of the 12 week intervention period. Statistically, $7-28 \%$ of the variance in voluntary physical activity was explained by changes in physical self-concept and self-efficacy (Annesi, 2006).

The Physical Activity Self-Efficacy scale has been shown to be valid and reliable for use in children (Saunders et al., 1997). This scale consisted of 17 items that assessed factors of support seeking, barriers, and positive alternatives (Saunders et al., 1997). The questions were assessed using a dichotomous scale (Saunders et al., 1997). This tool has the versatility to be used with a variety of populations in several settings. Modified versions of the scale have been used to measure psychosocial characteristics in school aged girls (Sherwood et al., 2004).

\section{Amherst Health and Activity Survey}

Amherst Health and Activity Survey is a fifty question survey of physical activity correlates in children that is completed by a parent or guardian. The survey assessed physical activity participation; sites of physical activity participation; neighborhood and environmental influences of physical activity; household influences of physical activity; physical activity of friends and family; and household description. Studies in which this survey was used concluded that parental support of physical activity was an important indicator of physical activity levels in children (Norman et al., 2005; Trost et al., 2003). The survey was designed to be used in all grades 1-12. Test-retest reliability has been established for all assessment variables of the survey with results ranging from $\mathrm{r}=0.55$ to $\mathrm{r}=1.00$ (Sallis, Taylor, Dowda, Freedson, \& Pate, 2002).

\section{Summary}

A multitude of factors have resulted in the increased incidence of overweight and obesity in children across the United States. Decreased physical activity is but one of the contributing factors. Whether the reduction of physical activity is related to lack of resources, unsafe environment, increased sedentary behavior, or decreased physical education in the school the result equates to increased adiposity and/or decreased health status. Increasing physical activity levels in this population has the potential to improve the health of a generation.

Physical activity guidelines recommend children participate in a variety of physical activities totaling a minimum of 60 minutes or more on all or most days of the week. Additionally, children should engage in periods of physical activity lasting at least 15 minutes several times a day and inactivity lasting 2 hours or more during the day should be discouraged (National Association for Sport and Physical Education, 2004). This equates to 12,000 daily steps for girls and 15,000 daily steps for boys utilizing a pedometer (Tudor-Locke et al., 2004). 
The benefits of physical activity in youth have been well established. Children participating in regular physical activity have lower adiposity and improvements in cognition and classroom behavior (Ekeland et al., 2004; Shephard, 1996; Rowlands, Eston, \& Ingledew, 1999). Physical activity in healthy weight and obese school-age youth is associated with lower rates of depression, anxiety, and improved self-concept (Strong et al., 2005). Direct relationships have been established between lower body mass index and higher self-efficacy levels (Melnyk et al., 2006).

School based intervention programs have effectively increased student physical activity levels during physical education classes (Luepker et al., 1996; Sallis et al., 2003). Several school based intervention programs have successfully increased physical activity in at risk populations (Butcher, Fairclough, Stratton, \& Richardson, 2007; Harrell, 1999; Oliver, 2006; Schofield et al., 2005; Stewart, 2004). Additional school based intervention programs that are easy to implement and cost-effective are essential in reversing the detrimental decline in physical activity among children. 


\section{CHAPTER 3. METHODOLOGY}

The methodology section will provide a description of the research design used in this study. Descriptions of the sample and setting, instruments, procedures, statistical analysis, and protection of human subjects will address the research questions proposed by this study.

\section{Research Design}

This quasi-experimental, intervention study, examined the relationships among self-efficacy levels, physical activity, aerobic fitness, and body composition (RBMI) in Kentucky middle school children. The study also, evaluated the effect of a 12 week intervention program on self-efficacy, physical activity levels, aerobic fitness, and RBMI in Kentucky middle school children of a treatment group (School 1) compared to a control group (School 2). All children in the sixth and seventh grade at two rural, Kentucky middle schools were recruited for participation. These schools were selected because of the similar demographic characteristics. Permission from each school's principal and Institutional Review Board (IRB) approval was received. Written parental consent and participant assent was obtained prior to student participation in the study. Each group was assessed for demographic information of age, gender, and race. Baseline height, weight, RBMI calculation, self efficacy, physical activity levels, and aerobic fitness were obtained on each participant in both groups. Baseline data was obtained for one week before beginning the intervention program. One school was randomly selected to serve as the control group. The pedometer activity intervention program was applied to the experimental school. The intervention program was implemented for 12 weeks. The intervention consisted of the use of pedometers as motivational tools combined with 10 minutes of daily moderate to vigorous school physical activity. Self-efficacy, physical activity levels, aerobic fitness, and RBMI was then compared between the two schools. The final week consisted of the collection of the conclusion data: self-efficacy, physical activity levels, aerobic fitness, and RBMI.

\section{Sample and Setting}

A convenience sample was recruited from two rural, Kentucky middle schools. Sixth and seventh grade students in each middle school were recruited to participate in the study. An estimated $99 \%$ of the 220 to 290 student populations at the schools were comprised of Caucasian students. Discounted or free lunch eligibility rates varied between schools with ranges from $30 \%$ to $55 \%$. This population was selected because of the decreased physical activity levels that have been associated with rural areas. Overall, Kentucky has seen increases in the incidence of overweight and obesity in the youth population over the past several years. Furthermore, schools across Kentucky have experienced cuts in physical education offerings as a result of education reform. For that reason, programs aimed at increasing physical activity are warranted in schools. 


\section{Inclusion Criteria}

Participation in this study was open to all who met the inclusion/exclusion criteria. Inclusion criteria of this study consisted of the following:

- $\quad$ Male or female

- $\quad$ Sixth or seventh grade student

- $\quad$ The physical ability to walk

- The cognitive ability to understand and follow directions

\section{Exclusion Criteria}

Exclusion criteria for the study consisted of the following:

- $\quad$ Physical disability or inability to walk

- $\quad$ Medical excuse

- $\quad$ Lack of student assent

- Lack of parental consent

\section{Recruitment}

The planned procedure for obtaining informed parental consent and children assent included contacting all sixth and seventh grade students at two rural, Kentucky middle schools in the classroom setting. Recruitment began upon receiving IRB approval and after meeting with school principals and teachers participating in the program. Students were contacted in the school setting with a verbal presentation of the program. Once this was completed, each student received a packet of information that they were responsible to take home to their parents. This packet contained a brief description of the proposed study, a consent form for the parent, an assent form for the student, and an invitation to an informational meeting. School open house programs served as informational meetings regarding the study. A table was set up during the open house activities and informed parental consent and student assent were obtained. School open house programs served as an opportunity to allow parents and students to receive more information about the study and allowed them to ask questions. A signed parental consent with student assent was required for the student's participation in the study. Letters and phone calls were used in addition to the informational meeting as part of the recruitment process. Copies of the forms were given to the student and parent.

\section{Sample Description}

The sample consisted of 116 sixth and seventh grade middle school students. The intervention school consisted of a total of 55 students with the majority being Caucasian $(94.5 \%, n=52)$. The control school consisted of a total of 61 students with all students 
being Caucasian. The average age of students was similar between the schools. The average age in the intervention and control schools were 11.49 years $(\mathrm{SD}=0.60)$ and 11.7 years $(\mathrm{SD}=0.78)$, respectively. Both groups had an even distribution of male $(51 \%, \mathrm{n}=59)$ and female $(49 \%, \mathrm{n}=57)$ student participants.

Students enrolled in physical education (PE) classes during the course of the study was greater in the control school with $32.7 \%$ of students enrolled in the first 9 week PE class $(n=38)$ and $6.0 \%$ enrolled in the second 9 week PE class. Students enrolled in the first 9 week PE class at the intervention school consisted of $6.0 \%(n=7)$ and $13.7 \%$ $(n=16)$ enrolled in the second 9 week PE class. Student participation in organized sports activities was also greater in the control school with $28.4 \%(n=33)$ of that population participating in a fall sport or sports compared to $12 \%(n=14)$ of students in the intervention school. Although both schools are rural, the control school is in closer proximity to public parks and has sidewalk access.

\section{Instrumentation}

\section{Anthropometric Assessment}

Anthropometric assessment, consisting of height and weight was assessed on each participant. Calculation of BMI and BMI percentile was obtained from the anthropometric measurements. Height was measured in each child without shoes using a scale-mounted measuring tool. Weight was assessed in each child in light clothing without shoes using a balance scale. The same equipment was used at each school.

Calculation of BMI and BMI percentile will be obtained from the anthropometric measurements. Body mass index (BMI) is used to classify overweight and obesity and is calculated by weight in kilograms divided by height in meters squared $\left(\mathrm{kg} / \mathrm{m}^{2}\right)$ (Anderson $\&$ Butcher, 2006). A mathematical conversion of BMI is calculated as (weight in pounds/[height in inches $]^{2}$ x 703) (Anderson \& Butcher, 2006). This formula was used for BMI calculation in this study.

\section{Relative Body Mass Index (RBMI)}

Calculation of BMI and BMI percentile will employee the use of Centers for Disease Control and Prevention (CDC) BMI-for-age-gender specific growth charts (CDC, 2000). Overweight classification is defined as BMI percentile between $85 \%$ and $94 \%$ on the CDC growth chart and obese as $95 \%$ or greater (Barlow \& Dietz, 1998). Because BMI changes during childhood, relative BMI (RBMI) will be used as an estimate of percent overweight $\left[\mathrm{BMI} /\left(50^{\text {th }}\right.\right.$ percentile $\mathrm{BMI}$ on $\mathrm{CDC}$ age-gender specific growth chart *100]. 


\section{Physical Activity Assessment}

Student physical activity levels were assessed using the Digiwalker 200 pedometer. The Digiwalker 200 pedometer is reliable and valid for step measurement in school age populations (Beets \& Pitetti, 2005). Positive correlations $(r=0.78)$ have been established between pedometer steps and oxygen uptake with treadmill walking using the Digiwalker 200 (Eston et al., 1998). A study examining the relationship of activity, fitness and body fat compared measurement findings between the Digiwalker 200, the Tritrac-R3D accelerometer, and a heart rate monitor (Rowlands et al., 1999). The results revealed that the Digiwalker 200 and the Tritrac-R3D yielded similar outcomes (Rowlands et al.). This study concluded the validity of this pedometer as an accurate assessment of physical activity (Rowlands et al.).

\section{Self-Efficacy}

The Physical Activity Self-Efficacy scale has been shown to be valid and reliable for use in children (Saunders et al., 1997). This scale was used to measure physical activity self-efficacy in this study. The Physical Activity Self-Efficacy scale consisted of 17 items that assessed factors of support seeking, barriers, and positive alternatives (Saunders et al.). The questions were assessed using a dichotomous scale (Saunders et al.). Validity of the self-efficacy scale consisted of: (1) support seeking (Cronbach's alpha $=0.52$, test-retest reliability $=0.76) ;(2)$ barriers (Cronbach's alpha $=0.55$, testretest reliability $=0.82$ ); and $(3)$ positive alternatives (Cronbach's alpha $=0.62$, test-retest reliability $=0.61)$ (Saunders et al.).

Students were provided with instructions regarding the completion of this scale. The instrument was completed in a group setting. Each student completed the scale within 20 minutes. Scores were then calculated on each student with a score of 17 indicating the highest level of self-efficacy.

\section{Aerobic Fitness Assessment}

Maximal oxygen uptake $\left(\mathrm{VO}_{2}\right.$ max $)$ is the gold standard measurement of aerobic fitness. Although a thorough measurement tool, the procedure requires special equipment and trained personnel in a controlled setting. This test is not practical for use in large settings related to the time consuming nature and expense involved with the testing. An alternate method, the one-mile walk test, was utilized in this study. The one-mile walk test has been identified as an appropriate assessment of aerobic fitness in children. Studies using this test in children age 8 and older have revealed reliability coefficients averaging above 0.80 (Cureton \& Plowman, 2001; McSwegin, Plowman, Wolff, \& Guttenberg, 1998).

Prior to beginning the one-mile walk test, distances were verified using a calibration wheel. Students were instructed to walk the mile as quickly as possible, while 
maintaining a steady pace. Completion times were assessed with a stop watch and the radial pulse rate was count for 15 seconds multiplied by 4 to obtain heart beats per minute. Students completed the one-mile walk test in small groups of approximately 1215 per group.

Data from the one-mile walk test was then used to calculate maximal oxygen consumption $\left(\mathrm{VO}_{2}\right.$ max) on each participant. The Rockport Fitness Walking Test (RFWT) utilizes an equation using the one-mile walk time, heart rate, gender, age, and weight to interpret $\mathrm{VO}_{2}$ max (Kline, et al., 1987). Cureton and Plowman report the one mile walk test prediction equation as: " $\mathrm{VO}_{2} \max =-0.3877$ (Age to the nearest year) +6.315 (Gender, $\mathrm{F}=0, \mathrm{M}=1)-0.0769$ (Weight in pounds) - 3.2649 (Time) -0.1565 (bpm) + 132.853" (2001, p. 15). Using this equation, various studies have reported a reliability coefficient of $>0.80$ in youth and young adults (Cureton et al., 1995; McSwegin et al., 1998). Onemile walk time, heart rate, gender, age, and weight were entered into a RFWT calculator and estimated $\mathrm{VO}_{2}$ max scores were obtained.

\section{Amherst Health and Activity Survey}

Evaluating parental support of physical activity is important and may help explain the impact of the intervention program. For that reason, the Amherst Health and Activity Survey (Sallis et al., 2002) was used to measure parental support of physical activity. This information served as useful information in examining external influences of physical activity in the population of study. The survey consisted of a fifty item tool; however, the parental support of physical activity scale was the only factor analyzed from this survey in this study. This scale consisted of five items that examined a typical week with which parents or guardians encouraged physical activity. The items in this scale include: "encouraged this child to do physical activities or play sports"; "done a physical activity or played sports with this child"; "provided transportation so this child can go to a place where he or she can do physical activities or play sports"; "watched this child participate in physical activities or sports"; and "told this child that physical activity is good for his or her health". Parental responses were recorded on a seven-point Likert scale with endpoints from none to daily, don't know, and not applicable. Trost et al.(2003) report the internal consistency of the scale as 0.78 by Cronbach's alpha and the test-retest reliability as $r=0.67$. This survey was sent home with parents and then returned to school with the children during the week of testing.

\section{Physical Activity Intervention Program}

The intervention consisted of the utilization of pedometers combined with 10 extra minutes of school day physical activity. Pedometers were given to all participating students in the intervention school. These students participated in 10 minutes of moderate to vigorous physical activity during each school day. Students had the choice to walk briskly or jog during that time. Brisk walking is classified as a moderate intensity activity equivalent to 3-6 METs while jogging is a vigorous intensity activity with greater than 6 
METs (Centers for Disease Control and Prevention, 1999). Table 3-1 provides a summary of the variable sources of measurement for each study variable.

\section{Procedure}

\section{Phase 1 (Baseline)}

This phase was implemented over a one-two week period at both the intervention and control schools. On day 1, anthropometric measurements were taken, self-efficacy scales were completed, and pedometers were distributed along with instructions of use and detailed instructions for the physical activity measurement procedure. On days 2-5, participants wore the Digiwalker pedometer with daily 24 hour step counts recorded. Due to extremely high heat index levels, the one-mile walk test was postponed on several occasions at both schools but was obtained within the first two weeks of beginning the study.

\section{Anthropometric Measurement}

The scale was calibrated before each individual was measured. Students were instructed to remove their shoes and any jackets prior to obtaining measures. Anthropometric measures included height as recorded in inches and weight as recorded in pounds. Calculation of BMI and RBMI was based on height and weight data.

\section{Physical Activity Levels}

Students were given a pedometer with instructions of operation and placement of the pedometer. They were instructed to wear the pedometer at all times, except for bathing and or swimming. The students were instructed to remove the pedometer at bedtime each night and to put the pedometer back on when getting dressed and worn to school. The principal investigator or physical education teacher recorded or monitored the recording of step counts. The above process was repeated for three consecutive days at the same time to ensure a 24 hour count was obtained. An average daily step count was calculated and used for baseline physical activity assessment. To avoid the potential for an exaggeration of physical activity that may be a novelty effect, the first day of the baseline was excluded from the average.

\section{Aerobic Fitness}

Each gym was measured prior to beginning the test with one mile distances established. Participants were required to sit on the bleachers 10 minutes before beginning the test and no "warm up" period was allowed. The participants began the test 
Table 3-1. Variables and Measurement Tools or Source Used for Data Collection

Instrument/Variables

Physical Activity

Aerobic Fitness

Self-Efficacy

Anthropometric Measures

Demographic Data

Parental Support of Physical Activity
Measurement/Source

Digiwalker 200 pedometer; 3-day step count

1 mile walk test; completion time in minutes Calculated estimated $\mathrm{VO}_{2}$ max

The Physical Activity Self-Efficacy Scale

Relative Body Mass Index

Derived from height/weight measures and BMI calculations

Age

Gender

Race

Amherst Health and Activity Survey 
by walking the designated area. The test was self-paced, without rest periods. Completion times were recorded for each participant with a stop watch. Heart rate was obtained by counting the radial pulse for 15 seconds, multiplied this by 4 , and the heart beats per minute was recorded for each participant.

\section{Self-Efficacy}

The Self-Efficacy Scale was provided to all participating students. The scale was completed in a group setting at school. Upon completion of the scale, the results were scored.

\section{Demographic Information}

Information on age, gender, race, enrollment in physical education courses, and participation in sports were obtained from each student participant in the school setting. Data was collected in a group setting. Each student self-assessed these factors.

\section{Amherst Health and Activity Survey}

The Amherst Health and Activity Survey was distributed to all parents or guardians of participating students for completion at home. Upon completion and return of the scale, the parental support of physical activity scale was calculated.

\section{Phase 2 (Intervention)}

The intervention program was applied to the intervention middle school only. Participating students obtained pedometers each morning for homeroom and properly positioned the pedometer on their waistband. Girls were encouraged to achieve at least 12,000 steps and boys 15,000 steps each day. Students participated in 10 minutes of daily school physical activity time beyond their usual activities. During the 10 minute physical activity time, the physical education teacher led the students in the activity. The physical activity consisted of walking briskly (moderate) or jogging (vigorous). Students were encouraged to record each day's step total before removing and clearing the pedometer at the end of the school day. At the end of the school day, pedometers were stored in the classroom and reapplied each morning in homeroom. This intervention was conducted for 12 weeks.

\section{Phase 3 (Conclusion)}

This phase was implemented over a one week period in both the intervention and control schools. Anthropometric measurements, physical activity levels, aerobic fitness, 
and self-efficacy were reassessed in the intervention and control group using the same procedures performed at the baseline assessment. (See above-Phase 1 Baseline). The phase 1 (baseline) and phase 3 (conclusion) data was then statistically compared between the intervention and control group.

\section{Data Analysis}

Statistical analysis was performed using Statistical Package for the Social Sciences (SPSS). Descriptive statistics of means, standard deviations, and frequencies were calculated. Descriptive data consisted of age, gender, race, height, weight, BMI, RBMI, physical activity (step counts), aerobic fitness scores (estimated $\mathrm{VO}_{2}$ max), selfefficacy scores, and parental support scores on the Amherst Health and Activity Survey.

\section{Specific Aim One}

The relationship between self-efficacy levels, physical activity, aerobic fitness, and body composition (RBMI) was examined using Pearson Product Moment Correlation coefficients. Correlational analysis was undertaken using only the baseline data. An alpha level of 0.05 was set a priori for statistical significance.

\section{Specific Aim Two}

The effectiveness of the 12-week intervention program to improve self-efficacy, physical activity, aerobic fitness, and maintain RBMI was examined using Repeated Measures ANOVA. An alpha level of 0.05 was set a priori for statistical significance.

\section{Consideration of Human Subjects}

This study received approval from the University of Tennessee Health Science Center Institutional Review Board. Approval from each school principal was received prior to beginning the study. Appropriate guidelines were maintained as to ensure anonymity and confidentiality for subject participants. A unique identification code was assigned to each subject to facilitate data analysis; however, data collection forms were stored in separate locations. At no time will participant names be reported and all publications and presentations will reflect aggregate data. 


\section{CHAPTER 4. RESULTS}

The purpose of this study was to examine the relationships among self-efficacy levels, physical activity, aerobic fitness, and RBMI in rural, middle school children. This quasi-experimental pre-test, post-test design study further evaluated the effectiveness of an intervention using pedometers combined with 10 minutes of daily physical activity to improve self-efficacy, physical activity, and aerobic fitness levels and to maintain RBMI in the intervention group (School 1) compared the control group (School 2). The initial discussion will describe the sample population in more detail and will present the mean scores of outcome variables. The results of each research question will be addressed.

\section{General Sample Description}

A convenience sample of 116 sixth and seventh grade middle school children in rural Kentucky participated in the study. All of the study participants were able to walk without assistance devices, were enrolled in regular education classes, and had the cognitive ability to understand and follow directions. Participants were enrolled during their first week of school at two rural middle schools in Kentucky. Baseline testing of anthropometric and physical activity levels was conducted the first week of school and baseline fitness levels were assessed within the first two weeks into the school year and repeated 12-weeks later. Baseline fitness level data collection was prolonged over two weeks, due to extreme high heat index levels during those weeks. Excessive high temperature days were avoided for data collection. A detailed description of the sample relative to each research aim is provided in that section.

\section{Specific Aim One-Correlations Among Self-Efficacy Levels, Physical Activity, Aerobic Fitness, and Body Composition}

Aim one examined the relationship between self-efficacy, physical activity levels, aerobic fitness levels, and body composition (RBMI) in middle school children. Specifically it was hypothesized that self-efficacy levels would be positively associated with physical activity and aerobic fitness and that RBMI would be inversely associated with self-efficacy, physical activity and aerobic fitness. Pearson's Product Moment Correlation Coefficients were used to examine relationships between study variables with an alpha level of 0.05 set for statistical significance.

\section{Sample}

The sample consisted of 116 sixth and seventh grade middle school children (mean age of $11.65+0.71$ years) with the majority being Caucasian with a similar distribution of male and female students ( $49.1 \%$ female and $50.9 \%$ male). Forty-two percent of the subjects were enrolled in physical education classes at their schools and 
$25.5 \%$ reported participating in extracurricular sports. Although the majority of the participants had study measures performed at baseline and 12-weeks later, only the baseline measures were selected for the correlational analysis. A summary of sample demographic attributes is provided in Table 4-1.

\section{Description of the Total Group's Self-Efficacy, Physical Activity, Fitness and RBMI}

A description of the middle school children's self-efficacy scores, physical activity level, aerobic fitness and RBMI are provided in the following paragraphs and depicted in Table 4-2. Additionally children were grouped by gender and information on each outcome variable is provided in Table 4-3. Information relating to parental support from the Amherst Health and Activity Survey is provided thereafter.

\section{Self-Efficacy}

Physical Activity Self-Efficacy scores ranged from 3 to 17 with higher scores reflecting greater self-efficacy. Scores from this instrument could range from 0-17. One questionnaire was not completed entirely and was removed from data analysis. The mean scores were similar between female and male students; however, lower ranges of scores were noted in males. This finding is not supported by literature, as literature reports female students typically having lower levels of physical activity self-efficacy when compared to male students (Norman, Schmid, Sallis, Calfas, \& Patrick, 2005; Strauss, Rodzilsky, Burack, \& Coin, 2001).

\section{Physical Activity}

The average 4-day step-count, measured by pedometer, was used as a measure of physical activity. Participants wore their pedometer for four consecutive days and evening, removing the pedometers at bedtime and reapplying them upon awakening. Steps from the first day were excluded in the calculation to minimize overestimation of steps due to the novelty effect. School events or absences resulted in four students wearing the pedometer for 3-days, rather than the planned 4-day period. Pearson's product moment correlation coefficients were used to examine relationships between 4day and 3-day step counts with an alpha level of 0.05 set for statistical significance. Results revealed a strong positive association between 4-day and 3-day physical activity step counts $(\mathrm{r}=0.814$ and $\mathrm{P}=0.000)$. Therefore, 3-day step counts were used in place of 4-day step counts for four of the participants. One student failed to wear the pedometer consistently to school and step count data was unattainable on that participant. Average step counts for boys $(10223.40 \pm 3386.25)$ and girls (10138.68 \pm 3371.33) were similar. However, baseline data revealed boys having an ever slightly higher level physical activity when compared to girls. Overall, both groups had significantly lower baseline step counts when compared to recommended step counts for their age. 
Table 4-1. Demographic Characteristics of Total Study Participants

Demographic Category

Number

Percent

Age (years)

10

11

12

13

45

55

12

$3.4 \%$

$38.7 \%$

$47.4 \%$

$10.3 \%$

Gender

Female

57

Male

59

$49.1 \%$

$50.9 \%$

Race

Caucasian

African American

113

3

$97.4 \%$

$2.6 \%$

PE Class

None

48

$41.3 \%$

First 9 weeks

45

$38.7 \%$

Second 9 weeks

23

$19.8 \%$

Sports

None

69

$59.4 \%$

Extra-curricular

47

$40.6 \%$ 
Table 4-2. Baseline Measures of Self-Efficacy, Physical Activity, Aerobic Fitness and Body Composition in Middle School Children

\begin{tabular}{lccc}
\hline Outcome Variables & $\mathrm{n}$ & Mean \pm SD & Range \\
\hline $\begin{array}{l}\text { Self-Efficacy } \\
\begin{array}{l}\text { Physical Activity } \\
\text { (Average Daily Steps) }\end{array}\end{array}$ & 115 & $14.95 \pm 2.55$ & $3-17$ \\
$\begin{array}{l}\text { Aerobic Fitness } \\
\text { Time (minutes) }\end{array}$ & 109 & $10181.41 \pm 3364.28$ & $3376-18620$ \\
$\quad$ Estimated VO2 & 109 & $17.03 \pm 3.26$ & $10.05-23.05$ \\
$\begin{array}{c}\text { Body Composition } \\
\text { BMI }\end{array}$ & 116 & $49.40 \pm 12.29$ & $23.21-77.89$ \\
$\quad$ RBMI & 116 & $21.84 \pm 5.09$ & $14.80-41.26$ \\
\hline
\end{tabular}


Table 4-3. Baseline Measures of Self-Efficacy, Physical Activity, Aerobic Fitness and Body Composition by Gender in Middle School Children

\begin{tabular}{|c|c|c|c|}
\hline Outcome Variables & $\mathrm{n}$ & Mean \pm SD & Range \\
\hline \multicolumn{4}{|l|}{ Self-Efficacy } \\
\hline Female & 57 & $15.47 \pm 1.95$ & $10-17$ \\
\hline Male & 58 & $14.43 \pm 2.95$ & $3-17$ \\
\hline \multicolumn{4}{|c|}{$\begin{array}{l}\text { Physical Activity } \\
\text { (Average Daily Steps) }\end{array}$} \\
\hline Female & 57 & $10138.68 \pm 3371.33$ & $3376-17218$ \\
\hline Male & 58 & $10223.40 \pm 3386.50$ & $3672-18620$ \\
\hline \multicolumn{4}{|l|}{ Aerobic Fitness } \\
\hline \multicolumn{4}{|l|}{ Time (minutes) } \\
\hline Female & 55 & $17.10 \pm 3.15$ & $10.42-23.00$ \\
\hline Male & 54 & $16.96 \pm 3.39$ & $10.05-23.15$ \\
\hline \multicolumn{4}{|l|}{ Estimated VO2 } \\
\hline Female & 55 & $46.45 \pm 10.96$ & $23.21-70.56$ \\
\hline Male & 54 & $52.42 \pm 12.92$ & $27.80-77.89$ \\
\hline \multicolumn{4}{|l|}{ Body Composition } \\
\hline & \multicolumn{2}{|c|}{ BMI } & \\
\hline $\begin{array}{l}\text { Female } \\
\text { Male }\end{array}$ & $5 /$ & $21.79 \pm 4.11$ & $15.30-31.00$ \\
\hline Male & 59 & $21.90 \pm 5.93$ & $14.80-41.26$ \\
\hline \multicolumn{4}{|l|}{ RBMI } \\
\hline Female & 57 & $122.26 \pm 23.31$ & $84.52-177.45$ \\
\hline Male & 59 & $124.19 \pm 33.40$ & $80.12-223.36$ \\
\hline
\end{tabular}




\section{Aerobic Fitness}

The one-mile walk test was used to measure aerobic fitness. Heart rate, gender, weight and amount of time were entered into the VO2 estimation equation. Estimated VO2 was $49.40 \pm 12.29$, with boys having similar or higher values than girls. Shorter periods of time for measuring heart rate may affect VO2 estimates. In this study, heart rate was measured for 15 seconds, rather than 30 or 60 seconds, which may result in higher estimation of VO2, thus time to complete the one-mile walk test was also used as a measure of aerobic fitness (see Table 4-2 and 4-3).

\section{Body Composition}

Height and weight were measured and BMI calculated. The mean BMI was 21.84 \pm 5.0 with boys and girls having similar BMIs $(21.90 \pm 5.9$ and $21.79 \pm 4.1$, respectively). Severity of overweight, measured by RBMI, was $123.24 \pm 28.7$. There was no significant difference in RBMI between gender groups $(124.19 \pm 33.4$ vs. $122.26 \pm$ 23.3). The CDC defines children and adolescents as overweight when the BMI percentile falls between $85 \%$ and $94 \%$ on the CDC growth chart and obese as $95 \%$ or greater (CDC, 2007). Aggregate data revealed that $56.9 \%(n=66)$ of the student participants were classified in the healthy weight range, while $13.8 \%(n=16)$ were overweight, and $29.3 \%$ $(n=34)$ were in the obese range.

\section{Parental Support for Physical Activity}

The Amherst Health and Activity Survey return rate was $81.8 \%(n=95)$. For the purposes of this study, the parental support of physical activity scale was the only scale analyzed. This scale consisted of five items. The results revealed that on a weekly basis, $9.6 \%(n=9)$ of the parents did not encourage their child to do physical activity or sports compared to $50 \%(n=58)$ that encouraged their child almost daily or daily to be physically active. Almost $16 \%(15.8 \%, n=18)$ reported that during a typical week they participate none to only once in a physical activity with their child as opposed to $27.6 \%$ $(n=32)$ who reported that they participate almost daily to daily with their child. Interestingly, $14.7 \%(\mathrm{n}=17)$ reported providing daily transportation for their child to participate in physical activity and $14.7 \%(n=17)$ reported no transportation. The majority $(27.6 \%, \mathrm{n}=32)$ of parents reported that during the week they sometimes watch their child participate in physical activity; $12.9 \%(n=15)$ reported never watching; $14.7 \%(n=17)$ reported watching daily. Finally, most parents $(27.6 \%, \mathrm{n}=32)$ reported that sometimes during the week they told their child that physical activity was good for his/her health. Only $15.5 \%(\mathrm{n}=18)$ reported telling their child daily that physical activity was good for his/her health and $12.9 \%(n=15)$ reported never telling this to their child. 


\section{Results of Correlational Analysis}

The relationships among self-efficacy, physical activity, aerobic fitness and RBMI in Kentucky middle school children were explored using correlational analysis. Weakly positive correlations between self-efficacy and physical activity $(r=0.269$ and $p$ $=0.004)$ and self-efficacy and aerobic fitness $(r=0.236$ and $p=0.013)$ were found. A weakly correlated inverse relationship was revealed between self-efficacy and RBMI $(\mathrm{r}=$ -0.243 and $p=0.009)$. Physical activity was weakly correlated with aerobic fitness $(r=$ 0.309 and $\mathrm{p}=0.001$ ), while a weak, negative correlation was found between physical activity and RBMI $(r=-0.361$ and $p=0.000)$. Finally, aerobic fitness was weakly, inversely correlated with RBMI $(r=-0.493$ and $p=0.000)$. Although the relationships among these variables are weakly correlated, the findings support the hypothesis that higher physical activity self-efficacy levels are associated with greater amounts of physical activity and higher aerobic fitness levels in middle school youth. Furthermore, the findings support the second hypothesis that higher RBMI is associated with lower self-efficacy, physical activity, and aerobic fitness levels. A summary of the Pearson correlation coefficient results follows in Table 4-4.

\section{Specific Aim Two-Effect of the Pedometer Intervention Program on Outcomes}

The effect of a 12-week pedometer intervention program on self-efficacy, physical activity levels, aerobic fitness, and RBMI was examined. It was hypothesized that students in the intervention school (School 1) would show an increase in selfefficacy, physical activity levels and aerobic fitness compared to students in the control school (School 2) and that RBMI would decrease or be maintained students participating in the intervention compared to the control group. Repeated measures ANOVA were used to analyze the effect of the pedometer intervention program between groups and within subjects.

\section{Sample}

The sample consisted of 116 sixth and seventh grade middle school students. The intervention school consisted of a total of 55 students with the majority being Caucasian $(94.5 \%, \mathrm{n}=52)$. The control school consisted of a total of 61 students with all students being Caucasian. The average age of students was similar between the schools. The average ages were 11.49 years $(\mathrm{SD}=0.60)$ in the intervention school and 11.7 years $(\mathrm{SD}=0.78)$ in the control school. Both groups had an even distribution of male and female student participants ( $49 \%$ female, $\mathrm{n}=57 ; 51 \%$ male, $\mathrm{n}=59)$.

Physical education (PE) class participation was a confounding factor that was discovered after the initiation of the study. Of the students participating in the study, $41.4 \%(n=48)$ were not enrolled in a physical education class at any time during the study. The percentage of students enrolled in PE classes during the course of the study 
Table 4-4. Correlational Analysis Among Self-Efficacy, Physical Activity, Aerobic Fitness and RBMI

\begin{tabular}{cccc}
\hline & Physical Activity & Aerobic Fitness & RBMI \\
& & & \\
Self-Efficacy & & \\
$\mathrm{r}=$ & 0.269 & 0.236 & -0.243 \\
$\mathrm{p}=$ & 0.004 & 0.013 & 0.009 \\
$\mathrm{n}=$ & 114 & 109 & 115 \\
& & & \\
Physical Activity & & -0.361 \\
$\mathrm{r}=$ & & 0.309 & 115 \\
$\mathrm{p}=$ & 0.001 & \\
$\mathrm{n}=$ & 109 & \\
& & & -0.493 \\
Aerobic Fitness & & 0.000 \\
$\mathrm{r}=$ & & & 109 \\
$\mathrm{p}=$ & & & \\
$\mathrm{n}=$ & & & \\
\hline
\end{tabular}


was greater in the control school with $32.7 \%$ of students enrolled in the first 9 week PE class $(n=38)$ and $6.0 \%$ enrolled in the second 9 week PE class. Students enrolled in the first 9 week PE class at the intervention school consisted of $6.0 \%(n=7)$ and $13.7 \%$ $(n=16)$ enrolled in the second 9 week PE class. Student participation in organized sports activities was also greater in the control school with $28.4 \%$ of that population participating in a fall sport or sports $(n=33)$ compared to the intervention school with $12.0 \%(\mathrm{n}=14)$. Although both schools are rural, the control school is in closer proximity to public parks and has sidewalk access. Demographic characteristics of subjects in the control and intervention groups were examined based upon their enrollment in PE classes during the study period and are summarized in Tables 4-5 and 4-6.

As previously indicated, $56.9 \%(\mathrm{n}=66)$ of the student participants were classified in the healthy weight range, while $13.8 \%(n=16)$ were overweight, and $29.3 \%(n=34)$ were in the obese range. When looking at the groups separately, the treatment school had higher numbers of students classified in the obese range with $40 \%(n=22)$ compared to the control school with $19.7 \%(n=12)$. Obviously, the treatment school had a lower level of healthy range students with $47.3 \%(n=26)$ compared to the control school with $65.6 \%$ $(n=40)$ in the healthy range. Both schools had similar numbers of students classified as overweight with the treatment school with $12.7 \%(\mathrm{n}=7)$ and the control school with $14.7 \%(n=9)$.

Results of ANOVA testing revealed the intervention school to have statistically significant $(\mathrm{p}<0.05)$ higher BMI and RBMI results when compared to the control school. Table 4-7 documents the results of ANOVA. Statistical differences between the groups were also present in physical activity and aerobic fitness levels. Significantly lower levels $(\mathrm{p}<0.05)$ of physical activity and aerobic fitness were noted in the treatment group when compared to the control group. There was no statistical significance noted in self-efficacy levels between groups.

School events or absences resulted in nineteen students wearing the pedometer for 3-days, rather than the planned 4-day period. Pearson's product moment correlation Coefficients were used to examine relationships between 4-day and 3-day step counts with an alpha level of 0.05 set for statistical significance. Results revealed a strong positive association between 4-day and 3-day physical activity step counts $(r=0.936$ and $\mathrm{p}=0.000$ ). Therefore, 3-day step counts were used in place of 4-day step counts for nineteen of the participants. Ten participants were missing post-physical activity levels related to prolonged absences and/or failure to follow the physical activity step count protocol. The mean scores of the outcome variables are summarized in Table 4-8.

As previously mentioned, a greater number of students in the control school were enrolled in PE during the collection of baseline data. The differences in physical activity levels may be explained by increased numbers of students enrolled in PE. As this is a confounding variable for the study, only students not enrolled in PE during the course of the study were used for data analysis when comparing intervention outcomes. Characteristics of these 48 subjects are summarized in Table 4-9. 
Table 4-5. Demographic Characteristics of Control School Participants by PE Group

\begin{tabular}{|c|c|c|c|}
\hline Demographic Category & $\begin{array}{l}\text { No PE } \\
(n=16) \\
n(\%)\end{array}$ & $\begin{array}{l}\text { First } 9 \text { weeks PE } \\
(\mathrm{n}=38) \\
\mathrm{n}(\%)\end{array}$ & $\begin{array}{l}\text { Second } 9 \text { weeks } \\
(\mathrm{n}=7) \\
\mathrm{n}(\%)\end{array}$ \\
\hline \multicolumn{4}{|l|}{ Age (years) } \\
\hline 10 & $1 \quad(6.25)$ & $1 \quad(2.6)$ & $0 \quad(0)$ \\
\hline 11 & $3(18.75)$ & $14(36.8)$ & $3(42.9)$ \\
\hline 12 & $9(56.25)$ & $16(42.2)$ & $3(42.9)$ \\
\hline 13 & $3(18.75)$ & $7(18.4)$ & $1(14.2)$ \\
\hline \multicolumn{4}{|l|}{ Gender } \\
\hline Female & $6(37.5)$ & $18(47.4)$ & $6(85.7)$ \\
\hline Male & $10(62.5)$ & $20(52.6)$ & $1(14.3)$ \\
\hline \multicolumn{4}{|l|}{ Race } \\
\hline Caucasian & $16(100)$ & $38(100)$ & $7(100)$ \\
\hline African American & $0 \quad(0)$ & $0 \quad(0)$ & $0 \quad(0)$ \\
\hline
\end{tabular}


Table 4-6. Demographic Characteristics of Intervention School Participants by PE Group

\begin{tabular}{|c|c|c|c|}
\hline Demographic Category & $\begin{array}{l}\text { No PE } \\
(\mathrm{n}=32) \\
\mathrm{n}(\%)\end{array}$ & $\begin{array}{l}\text { First } 9 \text { weeks PE } \\
(\mathrm{n}=7) \\
\mathrm{n}(\%)\end{array}$ & $\begin{array}{l}\text { Second } 9 \text { weeks } \\
(\mathrm{n}=16) \\
\mathrm{n}(\%)\end{array}$ \\
\hline \multicolumn{4}{|l|}{ Age (years) } \\
\hline 10 & $2(6.3)$ & $0 \quad(0)$ & $0 \quad(0)$ \\
\hline 11 & $15(46.8)$ & $3(42.9)$ & $7(43.75)$ \\
\hline 12 & $14(43.8)$ & $4(57.1)$ & $9(56.25)$ \\
\hline 13 & $1(3.1)$ & $0 \quad(0)$ & $0 \quad(0)$ \\
\hline \multicolumn{4}{|l|}{ Gender } \\
\hline Female & $12(37.5)$ & $4(57.1)$ & $11(68.75)$ \\
\hline Male & $20(62.5)$ & $3(42.9)$ & $5(31.25)$ \\
\hline \multicolumn{4}{|l|}{ Race } \\
\hline Caucasian & $30(93.75)$ & $7(100)$ & $15(93.75)$ \\
\hline African American & $2(6.25)$ & $0 \quad(0)$ & $1(6.25)$ \\
\hline
\end{tabular}


Table 4-7. Summary of ANOVA Findings between Groups

\begin{tabular}{lcccc}
\hline \multicolumn{1}{c}{ Variable } & $\mathrm{dF}$ & $\mathrm{MS}$ & $\mathrm{F}$ & $\mathrm{P}$ \\
\hline Self Efficacy & 1 & 4.36 & .669 & .415 \\
Physical Activity & 1 & 156264349.51 & 15.57 & .000 \\
Aerobic Fitness & 1 & 677.62 & 4.63 & .034 \\
BMI & 1 & 134.34 & 5.36 & .022 \\
RBMI & 1 & 5035.31 & 6.36 & .013 \\
\hline
\end{tabular}


Table 4-8. Mean Results of Outcome Variables

Outcome Variables

Baseline Data

12 Week Data

\begin{tabular}{lll}
\hline & Mean \pm SD & Mean \pm SD \\
Self-Efficacy & & \\
Intervention Group & & $15.28 \pm 2.31(\mathrm{n}=29)$ \\
$\quad$ No PE & $14.53 \pm 3.15(\mathrm{n}=32)$ & $15.67 \pm 2.80(\mathrm{n}=6)$ \\
$\quad$ First 9 weeks PE & $15.00 \pm 3.31(\mathrm{n}=7)$ & $16.00 \pm 1.19(\mathrm{n}=15)$ \\
Second 9 weeks PE & $15.07 \pm 2.12(\mathrm{n}=15)$ & $15.54 \pm 2.09(\mathrm{n}=50)$ \\
Total & $14.74 \pm 2.88(\mathrm{n}=54)$ & \\
& & \\
Control Group & & $14.18 \pm 2.05(\mathrm{n}=16)$ \\
$\quad$ No PE & $14.31 \pm 2.35(\mathrm{n}=16)$ & $15.86 \pm 2.07(\mathrm{n}=37)$ \\
First 9 weeks PE & $15.50 \pm 2.14(\mathrm{n}=38)$ & $16.57 \pm 0.53(\mathrm{n}=7)$ \\
$\quad$ Second 9 weeks PE & $15.00 \pm 2.16(\mathrm{n}=7)$ & $15.67 \pm 2.13(\mathrm{n}=60)$ \\
Total & $15.13 \pm 2.22(\mathrm{n}=61)$ & \\
&
\end{tabular}

Physical Activity

Intervention Group

No PE

$8469.6 \pm 2699.9(\mathrm{n}=32)$

$7906.6 \pm 2700.7(\mathrm{n}=31)$

First 9 weeks PE

$8452.4 \pm 3111.0(n=7)$

$6969.2 \pm 1746.5(\mathrm{n}=5)$

Second 9 weeks PE

$10176.1 \pm 2953.2(n=16)$

$7327.9 \pm 1576.9(\mathrm{n}=15)$

Total

$8963.8 \pm 2880.4(n=55)$

$7644.5 \pm 2331.3(n=51)$

Control Group

$\begin{array}{lll}\text { No PE } & 10208.2 \pm 2915.7(n=16) & 9753.0 \pm 3824.1(n=14) \\ \text { First 9 weeks PE } & 12079.1 \pm 3616.3(n=31) & 11481.6 \pm 3429.0(n=35) \\ \text { Second 9 weeks PE } & 9655.2 \pm 8946.3(n=6) & 8946.3 \pm 1759.8(n=6) \\ \text { Total } & 11297.4 \pm 3409.8(n=60) & 10765.0 \pm 3489.4(n=55)\end{array}$


Table 4-8. Mean Results of Outcome Variables (continued)

Outcome Variables

Aerobic Fitness

Intervention Group

No PE

First 9 weeks PE

Second 9 weeks PE

Total

Control Group

No PE

First 9 weeks PE

Second 9 weeks PE

Total
Baseline Data

$47.11 \pm 9.66(\mathrm{n}=31)$

$41.37 \pm 15.53(\mathrm{n}=6)$

$48.32 \pm 11.50(\mathrm{n}=15)$

$46.79 \pm 10.91(\mathrm{n}=52)$

$51.49 \pm 15.31(\mathrm{n}=13)$

$53.53 \pm 12.43(\mathrm{n}=37)$

$43.14 \pm 9.46(\mathrm{n}=7)$

$51.79 \pm 13.06(\mathrm{n}=57)$
12 Week Data

$50.10 \pm 9.66(\mathrm{n}=29)$

$49.31 \pm 15.11(\mathrm{n}=5)$

$48.61 \pm 8.70(\mathrm{n}=15)$

$49.57 \pm 9.80(n=49)$

$52.41 \pm 13.63(\mathrm{n}=12)$

$52.64+12.88(\mathrm{n}=36)$

$42.14 \pm 7.52(\mathrm{n}=6)$

$51.42 \pm 12.82(\mathrm{n}=54)$

\section{RBMI}

Intervention Group

No PE

$133.76 \pm 32.41(\mathrm{n}=32)$

$125.05 \pm 35.37(\mathrm{n}=31)$

First 9 weeks PE

$134.02 \pm 34.60(\mathrm{n}=7)$

$125.22 \pm 33.46(\mathrm{n}=6)$

Second 9 weeks PE

$121.34 \pm 21.55(\mathrm{n}=16)$

$109.77 \pm 36.98(\mathrm{n}=16)$

Total

$130.18 \pm 29.96(n=55)$

$120.45 \pm 35.70(\mathrm{n}=53)$

\section{Control Group}

No PE

$123.28 \pm 26.05(\mathrm{n}=16)$

$121.50 \pm 24.56(\mathrm{n}=16)$

First 9 weeks PE

$113.55 \pm 25.66(\mathrm{n}=38)$

$109.93 \pm 24.53(\mathrm{n}=37)$

Second 9 weeks PE

$121.29 \pm 31.49(\mathrm{n}=7)$

$118.93 \pm 32.96(\mathrm{n}=7)$

Total

$116.99 \pm 26.37(\mathrm{n}=61)$

$114.07 \pm 25.68(\mathrm{n}=60)$ 
Table 4-9. Demographic Characteristics of Control School and Intervention School Participants Who Were Not Enrolled in Concomitant PE Class

\begin{tabular}{lcc}
\hline Demographic Category & $\begin{array}{c}\text { Control School } \\
(\mathrm{n}=16)\end{array}$ & $\begin{array}{c}\text { Intervention School } \\
\mathrm{n}(\mathrm{n}=32) \\
\mathrm{n}(\%)\end{array}$ \\
& & \\
Age (years) & $1(6.25)$ & $2(6.3)$ \\
10 & $3(18.75)$ & $15(46.8)$ \\
11 & $9(56.25)$ & $14(43.8)$ \\
12 & $3(18.75)$ & $1(3.1)$ \\
13 & & $12(37.5)$ \\
Gender & $6(37.5)$ & $20(62.5)$ \\
Female & $10(62.5)$ & \\
Male & & $30(93.75)$ \\
Race & $16(100)$ & $2(6.25)$ \\
Caucasian & $0(0)$ & \\
African American & & \\
\hline
\end{tabular}


Repeated measures-ANOVA was used to analyze the outcome variables between groups and within subjects. There were a total of 48 participants not enrolled in PE at any time during the study. However, due to absences, failure to follow step count instructions, incomplete questionnaires, and physical injury the total sample of students not enrolled in concomitant PE consisted of 29 students in the intervention school and 9 students in the control school. Results of repeated measures-ANOVA revealed there were no statistical differences between groups and between subjects when analyzing all variables. Therefore, there was no statistical significance to support the hypotheses that the intervention program would increase self-efficacy, physical activity, and aerobic fitness while maintaining or decreasing RBMI in the treatment group when compared to the control group. A summary of the repeated measures results are provided in Table 4-10.

Although not statistically significant, improvements were noted in mean scores of self-efficacy, aerobic fitness, and RBMI in both groups who did not participate in PE. However, when examining these three variables, the mean results revealed the greatest improvements in the intervention group when compared to mean results of the control group. The intervention group experienced a 0.75 increase in self-efficacy scores and a 2.99 increase in aerobic fitness levels. These results exceeded the control group's 0.50 improvements in self-efficacy and the 0.92 increase in aerobic fitness. Improved levels of body composition was most impressive in the intervention group with an 8.71 reduction in RBMI compared to a 1.78 reduction of RBMI in the control group. Unfortunately, for both groups there was a reduction in physical activity levels by approximately 500 steps. Table 4-11 summarizes the mean scores of the outcomes measures at baseline and study completion in the intervention and control groups who were not enrolled in PE classes. 
Table 4-10. Results of Repeated Measure-ANOVA for Study Outcomes Following Completion of the 12 Week Intervention

\begin{tabular}{|c|c|c|c|c|c|}
\hline Outcome Variables & Value & $\mathrm{F}$ & Нypo. df & Error df & $\mathrm{P}$ \\
\hline Self-Efficacy & \multicolumn{3}{|c|}{ Intervention: $\mathrm{n}=28$} & \multicolumn{2}{|c|}{ Control: $\mathrm{n}=9$} \\
\hline \multicolumn{6}{|l|}{ Wilks' Lambda } \\
\hline Within Subjects & 0.994 & 0.198 & 1.0 & 35.0 & 0.659 \\
\hline Between Groups & 0.988 & 0.434 & 1.0 & 35.0 & 0.514 \\
\hline Physical Activity & \multicolumn{3}{|c|}{ Intervention: $\mathrm{n}=28$} & \multicolumn{2}{|c|}{ Control: $\mathrm{n}=9$} \\
\hline \multicolumn{6}{|l|}{ Wilks' Lambda } \\
\hline Within Subjects & 0.987 & 0.452 & 1.0 & 35.0 & 0.506 \\
\hline Between Groups & 0.998 & 0.084 & 1.0 & 35.0 & 0.774 \\
\hline Aerobic Fitness & \multicolumn{3}{|c|}{ Intervention: $\mathrm{n}=28$} & \multicolumn{2}{|c|}{ Control: $n=9$} \\
\hline \multicolumn{6}{|l|}{ Wilks' Lambda } \\
\hline Within Subjects & 0.996 & 0.135 & 1.0 & 35.0 & 0.716 \\
\hline Between Groups & 0.995 & 0.187 & 1.0 & 35.0 & 0.668 \\
\hline RBMI & \multicolumn{3}{|c|}{ Intervention: $\mathrm{n}=28$} & \multicolumn{2}{|c|}{ Control: $\mathrm{n}=9$} \\
\hline \multicolumn{6}{|l|}{ Wilks'Lambda } \\
\hline Within Subjects & 0.984 & 0.553 & 1.0 & 35.0 & 0.462 \\
\hline Between Groups & 0.956 & 1.650 & 1.0 & 35.0 & 0.214 \\
\hline
\end{tabular}


Table 4-11. Mean Results of Outcome Variables in Participants Who Were Not Enrolled in Concomitant PE Class

\begin{tabular}{lll}
\hline $\begin{array}{l}\text { Outcome Variables } \\
\text { Mean }+ \text { SD }\end{array}$ & $\begin{array}{l}\text { 12 Week Data } \\
\text { Mean }+ \text { SD }\end{array}$ \\
\hline $\begin{array}{l}\text { Self-Efficacy } \\
\text { Intervention Group }\end{array}$ & $14.53 \pm 3.15(\mathrm{n}=32)$ & $15.28 \pm 2.31(\mathrm{n}=29)$ \\
$\quad$ Control Group & $14.31 \pm 2.35(\mathrm{n}=16)$ & $14.81 \pm 2.05(\mathrm{n}=16)$ \\
$\begin{array}{l}\text { Physical Activity } \\
\text { Intervention Group }\end{array}$ & $8469.65 \pm 2699.92(\mathrm{n}=32)$ & $7906.67 \pm 2700.74(\mathrm{n}=31)$ \\
$\quad$ Control Group & $10208.25 \pm 2915.74(\mathrm{n}=16)$ & $9753.07 \pm 3824.15(\mathrm{n}=14)$ \\
$\begin{array}{l}\text { Aerobic Fitness } \\
\text { Intervention Group }\end{array}$ & $47.11 \pm 9.66(\mathrm{n}=31)$ & $50.10 \pm 9.66(\mathrm{n}=29)$ \\
$\quad$ Control Group & $51.49 \pm 15.31(\mathrm{n}=13)$ & $52.41 \pm 13.63(\mathrm{n}=12)$ \\
& $133.76 \pm 32.41(\mathrm{n}=32)$ & $125.05 \pm 35.37(\mathrm{n}=31)$ \\
RBMI & $123.28 \pm 26.05(\mathrm{n}=16)$ & $121.50 \pm 24.56(\mathrm{n}=16)$ \\
Intervention Group & & \\
Control Group & & \\
\hline
\end{tabular}




\section{CHAPTER 5. DISCUSSION, IMPLICATIONS, AND CONCLUSIONS}

This study evaluated the relationship of self-efficacy, physical activity, aerobic fitness and RBMI in sixth and seventh grade middle school students in two rural Kentucky schools. Furthermore, the study was an evaluation of a 12 week intervention implemented in a treatment school compared with a control school. Chapter five provides a discussion of the study findings relevant to each research aim and provides implications for theory, practice, and research.

The sample consisted of 116 middle school children with an average age of 11.65 years of age. The majority of the participants were Caucasian with an even distribution of male and female students. Based on CDC growth chart reference data, over half of the student participants were classified in the healthy weight range; however, $29.3 \%(n=34)$ of the sample were classified in the obese range. This result exceeds the 2003-2004 estimated $17.1 \%$ of obese children and adolescents in the United States (Ogden et al., 2006). Furthermore, the result exceeds the estimated $20.6 \%$ of children aged $10-17$ classified as obese in Kentucky (United State Department of Health and Human Services, 2005). These findings support research that concludes increased rates of overweight and obesity in children are being seen in rural areas (Goran, 2001). Although research concludes that overweight and obesity tends to be increased in female students, there were no statistical differences that occurred in BMI and RBMI between male and female participants in this study (Ogden et al).

Baseline findings revealed significant differences between groups in all variables with the exception of self-efficacy. Although not statistically different, the intervention school scored 0.39 lower on the baseline self-efficacy scale with a mean of 14.74 compared to the control school score of 15.13. A score of 17 on the scale reflects optimal physical activity self-efficacy (Saunders et al., 1997).

Both schools had relatively high physical activity self-efficacy scores. Research indicates that higher levels of physical activity self-efficacy and physical activity enjoyment correlate with higher levels of physical activity participation (Robbins, Pender, \& Kazanis, 2003; Robbins, Pis, Pender, \& Kazanis, 2004; Sherwood et al., 2004; Strauss, Rodzilsky, Burack, \& Colin, 2001). The high levels of self-efficacy can further be substantiated by the number of students self-reporting their participation in organized sports that semester. Almost half $(40.5 \%, \mathrm{n}=47)$ of the students reported being active participants in an organized fall sport during the time of baseline data collection. This finding supports research findings that conclude self-efficacy or physical activity confidence as being one of the most influential correlates of physical activity and sports participation (Dishman et al., 2004, 2005; Sallis, Prochaska, \& Taylor, 2000).

Significant differences between the intervention and control school were noted. Baseline data revealed significantly increased levels of physical activity, aerobic fitness, and lower RBMI in the control school when compared to the intervention school. Several factors may attribute to the differences between the schools. Firstly, 32.7\% $(n=38)$ of the 
students at the control school were enrolled in the first 9 weeks PE compared to the intervention school with $6 \%(\mathrm{n}=7)$. Secondly, parks and other recreation areas are in closer proximity and are in walking distance to the control school. Research supports this suggestion that environmental factors, such as, access to equipment, physical activity space, and physical activity facilities correlate with levels of physical activity (Council on Sports Medicine and Fitness and Council on School Health, 2006; Sallis, Prochaska, \& Taylor, 2000). Finally, socioeconomic status is a contributing factor that research has found to influence physical activity levels. Pratt, Macera, and Blanton (1999) report that physical activity decreases from $42.6 \%$ to $15.1 \%$ as family income levels decrease. Although socioeconomic status was not assessed among participants, discounted or free lunch eligibility rates were greater in the intervention school at 55\% compared to the control school with $30 \%$.

It can be assumed that higher levels of physical activity are associated with improved levels of aerobic fitness and lower body composition. Obert et al. (2003) report that children participating in maximal exercise have increased $\mathrm{VO}_{2}$ max. Furthermore, research has confirmed that $\mathrm{VO}_{2}$ peak levels are higher in children participating in daily physical activity and in those children with more lean body mass (Dencker et al., 2007; Dencker, 2006).

\section{Discussion of Specific Aims}

\section{Specific Aim One}

The first specific aim examined the relationships among self-efficacy, physical activity, aerobic fitness levels, and RBMI in rural Kentucky middle school children. The results revealed a weak positive correlation between self-efficacy and physical activity and between self-efficacy and aerobic fitness. Furthermore, lower self-efficacy levels were associated with higher RBMI levels in the sample. Based on these findings, higher levels of self-efficacy were associated with higher levels of physical activity and aerobic fitness and lower RBMI in the sample.

Albeit weak, these findings are consistent with a previous study that found significant positive correlations between self-efficacy and high levels of physical activity in children (Strauss, Rodzilsky, Burack, \& Colin, 2001). An additional intervention study aimed at decreasing television viewing time in children, found that higher levels of BMI and lower levels of physical activity and aerobic fitness were associated with lower selfefficacy levels (Harrison, Burns, McGuinness, Heslin, \& Murphy, 2006). Another study concluded that overweight adolescents reported lower levels of physical activity selfefficacy when compared to healthy weight adolescents (De Bourdeaudhuij et al., 2005).

Physical activity was weakly correlated with aerobic fitness. This finding is consistent with other studies that determine a positive correlation between physical activity and aerobic fitness (Dencker et al., 2006; La Masurier \& Corbin, 2006; 
Rowlands, Eston, \& Ingledew, 1999). Although a direct relationship cannot be established, this finding suggests that increased levels of physical activity are related to higher levels of aerobic fitness in this population. Additionally, a weak, negative correlation was found between physical activity and RBMI. Although it is expected that higher BMI levels would be related to lower levels of physical activity, this association has only been associated with males in a previous study (Norman, Schmid, Sallis, Calfas, \& Patrick, 2005).

Finally, aerobic fitness was weakly, inversely correlated with RBMI. Previous studies have reported no significant differences in $\mathrm{VO}_{2}$ max of overweight and healthy weight adolescents (Drinkard et al., 2001; Goran, Fields, Hunter, Herd, \& Weinsier, 2000). However, a more recent study found that $\mathrm{VO}_{2}$ max was significantly lower in overweight children and adolescents (Norman et al., 2005). It has been suggested that the differences in $\mathrm{VO}_{2}$ max can be attributed to the "normalization measures" of weight and on how "VO ${ }_{2}$ max is scaled" from study to study (Norman et al., 2005, p. e694). This study used a 1 mile walk time entered into an equation using age, gender, and heart rate to estimate $\mathrm{VO}_{2}$ max in study participants. Therefore, the estimation of $\mathrm{VO}_{2}$ max and the field setting of the 1 mile walk test could be contributing factors to these results.

\section{Specific Aim Two}

Specific aim two addressed the evaluation of the effect of the 12 week intervention program on self-efficacy, physical activity levels, aerobic fitness, and RBMI in the intervention group (School 1) compared the control group (School 2). Statistically, the results revealed no differences between groups and between subjects when analyzing all variables. Although there was no statistical significance between groups and subjects, there were small improvements noted between group variables with the greatest improvements noted in the intervention group. For example, aerobic fitness scores increased by 2.78 from pre to post testing in the intervention school compared to only 0.37 in the control school. Greater mean improvements in self-efficacy were noted in the intervention group with 0.8 compared to the control schools improvement of 0.54 . Improvements in RBMI were approximately four times greater in the intervention school with a reduction of RBMI by 9.73 compared to the control school's reduction of 2.92 . Unfortunately, physical activity levels decreased in both groups with greater reductions noted in the intervention group.

There are several contributing factors that may have impacted the less than optimal outcomes of the intervention program. Firstly, PE enrollment was a major confounding variable that was unable to be controlled for in the study. Over half of the participants were concomitantly enrolled in PE. These PE classes were conducted over a 9 week period. Thus, some students were completing PE 9 weeks into the intervention study while others began PE classes 5 weeks before post data was collected. This resulted in data outcome analysis being conducted only on those students not enrolled in PE during the course of the study. Ultimately, this resulted in much smaller sample sizes for data analysis; thus, impacting statistical measures. 
Secondly, post-data collection of physical activity in both schools was more challenging when compared with pre-data collection. During post-data collection of physical activity, participants were more likely to lose or forget to wear their pedometer when compared to baseline collection. This contributed to more missing data. Also, baseline collection began in August in comparison to post data collection in October. It would be assumed that warmer weather and more day light after school could influence greater amounts of physical activity after school in August as opposed to October. A final contributing factor is related to post step data collection. In both schools, post step data collection was completed exclusively by the primary investigator. In pre step data collection both the primary investigator and the physical education teacher collected data. Research has concluded that teachers and coaches play a significant role in the motivation of children's participation in physical activity (Weiss, 2000). The lack of teacher involvement during the post step collection period could have resulted in students feeling less motivated to accomplish optimal physical activity levels.

Thirdly, challenges regarding pedometer accountability developed early in the study implementation period. The initial methodological design called for participants to wear the pedometer at all times and record step counts at school at the beginning and end of the day. After the first few days of intervention, it became clear that there were major problems with this methodology. Students were forgetting to wear their pedometer to school and several students lost the pedometers. For these reasons, the methodology was changed. Participants were instructed to apply a pedometer at the beginning of each school day, wear it throughout the day, and return the pedometer to the participating teacher at the end of the day after the 10 minutes of physical activity. This improved pedometer access and accountability for students. However, recording of daily step counts remained a challenge. Initially, students were encouraged to record daily step counts at the end of each day through the 12 week intervention period. However, the lack of participation in this area deemed this procedure to be an optional activity; thus, the majority of participants did not complete daily step counts.

Fourthly, participants were less enthusiastic regarding the use of the pedometer during the post-data collection phase. This lack of interest was much more apparent in the intervention group during the post-data collection phase. A loss of the novelty effect may explain this lack of enthusiasm and furthermore the deficiencies in physical activity at the end of the study.

Finally, seasonal variations in physical activity may be a contributing factor to the decreased physical activity levels from the baseline to post-data collection period. Baseline data collection was conducted in August, while post data collection was conducted late October and early November. Studies have shown that seasonal variations in physical activity occur in children (Baranowski, Thompson, DuRant, Baranowski, \& Puhl, 1993; Fisher et al., 2005; Riddoch et al., 2007).

Longitudinal studies examining seasonal variation in physical activity among children have yielded contradictory findings. Fisher et al. reported young children (3-5 years of age) from the United Kingdom were more physically active during summer 
months. This is consistent with cross-sectional measurements of physical activity in children (Goran, Nagy, Gower, \& Johnson, 1998). In contrast, Baranowski et al. (1993) reported adolescents residing in southwestern USA were more active during winter months.

Loucaides, Chedzoy, and Bennett (2004) reported that physical activity levels varied by seasons among rural and urban children aged 11-12 living in Cyprus. Those children in rural areas were most physically active in summer months compared to urban children that were most physically active in winter months (Loucaides, Chedzoy, \& Bennett, 2004). A recent study by Riddoch et al. (2007) examined levels and patterns of physical activity in 11 year old children. Results revealed that children were most active in the summer months (Riddoch et al.) Substantial variation occurred with higher levels of moderate to vigorous physical activity occurring during summer months (June 1August 31) (Riddoch et al.).

Results from the present study revealed a mean pedometer step count that was approximately 1,319 steps higher at baseline (August) when compared to post-data collection steps in the intervention school. The control school had a mean pedometer step count that was 532 steps higher at baseline (August). Both schools had higher mean physical activity levels in August compared to late October or November step counts. Thus, the present study supports the findings in literature that suggest seasonal differences of physical activity occurs in children with increased physical activity levels occurring in summer months.

\section{Strengths and Limitations}

Strengths of the study include the use an intervention tool that is easy to use and cost effective for use in large population groups. Furthermore, an additional 10 minutes of physical activity incorporated into a school day is practical to implement. The study used valid and reliable instruments for data collection and provided a health promotion activity to a group of rural school aged children.

Unfortunately, there are several methodological limitations associated with the study. Major limitations of the study are the inherent problems of using a convenience sample and a quasi-experimental design. This study design resulted in the lack of randomization and random assignment, which decreases the external and internal validity of the study findings. As previously discussed, $58.6 \%$ of the participants were enrolled in $\mathrm{PE}$ at some point during the course of the study. Enrollment in PE was a major confounding variable potentially influencing variable outcomes. This confounding variable resulted in a smaller sample size for data analysis of intervention outcomes.

A second methodological limitation of the study was the lack of cultural diversity. The population represented in this study is predominantly Caucasian with little diversity across the county. Additional research in more culturally diverse areas of Kentucky is a goal of future research. A third methodological limitation of the study was the relatively 
short time frame of the study. Although one particular intervention program or length of intervention has not been determined to be most effective in increasing physical activity and reducing overweight in children, a minimum intervention time is 12 weeks with an average length of effective interventions being one year (Summerbell et al., 2001). Therefore, the lack of statistical significance between intervention and control groups may be related to the short duration of the study.

Although pedometers provide a method to quantify physical activity, certain factors may influence the number of step counts that pedometers will be measuring, attributing to another limitation of the study. For example, failure to wear the pedometer in the proper position or participation in activities that result in bouncing of the body (i.e. horseback riding, jumping rope, etc.) may result in inaccurate step counts. Furthermore, pedometers are limited in measuring activities involving water sport. This limitation may result in inaccurate physical activity levels.

Finally, it is recognized that history was a major threat to internal validity in this study. There are a variety of external events that may have occurred along with the independent variable that could have affected the dependent variables. It was impossible to control for these confounding variables.

\section{Additional Findings}

In addition to the above study findings, results revealed that overall physical activity levels were lower than nationally recommended levels. Collectively the mean number of steps taken at baseline was 10,181.41 $\pm 3364.28(\mathrm{n}=115)$ and during post-data collection step counts were $9211.92 \pm 3450.81(\mathrm{n}=87)$. Baseline physical activity levels revealed that 19 out of 100 or $19 \%$ of students completing physical activity step counts met recommended physical activity guidelines. Post-data collection revealed even lower numbers with 9 out of 92 or $9.8 \%$ of participants achieving recommended physical activity levels. Between groups the numbers were similar with the intervention school achieving lower step counts at baseline and post-data collection periods; however, both groups were far below recommended levels. Physical activity guidelines recommend children participate in a variety of physical activities totaling a minimum of 60 minutes or more on all or most days; 15 minutes of physical activity several times a day; and discourages inactivity lasting 2 hours or more during the day (National Association for Sport and Physical Education, 2004). This equates to 12,000 daily steps for girls and 15,000 daily steps for boys utilizing a pedometer (Tudor-Locke et al., 2004). An additional concern is that over half of the participants were enrolled in PE; equating to the fact, that even when in PE, students were not achieving basic recommended physical activity levels. 


\section{Theoretical Implications}

The implementation of this program was based on the Social Cognitive Theory, which assumes relationships between environment, behavior, and personal factors are used to define the interaction of the phenomenon (Bandura, 1986). The program incorporated the concepts to enhance the reciprocal triad associated with the theory of person-behavior, environment-behavior, and environment-person (Pajares, 2002). Personbehavior was enhanced through the use of peers. Peers were influential in supporting and encouraging the physical activity participation of one another in the program. The environment-behavior concept was enhanced by providing the opportunity for students to participate in a physical activity outside scheduled PE classes. Providing opportunities for physical activity is an avenue for students to receive additional physical activity on a daily basis. Finally, the environment-person concept was incorporated in the program through the use of a non-competitive approach with the intention to improve physical activity self-efficacy.

Despite the fact that both groups had relatively high levels of self-efficacy at baseline, there were improvements in self-efficacy averages among both groups at the end of the intervention. Although there were no statistically significant improvements in self-efficacy levels, the intervention is promising especially if implemented in a larger sample size.

\section{Clinical Practice Implications}

Although the intervention lacked statistical significance, there are several clinical practice implications relating to this study. The study findings support the need for interventions aimed at reducing the rates of overweight among children and adolescents in rural areas. Study findings revealed overweight rates among this sample to be exceedingly higher than the United States and Kentucky rates. Effective interventions focusing on improving physical activity and aerobic fitness are capable of reducing the incidence and prevalence of overweight among this population.

Physical activity levels among these participants were below national recommended daily step counts, even with $58.6 \%$ of the participants being enrolled in a PE class within the first or second nine week period of school. This finding supports research that the majority of school aged children do not acquire adequate amounts of daily physical activity (Gordon-Larsen, Nelson, Popkin, 2004; Grunbaum et al., 2004). Furthermore, the significance of the finding lies in the numbers of children enrolled in PE and still not reaching recommended activity levels. Improving physical activity levels in children requires a multi-level, collaborative approach. A collaborative effort between caregivers of children, educators, health care professionals, and community leaders are necessary to provide effective outcomes that increase physical activity in this population (Roberts, 2000). 
Parents and caregivers of children need to be educated regarding the fact that physical activity acquired at school is not enough. Almost $13 \%$ of parents completing the Amherst Health and Activity Survey reported that they never told their child that physical activity was good for his/her health. From these findings, it is evident that parents and caregivers of children need additional information regarding the importance of daily physical activity for their child and the benefits of physical activity on health.

Furthermore, parents and caregivers need to understand that they serve as role models and that they shape the health promotion behaviors of their children for a lifetime (Roberts, 2000). A caregiver's simple encouragement and support of physical activity can improve physical activity levels in children (Sallis, Prochaska, \& Taylor, 2000). Results from the Amherst Health and Activity Survey revealed that almost $10 \%$ of parents in this study never encouraged their child to be physically active. Thus, innovative health education delivery methods are necessary to provide parents and caregiver the knowledge they need to positively influence the health outcomes of this generation. Additionally, health care professionals are responsible for implementing primary prevention, intervention programs, and to continue research in this area.

Physical education and health educators in the school setting have the unique opportunity to positively influence the physical activity status of America's youth. Unfortunately in 2000 , it was estimated that only $8 \%$ of elementary, $6.4 \%$ of middle school, and 5.8\% of high school students across the United States participate in daily physical education (Council on Sports Medicine and Fitness and Council on School Health, 2006). Community Preventive Services has recommended an increase in the amount of physical education across the United States and is encouraging PE curricula to become more intense (Task Force on Community Preventive Services, 2005). Findings from a systematic review of studies examining PE classes that increased the length and intensity of the class activities revealed improvements in aerobic fitness by $8 \%$ across age, gender, race, and socioeconomic levels (Task Force on Community Preventive Services, 2005). The present study findings support the need of the evaluation of PE curricula in regards to amount and length of classes, types of activities, amount of participation, and intensity levels of activities.

\section{Recommendations for Future Research}

Future research on self-efficacy, physical activity, aerobic fitness, and body composition in middle school children is warranted. Research incorporating a culturally diverse sample in rural Kentucky is indicated. Also, randomization of sampling with a larger sample size is recommended to determine the effectiveness of the intervention and to generalize the findings. Future research should also assess socioeconomic factors of participants. Additionally, it is recommended that improvements in the methodology occur by utilizing a larger, collaborative school-based approach and incorporating a goalsetting piece to the program. Involvement by additional faculty and school leaders in the program will allow for a more structured, collaborative approach. Furthermore, the larger number of faculty participants will provide structure and assistance to the implementation 
of the program, as well as, enhancing the encouragement of physical activity for participants. The incorporation of a goal-setting piece to the program helps to enhance student participation. A recent intervention study revealed that students actively participating in goal setting and receiving pedometer feedback and health education had significantly more pedometer steps when compared to those receiving only feedback and those receiving neither (Butcher, Fairclough, Stratton, \& Richardson, 2007). Thus, improvements in the methodology are aimed at improving program outcomes.

\section{Conclusions}

These study results support the findings from other research regarding the high prevalence of overweight and low levels of physical activity in rural children. The results enhance the current research findings that suggest improved self-efficacy is associated with higher levels of physical activity and aerobic fitness and healthy body composition in youth. Furthermore, these findings emphasize the need for effective intervention programs that collectively include children, their caregivers, healthcare providers, educators, and the community at large.

These findings are suggestive of the importance of the incorporation of daily physical activity into the lifestyle of youth. The findings propose the evaluation of PE curricula in the school setting by evaluating; the length of time involved in the program, the types of activities, and intensity levels of the activities. Furthermore, the results verify the necessity of parental involvement and support of physical activity outside the school setting. Although this physical activity intervention was not statistically significant, the findings are promising as the use of pedometers were cost effective and easy to implement. Improvements in methodological design and sampling are warranted in future research. Further research focusing on community based interventions that increase physical activity in this population is indicated. 


\section{LIST OF REFERENCES}

Aggoun, Y. (2007). Obesity, metabolic syndrome, and cardiovascular disease. Pediatric Research, 61(6), 1-8.

Allen, N.A. (2004). Social cognitive theory in diabetes exercise research: An integrative literature review. The Diabetes Educator, 30(5), 805-819.

Anderson, P. M., \& Butcher, K. E. (2006). Childhood obesity: Trends and potential causes. Future Child, 16(1), 19-45.

Annesi, J.J. (2006). Relations of physical self-concept and self-efficacy with frequency of voluntary physical activity in preadolescents: Implications for after-school care programming. Journal of Psychosomatic Research, 61(4), 515-520.

Bandura, A. (1977). Self-efficacy: toward a unifying theory of behavioral change. Psychological Review, 84(2), 191-215.

Bandura, A. (1986). Social foundations of thought and action: A social cognitive theory. Englewood Cliffs, NJ: Prentice Hall.

Baranowski, T., Thompson, W.O., DuRant, R.H., Baranowski, J., \& Puhl, J. (1993). Observations on physical activity in physical locations: Age, gender, ethnicity, and month effects. Research Quarterly for Exercise and Sport, 64(2), 127-133.

Barlow, S. E., \& Dietz, W. H. (1998). Obesity evaluation and treatment: Expert committee recommendations. The maternal and child health bureau, health resources and services administration and the department of health and human services. Pediatrics, 102(3), E29.

Beets, M.W., Patton, M.M., \& Edwards, S. (2005). The accuracy of pedometer steps and time during walking in children. Medicine and Sports and Exercise, 37(3), 513520 .

Beets, M. W., \& Pitetti, K. H. (2004). One-mile run/walk and body mass index of an ethnically diverse sample of youth. Medicine and Science in Sports and Exercise, 36(10), 1796-1803.

Berkey, C.S., Rockett, H.R., Gillman, M.W., \& Colditz, G.A. (2003). One-year changes in activity and in inactivity among 10 to 15 year old boys and girls: Relationship to change in body mass index. Pediatrics, 111(4 part 1), 836-843.

Bjornson, K. F. (2005). Physical activity monitoring in children and youths. Pediatric Physical Therapy, 17(1), 37-45. 
Bocquier, A., Boullu-Ciocca, S., Verger, P., \& Oliver, C. (2006). Obesity: Where are we now? Presse Med, 35(2 Pt 2), 270-276.

Brown, S.P., Miller, W.C., \& Eason, J.M. (2006). Exercise physiology: Basis of human movement in health and disease. Baltimore, MD: Lippincott, Williams, \& Wilkins.

Burgeson, C. R., Wechsler, H, Brener, N.D., Young, J.C., \& Spain, C.G. (2001). Physical education and activity: Results from the school health policies and programs study 2000. Journal of School Health, 71(7), 279-293.

Butcher, Z, Fairclough, S., Gareth, Stratton, \& Richardson, D. (2007). The effect of feedback and information on children's pedometer step counts at school. Pediatric Exercise Science, 19(1), 29-38.

Cardinal, B. J. (1999). Acsm/aha joint position statement. Medicine and Science in Sports and Exercise, 31(2), 353-354.

Carrel, A. L., Clark, R. R., Peterson, S. E., Nemeth, B. A., Sullivan, J., \& Allen, D. B. (2005). Improvement of fitness, body composition, and insulin sensitivity in overweight children in a school-based exercise program: A randomized, controlled study. Archives of Pediatric Adolescent Medicine, 159(10), 963-968.

Caspersen, C. J., Powell, K. E., \& Christenson, G. M. (1985). Physical activity, exercise, and physical fitness: Definitions and distinctions for health-related research. Public Health Report, 100(2), 126-131.

Centers for Disease Control \& Prevention. (1999). Promoting physical activity: A guide for community action. Retrieved February 20, 2006 from http://www.cdc.gov/nccdphp/dnpa/pahand.htm

Centers for Disease Control \& Prevention. (2000). CDC growth charts U.S. Retrieved April 6, 2006 from http://www.cdc.gov/growthcharts/

Centers for Disease Control \& Prevention. (2003). Physical activity levels among children aged 9-13 years-United States, 2002. Retrieved April 6, 2006, from http://www.cdc.gov/mmwr/preview/mmwrhtml $/ \mathrm{mm} 5233 \mathrm{a} 1 . \mathrm{htm}$

Centers for Disease Control \& Prevention. (2006). Physical activity for everyone: Measuring physical activity intensity: Metabolic equivalent (met) level. Retrieved February 20, 2006 from http://www.cdc.gov/nccdphp/dnpa/physical/measuring/met.htm

Centers for Disease Control \& Prevention. (2007). National Center for Health Statistics definitions. Retrieved February 16, 2008 from http://www.cdc.gov/nchs/datawh/nchsdefs/bmi.htm\#overweight 
Cole, D., Waldrop, J., D'Auria, J., \& Garner, H. (2006). An integrative research review: Effective school-based childhood overweight interventions. Journal for Specialists in Pediatric Nursing, 11(3), 166-177.

Council on Sports Medicine and Fitness and Council on School Health. (2006). Active healthy living: Prevention of childhood obesity through increased physical activity. Pediatrics, 117(5), 1834-1842.

Cureton, K.J. \& Plowman, S.A. (2001). Aerobic capacity assessments. In Welk, G.J., Morrow, J., and Falls, H (Eds.), FITNESSGRAM Reference Guide, Dallas TX: The Cooper Institute. Retrieved February 2, 2006 from http://www.cooperinstitute.org/products/grams/documents/FITNESSGRAM_Refe renceGuide.pdf

Daniels, S. R. (2006). The consequences of childhood overweight and obesity. Future Child, 16(1), 47-67.

De Bourdeaudhuij, I., Lefevre, J., Deforche, B., Wijndaele, K., Matton, L., \& Philippaerts, R. (2005). Physical activity and psychosocial correlates in normal weight and overweight 11 to 19 year olds. Obesity Research, 13(6), 1097-1105.

Dencker, M., Thorsson, O., Karlsson, M.K., Linden, S.E., Svenson, J., Wollmer, P., \& Andersen, L.B. (2006). Daily physical activity and its relation to aerobic fitness in children aged 8-11 years. European Journal of Applied Physiology, 96(5), 587592.

Dencker, M., Thorsson, O., Karlsson, M.K., Linden, C., Eiberg, S., Wollmer, P., \& Andersen, L.B. (2007). Gender differences and determinants of aerobic fitness in children aged 8-11 years. European Journal of Applied Physiology, 99(1), 19-26.

Dennison, B. A., Straus, J. H., Mellits, E. D., \& Charney, E. (1988). Childhood physical fitness tests: Predictor of adult physical activity levels? Pediatrics, 82(3), 324330 .

Dietz, W. H., \& Bellizzi, M. C. (1999). Introduction: The use of body mass index to assess obesity in children. American Journal of Clinical Nutrition, 70(1 Part 2), $123 \mathrm{~S}-125 \mathrm{~S}$.

DiPietro, L., Mossberg, H. O., \& Stunkard, A. J. (1994). A 40-year history of overweight children in Stockholm: Life-time overweight, morbidity, and mortality. International Journal of Obesity and Related Metabolic Disorders, 18(9), 585590. 
Dishman, R. K., Motl, R. W., Saunders, R., Felton, G., Ward, D. S., Dowda, M., et al. (2004). Self-efficacy partially mediates the effect of a school-based physicalactivity intervention among adolescent girls. Preventive Medicine, 38(5), 628636.

Dishman, R. K., Motl, R. W., Saunders, R., Felton, G., Ward, D. S., Dowda, M., et al. (2005). Enjoyment mediates effects of a school-based physical-activity intervention. Medicine and Science in Sports and Exercise, 37(3), 478-487.

Drinkard, B., McDuffie, J., McCann, S., Uwaifo, G.I., Nicholson, J., \& Yanovski, J.A. (2001). Relationships between walk/run performance and cardiorespiratory fitness in adolescents who are overweight. Physical Therapy, 81(12), 1889-1896.

Ekelund, U., Sandinha, L.B., Anderssen, S.A., Harro, M., Franks, P.W., Brage, S., et al. (2004). Associations between objectively assessed physical activity and indicators of body fatness in 9 to 10 year old European children: A population-based study from 4 district regions in Europe (the European Youth Heart Study). American Journal of Clinical Nutrition, 80(3), 584-590.

Eston, R. G., Rowlands, A. V., \& Ingledew, D. K. (1998). Validity of heart rate, pedometry, and accelerometry for predicting the energy cost of children's activities. Journal of Applied Physiology, 84(1), 362-371.

Fisher, A., Reilly, J.J., Montgomery, C., Kelly, L., Williamson, A., \& Jackson, D.M. (2005). Seasonality in physical activity and sedentary behaviour in young children. Pediatric Exercise Science, 17(1), 31-40.

Goran, M. I. (2001). Metabolic precursors and effects of obesity in children: A decade of progress, 1990-1999. American Journal of Clinical Nutrition, 73(2), 158-171.

Goran, M., Fields, D.A., Hunter, G.R., Herd, S.L., \& Weinsier, R.L. (2000). Total body fat does not influence maximal aerobic capacity. International Journal of Obesity, 24(7), 841-848.

Goran, M.I., Nagy, T.R., Gower, B.A., \& Johnson, R. (1998). Developmental changes in energy expenditure and physical activity in children: Evidence for energy conservation in girls prior to puberty. Pediatrics, 101(5), 887-891.

Gordon-Larsen, P., Nelson, M.C., \& Popkin, B.M. (2004). Longitudinal physical activity and sedentary behavior trends: Adolescence to adulthood. American Journal of Preventive Medicine, 27(4), 277-283.

Grunbaum, J., Kann, L., Kinchen, S., Ross, J., Hawkins, J., Lowry, R., et al. (2004). Youth risk behavior surveillance--United States, 2003 (abridged). Journal of School Health, 74(8), 307-324. 
Hardin, D. S., Hebert, J. D., Bayden, T., Dehart, M., \& Mazur, L. (1997). Treatment of childhood syndrome x. Pediatrics, 100(2), E5.

Harrell, J., McMurray, R.G., Gansky, S.A., Bangdiwala, S.I., \& Bradley, C.B. (1999). A public health versus a risk-based intervention to improve cardiovascular health in elementary school children: The cardiovascular health in children study. American Journal of Public Health, 89(10), 1529-1535.

Harrison, M., Burns, C.F., McGuinness, M., Heslin, J., \& Murphy, N.M. (2006). Influence of a health education intervention on physical activity and screen time in primary school children: 'Switch Off-Get Active'. Journal of Science in Sport and Medicine, 9(5), 388-394.

Haskell, W. L., \& Kiernan, M. (2000). Methodological issues in measuring physical activity and physical fitness when evaluating the role of dietary supplements for physically active people. American Journal of Clinical Nutrition, 72(2 Suppl), 541S-550S.

Hayman, L.L., Williams, C.L., Daniels, S.R., Steinberger, J., Paridon, S., Dennison, B.A., et al. (2004). Cardiovascular health promotion in the schools: A statement for health and education professionals and child health advocates from the committee on atherosclerosis, hypertension, and obesity in youth of the council on cardiovascular disease in the young, American Heart Association. Circulation, 110 (15), 2266-2275.

Hills, A.P., King, N.A., \& Armstrong, T.P. (2007). The contribution of physical activity and sedentary behaviors to the growth and development of children and adolescents: Implications for overweight and obesity. Sports Medicine, 37(6), 533-545.

Hoos, M.B., Gerver, W.J.M., Kester, A.D., \& Westerterp, K.R. (2003). Physical activity levels in children and adolescents. International Journal of Obesity, 27(5), 605609.

Hortz, B. \& Petosa, R. (2006). Impact of the "planning to be active" leisure time physical exercise program on rural high school students. Journal of Adolescent Health, 39(4), 530-535.

Kline, G.M., Porcari, J.P., Hintermeister, R., Freedson, P.S., Ward, A., McCarron, R.F., et al. (1987). Estimation of $\mathrm{VO}^{2}$ max from a one-mile track walk, gender, age, and body weight. Medicine and Science in Sports and Exercise, 19(3), 253-259.

Lazaar, N., Aucouturier, J., Ratel, S., Rance, M., Meyer, \& Duche', P. (2007). Effect of physical activity intervention on body composition in young children: Influence of body mass index status and gender. Acta Paediatrica, 96(9), 1315-1320. 
LeMasurier, G.C. \& Corbin, C.B. (2006). Steps counts among middle school students Vary with aerobic fitness level. Research Quarterly for Exercise and Sport, 77(1), 14-29.

Loucaides, C.A., Chedzoy, S.M., \& Bennett, N. (2004). Differences in physical activity levels between urban and rural school children in Cyprus. Health Education Research, 19(2), 138-147.

Luepker, R. V., Perry, C.L., McKinlay, S.M., Nader, P.R., Parcel, G.S., Stone, E.J., et al. (1996). Outcomes of a field trial to improve children's dietary patterns and physical activity. The child and adolescent trial for cardiovascular health. Catch collaborative group. JAMA, 275(10), 768-776.

Mahar, M.T., Murphy, S.K., Rowe, D.A., Golden, J., Shields, T., \& Raedeke, T.D. (2006). Effects of a classroom-based program on physical activity and on-task behavior. Medicine and Science in Sports and Exercise, 38(12), 2086-2094.

Mauriello, L.M., Driskell, M.M, Sherman, K.J., Johnson, S.S., Prochaska, J.M., \& Prochaska, J.M. (2006). Acceptability of a school-based intervention for the prevention of adolescent obesity. Journal of School Nursing, 22(5), 269-277.

McSwegin, P.J., Plowman, S.A., Wolff, G.M., \& Guttenberg, G.L. (1998). The validity of a one-mile walk test for high school age individuals. Measurement in Physical Education and Exercise Science, 2(1), 47-63.

Melnyk, B.M., Small, L., Morrison-Beedy, D., Strasser, A., Kreipe, R., Jacobson, K., et al. (2006). Mental health correlates of healthy lifestyle attitudes, beliefs, choices, and behaviors in overweight adolescents. Journal of Pediatric Health Care, 20(6), 401-406.

Molnar, D., \& Livingstone, B. (2000). Physical activity in relation to overweight and obesity in children and adolescents. European Journal of Pediatrics, 159(Suppl 1), S45-55.

Muntner, P., He, J., Cutler, J. A., Wildman, R. P., \& Whelton, P. K. (2004). Trends in blood pressure among children and adolescents. JAMA, 291(17), 2107-2113.

Must, A., Jacques, P. F., Dallal, G. E., Bajema, C. J., \& Dietz, W. H. (1992). Long-term morbidity and mortality of overweight adolescents. A follow-up of the Harvard growth study of 1922 to 1935. New England Journal of Medicine, 327(19), 13501355.

National Center for Health \& Statistics. (2000). Prevalence of overweight among children and adolescents: United States. Retrieved February 20, 2006 from http://www.cdc.gov/nchs/products/pubs/pubd/hestats/overwght99.htm 
National Association for Sport and Physical Education. (2003). Guidelines for appropriate physical activity for elementary school children 2003 update. Reston, VA: Corbin, C.B. \& Pangrazi, R.P.

National Association for Sport and Physical Education. (2004). Physical activity for children: A statement of guidelines for children ages 5-12 ( $2^{\text {nd }}$ edition$)$.

Nieto, F. J., Szklo, M., \& Comstock, G. W. (1992). Childhood weight and growth rate as predictors of adult mortality. American Journal of Epidemiology, 136(2), 201213.

Norman, A.C., Drinkard, B., McDuffie, J.R., Ghorbani, S., Yanoff, L.B., \& Yanovski, J.A. (2005). Influence of excess adiposity on exercise fitness and performance in overweight children and adolescents. Pediatrics, 115(6), (e690-e696).

Norman, G.J., Schmid, B.A., Sallis, J.F., Calfas, K.J., \& Patrick, K. (2005). Psychosocial and environmental correlates of adolescent sedentary behaviors. Pediatrics, 116(4), 908-916.

Obert, P. Mandigouts, S., Nottin, S., Vinet, A., N'Guyen, L.D., \& Lecoq, A.M. (2003). Cardiovascular responses to endurance training in children: Effect of gender. European Journal of Clinical Investigation, 33(3), 199-208.

Ogden, C. L., Carroll, M.D., Curtin, L.R., McDowell, M.A., Tabak, C.J., \& Flegal, K.M. (2006). Prevalence of overweight and obesity in the United States, 1999-2004. JAMA, 295(13), 1549-1555.

Ohtake, P.J. (2005). Field tests of aerobic capacity for children and older adults. Cardiopulmonary Physical Therapy Journal, 16(2), 5-11.

Oliver, M., Schofield, G., \& McEvoy, E. (2006). An integrated curriculum approach to increasing habitual physical activity in children: A feasibility study. Journal of School Health, 76(2), 74-79.

Ornstein, R.M. \& Jacobson, M.S. (2006). Supersize teens: The metabolic syndrome. Adolescent Medicine Clinics, 17(3), 565-587.

Pajares, F. (2002). Overview of social cognitive theory and of self-efficacy. Retrieved October 28, 2006 from http://www.emory.edu/EDUCATION/mfp/eff.html

Pangrazi, R. P., Beighle, A., Vehige, T., \& Vack, C. (2003). Impact of promoting lifestyle activity for youth (play) on children's physical activity. Journal of School Health, 73(8), 317-321. 
Pate, R.R., Wang, C.Y., Dowda, M., Farrell, S.W., \& O’Neill, J.R. (2006). Cardiorespiratory fitness levels among US youth 12 to 19 years of age. Archives of Pediatric and Adolescent Medicine, 160(10), 1005-1012.

Polit, D.F. \& Beck, C.T. (2004). Nursing research: Principles and Methods (7th ed.). Philadelphia, PA: Lippincott, Williams, \& Wilkins.

Pratt, M., Macera, C. A., \& Blanton, C. (1999). Levels of physical activity and inactivity in children and adults in the United States: Current evidence and research issues. Medicine and Science in Sports Exercise, 31(11 Suppl), S526-533.

Riddoch, C.J., Mattocks, C., Deere, K., Saunders, J., Kirkby, J., Tilling, K., et al. (2007). Objective measurement of levels and patterns of physical activity. Archives of Disease in Childhood, 92(11), 963-969.

Robbins, L.B., Pender, N.J., \& Kazanis, A. (2003). Barriers to physical activity perceived by adolescent girls. American College of Nurse-Midwives, 48(3), 206-212.

Robbins, L.B., Pis, M.B., Pender, N.J., \& Kazanis, A. (2004). Exercise self-efficacy, enjoyment, and feeling states among adolescents. Western Journal of Nursing Research, 26(7), 699-715.

Roberts, S.O. (2000). The role of physical activity in the prevention and treatment of childhood obesity. Pediatric Nursing, 26(1), 33-42.

Rowlands, A.V., Eston, R.G., \& Ingledew, D.K. (1997). Measurement of physical activity in children with particular reference to the use of heart rate and pedometry. Sports Medicine, 24(4), 258-272.

Rowlands, A. V., Eston, R. G., \& Ingledew, D. K. (1999). Relationship between activity levels, aerobic fitness, and body fat in 8- to 10-yr-old children. Journal of Applied Physiology, 86(4), 1428-1435.

Sallis, J. F., McKenzie, T.L, Elder, J.P., Prochaska, J.J., Brown, M., Zive, M.M., et al. (2003). Environmental interventions for eating and physical activity: A randomized controlled trial in middle schools. American Journal of Preventive Medicine, 24, 209-217.

Sallis, J. F., Prochaska, J. J., \& Taylor, W. C. (2000). A review of correlates of physical activity of children and adolescents. Medicine and Science in Sports and Exercise, 32(5), 963-975.

Sallis, J.F., Taylor, W.C., Dowda, M., Freedson, P.S., \& Pate, R.R. (2002). Correlates of vigorous physical activity for children in grades 1 through 12: Comparing parentreported and objectively measured physical activity. Pediatric Exercise Science, 14(1), 30-44. 
Saunders, R. P., Pate, R. R., Felton, G., Dowda, M., Weinrich, M. C., Ward, D. S., et al. (1997). Development of questionnaires to measure psychosocial influences on children's physical activity. Preventive Medicine, 26(2), 241-247.

Schofield, L., Mummery, W. K., \& Schofield, G. (2005). Effects of a controlled pedometer-intervention trial for low-active adolescent girls. Medicine and Science in Sports and Exercise, 37(8), 1414-1420.

Scott, L. (2006). Insulin resistance syndrome in children. Pediatric Nursing, 32(2), 119143.

Scruggs, P.W. (2007a). Middle school physical education activity quantification: A pedometer steps/minute guideline. Research Quarterly for Exercise and Sport, 78(4), 284-289.

Scruggs, P.W. (2007b). Quantifying activity time via pedometry in fifth and sixth grade physical education. Journal of Physical Activity and Health, 4(2), 215-227.

Scruggs, P. W., Beveridge, S. K., Eisenman, P. A., Watson, D. L., Shultz, B. B., \& Ransdell, L. B. (2003). Quantifying physical activity via pedometry in elementary physical education. Medicine and Science in Sports and Exercise, 35(6), 10651071.

Scruggs, P.W., Beveridge, S.K., Watson, D.L., \& Clocksin, B.D. (2005). Quantifying physical activity in first through fourth grade physical education via pedometry. Research Quarterly for Exercise and Sport, 76(2), 166-175.

Shephard, R. J. (1997). Curricular physical activity and academic performance. Pediatric Exercise Science, 9(13), 113-125.

Sherwood, N.E., Taylor, W.C., Treuth, M., Klesges, L.M., Baranowski, T., Zhou, A., et al. (2004). Measurement characteristics of activity-related psychosocial measures in 8 to 10 year old African American girls in the Girls health Enrichment Multisite Study (GEMS). Preventive Medicine, 38(Supp.), S60-S68.

Steinberger, J. \& Daniels, S. (2003). Obesity, insulin resistance, diabetes, and cardiovascular risk in children: An American Heart Association scientific statement from the Atherosclerosis, Hypertension, and Obesity in the Young Committee (Council on Cardiovascular Disease in the Young) and the Diabetes Committee (Council on Nutrition, Physical Activity, and Metabolism). Circulation, 107(10), 1448-1453.

Stewart, J. A., Dennison, D.A., Kohl, H.W., \& Doyle, A. (2004). Exercise level and energy expenditure in the take 10 ! In-class physical activity program. Journal of School Health, 74(10), 397-400. 
Strauss, R.S., Rodzilsky, D., Burack, G., \& Colin, M. (2001). Psychosocial correlates of physical activity in healthy children. Archives of Pediatric and Adolescent Medicine, 155(8), 897-902.

Strong, W. B., Malina, R. M., Blimkie, C. J., Daniels, S. R., Dishman, R. K., Gutin, B., et al. (2005). Evidence based physical activity for school-age youth. Journal of Pediatrics, 146(6), 732-737.

Summerbell, C.D., Waters, E., Edmunds, L.D., Kelly, S., Brown, T., \& Campbell, K.J. (2001). Interventions for preventing obesity in children. Cochrane Database of Systematic Reviews, 2001(1). Retrieved February 27, 2008 from http://www.cochrane.org/reviews/en/ab001871.html

Task Force on Community Preventive Services. (2005). Enhanced physical education classes in schools are recommended to increase physical activity among young people. Guide to Community Preventive Services. Retrieved March 2, 2008 from http://www.thecommunityguide.org/pa/pa-int-school-pe.pdf

Trost, S.G. (2001). Objective measurement of physical activity in youth: Current issues, future directions. Exercise and Sport Sciences Reviews, 29(1), 32-36.

Trost, S.G., Sallis, J.F., Pate, R.R., Freedson, P.S., Taylor, W.C., \& Dowda, M. (2003). Evaluating a model of parental influence on youth physical activity. American Journal of Preventive Medicine, 25(4), 277-282.

Tudor-Locke, C. (2002). Taking steps toward increased physical activity: Using pedometers to measure and motivate. In C.B.Corbin, R.B. Pangrazi, \& D. Franks (Eds.), Research Digest, 3(17) (President's Council on Physical Fitness and Sports, Vol. 3, pp. 1-8). Washington, D.C.: U.S. Department of Health and Human Services. Retrieved November 13, 2005 from http://www.fitness.gov/pcpfsdigestjune2002.pdf

Tudor-Locke, C., Pangrazi, R.P., Corbin, C.B., Rutherford, W.J., Vincent, S.D., Raustorp, A., et al., (2004). BMI-referenced standards for recommended pedometer-determined steps/day in children. Preventive Medicine, 38(6), 85764.

United States Department of Health and Human Services (2001). Healthy People 2010, 2nd ed. with understanding and improving health and objectives for improving health (2 vols.): U.S. Department of Health and Human Services.

United States Department of Health and Human Services (2004). Healthy People 2010. Retrieved October 23, 2006, from http://www.healthypeople.gov/document/html/objectives/.htm 
United States Department of Health and Human Services (2005). The national survey of children's health 2003. Retrieved November 14, 2006, from http://mchb.hrsa.gov/overweight/states/kentucky.htm

Vincent, S.D., Pangrazi, R.P., \& Raustorp, A. (2003). Activity levels and body mass index of children in the United States, Sweden, and Australia. Medicine and Science in Sports and Exercise, 35(8), 1367-1373.

Wang, G., \& Dietz, W. H. (2002). Economic burden of obesity in youths aged 6 to 17 years: 1979-1999. Pediatrics, 109(5), E81-81.

Washington, R.L. Bricker, T.J., Alpet, B.S, Daniels, S.R., Deckelbaum, R.J., Fisher, E.A., et al. (1994). Guidelines for exercise testing in the pediatric age group: From the Committee on Atherosclerosis and Hypertension in Children, Council on Cardiovascular Disease in the Young the American Heart Association. Circulation, 90(4), 2166-2179.

Weiss, M.R. (2000). Motivating kids in physical activity. In C.B.Corbin \& R.B. Pangrazi (Eds.), Research Digest, 3(11) (President's Council on Physical Fitness and Sports, Vol. 3, pp. 1-8). Washington, D.C.: U.S. Department of Health and Human Services. Retrieved November 13, 2005 from http://www.presidentschallenge.org/misc/news_research/research_digests/59547a. pdf

Weiss, R., Dziura, J., Burgert, T.S., Tamborlane, W.V., Taksali, S.E., Yeckel, C.W., et al. (2004). Obesity and the metabolic syndrome in children and adolescents. New England Journal of Medicine, 350(23), 2362-2374.

Welk, G.J., Corbin, C.B., \& Dale, D. (2000). Measurement issues in the assessment of physical activity in children. Research Quarterly for Exercise and Sport, 71(2), 59-73.

Whitaker, R. C., Wright, J. A., Pepe, M. S., Seidel, K. D., \& Dietz, W. H. (1997). Predicting obesity in young adulthood from childhood and parental obesity. New England Journal of Medicine, 337(13), 869-873. 
APPENDICES 


\section{Appendix A. Amherst Health and Activity Survey}

\section{THIS CHILD'S ACTIVITIES}

This part of the survey is about this child's activities over the past 7 days including activities done at school, after school, at home, and on weekends. Please give all answers only about the child or teenager named at the top of the survey.

It may help you remember if you think about the following things:

- In the past week what did this child do for recreation?

- What sports, exercise, or physical activity teams, classes, lessons, or practices did this child participate in last week?

- Did this child go anywhere unusual last week, for a weekend outing or after-school event?

- What activities did this child do with his or her friends?

We know that you are probably not aware of all the activities this child does. You will have to make estimates of the amount of time this child spent in various activities. If you simply do not know whether this child has done a particular activity in the past 7 days, then circle the "don't know" number.

We prefer that you complete this survey based on your own knowledge of this child's activities.

For each activity, please answer three questions

A. Did this child do this activity in the past 7 days? (CIRCLE YES, NO, DONT KNOW)

B. If yes, on how many days did this child do the activity in the past 7 days?

C. On average, how many minutes did this child do this activity on days when he or she did the activity?

Think about this child's activities during the last 7 days.

\begin{tabular}{|c|c|c|c|c|c|}
\hline \multirow{2}{*}{$\frac{\text { ACTIVTY }}{\text { 1. Aerobics/aerobic dancing }}$} & \multicolumn{3}{|c|}{$\begin{array}{l}\text { Was this activity } \\
\text { done in the last } \\
\text { seven days? } \\
\text { Don't }\end{array}$} & $\begin{array}{l}\text { How many } \\
\text { days in the } \\
\text { last } 7 \text { days? }\end{array}$ & $\begin{array}{l}\text { On average } \\
\text { how many } \\
\text { minutes each } \\
\text { day activity was } \\
\text { done? }\end{array}$ \\
\hline & 0 & & 2 & ___ days & _minutes \\
\hline 2. Ball play: 4-square, dodge ball, kickball, catch & 0 & & 2 & _days & minutes \\
\hline 3. Baseball/softball & 0 & & 2 & __ days & -minutes \\
\hline 4. Basketball & 0 & & 2 & ___days & minutes \\
\hline 5. Bicycling or exercise cycling & 0 & & 2 & _ days & minutes \\
\hline 6. Calisthenics: push-ups, sit-ups, jumping jacks & 0 & & 2 & _ days & minutes \\
\hline 7. Cheerleading, marching band, drill team & 0 & & 2 & _ days & minutes \\
\hline 8. Climbing stairs for exercise, stairmaster & 0 & & 2 & ___ days & __ _ minutes \\
\hline 9. Computer/video games/internet & 0 & 1 & 2 & __ days & minutes \\
\hline 10. Dance classes (ballet, jaz, modem, tap) & 0 & 1 & 2 & — days & _ minutes \\
\hline 11. Dancing (social, recreational) & 0 & 1 & 2 & __days & _minutes \\
\hline 12. Football & 0 & 1 & 2 & _ days & minutes \\
\hline 13. Field hockey & 0 & & 2 & _ days & minutes \\
\hline 14. Frisbee games & 0 & & 2 & — days & minutes \\
\hline 15. Gardening, yardwork, mowing & 0 & & 2 & — days & minutes \\
\hline 16. Golfing & 0 & & 2 & _ days & minutes \\
\hline
\end{tabular}




\section{ACTIMTY}

17. Cymnastics, tumbling trampoline

18. Hiking

19. Homework, studying

20. Housecleaning that involves mopping, scrubbing, sweeping, vacuuming

21. Ice hockey

22. Indoor or outdoor playground: swing, slide, monkey bars, Kidsports

23. Jumping rope

24. Laser tag

25. Martial arts: karate, judo

26. Outdoor play: war, climb trees, hide \& seek

27. Racquet sports: tennis, squash, paddle ball, badminton, etc

28. Reading (not for school)

29. Rowing or rowing machine

30. Running jogging, treadmill

31 . Sitting and listening to music

32. Sitting and talking with friends (not on phone)

33. Skate boarding

34. Skating: ice, roller, in-line

35. Sking: cross-country or NordicTrack

36. Sking: downhill or water

37. Soccer

38. Swimming laps

39. Talking on the phone

40. Television or video watching

41. Volleyball

42. Walking for exercise (including treadmill)

43. Walking for transportation

44. Water play: in pool or lake

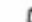

Was this activity

done in the last

seven days?

No Yes recall

$0 \quad 12$

02

0

2

How many

days in the

last 7 days?

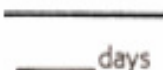

days

days

days

On average

how many

minutes each

day activity was

done?

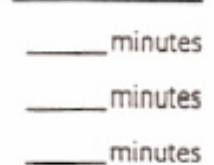

minutes

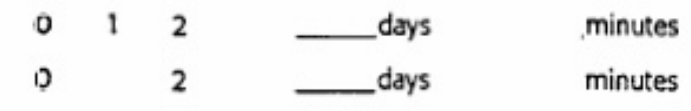

o 2
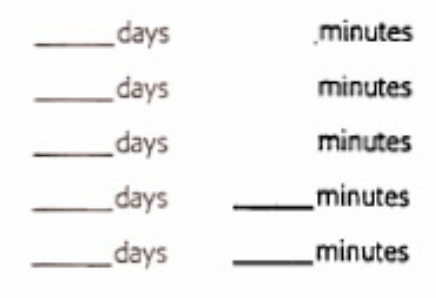

$\begin{array}{lll}0 & 1 & 2\end{array}$

days
days
days $\begin{array}{r}\text { minutes } \\ \text { minutes } \\ \text { days }\end{array}$ days ${ }_{\text {dinutes }}^{\text {minutes }}$




\section{ACTIVTY}

45. Weight lifting

46. Wrestling

47. Other

48. Other

49. Other
Was this activity

done in the last

seven days?

Don't

No Yes recall

0

0

0

01

0

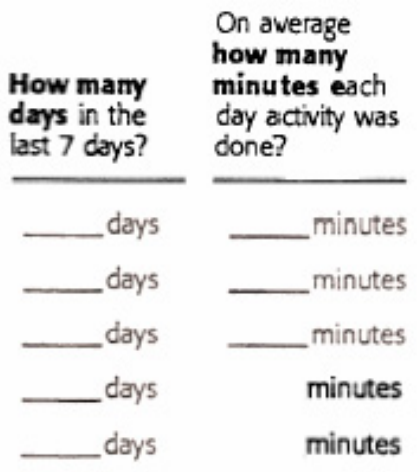

Q8. How confident are you in the accuracy of the estimates in the preceding list? (CIRCLE ONE NUMBER ONLY)

1. Very confident

2. Somewhat confident

3. Not sure how confident

4. Slightly confident

5. Not at all confident

Q9. How do you rate this child's level of physical activity, compared to others of the same age and sex? (CIRCLE ONE NUMBER ONLY)

1. Much less than others

2. Somewhat less than others

3. About the same

4. Somewhat more than others

5. Much more than others

Q10. In the past 7 days, how many days did this child do physical activity or sports at these locations? (CIRCLE ONE NUMBER FOR EACH IIEM)
A. School grounds (after-school only)
B. Park or playground
C. Neighborhood
D. After-school care
E. Commercial facility
(MMCANWCA health club, dance studio)
F. Public recreation center
G. Other, please specify:

Number of days in the past week

$\begin{array}{llllllll}0 & 1 & 2 & 3 & 4 & 5 & 6 & 7 \\ 0 & 1 & 2 & 3 & 4 & 5 & 6 & 7 \\ 0 & 1 & 2 & 3 & 4 & 5 & 6 & 7 \\ 0 & 1 & 2 & 3 & 4 & 5 & 6 & 7 \\ 0 & 1 & 2 & 3 & 4 & 5 & 6 & 7 \\ 0 & & 2 & 3 & 4 & 5 & 6 & 7 \\ 0 & & 2 & 3 & 4 & 5 & 6 & 7\end{array}$

Q11. Where does this child go most often after School? (CIRCLE ONE NUMBER ONLY)

1. After-school program at school

2. After-school program at another location

3. Home, with supervision

4. Home, without supervision

5. Home of relative or friend

6. Other, please specify: 
Q12 Indicate which of the following sports teams this child was on during the past year at school and outside of school: (CIRCLE NO "O" OR YES " 1 " FOR EACH TTEM)

\section{At School}

Ne Yes

A. Baseball or softball

B. Basketball

C. Fieid hockey

D. Frisbee

E Football

F. Golf

C. Ice hockey

H. Lacrosse

l. Soccer

J. Swimming

K. Tennis

L. Track and field

$M$. Volleyball

N. Other (specify):

\section{Outside of School}

Ne Yes

$\begin{array}{llll}0 & 1 & 0 & 1 \\ 0 & & 0 & 1 \\ 0 & & 0 & 1 \\ 0 & & 0 & 1 \\ 0 & & 0 & \\ 0 & 1 & 0 & 1 \\ 0 & & 0 & 1 \\ 0 & & 0 & 1 \\ 0 & & 0 & 1 \\ 0 & & 0 & 1 \\ 0 & & 0 & 1 \\ 0 & & 0 & \\ 0 & 1 & 0 & \end{array}$

Q13. Indicate which of the following classes or lessons this child took during the past year outside of school: (CIRCLE NO "O" OR YES "1" FOR EACH ITEM)
A. Dance (ballet, jazz, modern)
B. Aerobics
C. Figure skating
D. Gymnastics
E. Martial arts
F. Skiing
C. Swimming
H. Tennis
L. Baseball or softball
J. Basketball
K. Field Hockey
L Football
M. Golf
N. Ice Hockey
O. Lacrosse
P. Soccer
Q. Track and Field
R. Other (specify):

$\begin{array}{ll}0 & 1 \\ 0 & \\ 0 & \\ 0 & 1 \\ 0 & \\ 0 & \\ 0 & \\ 0 & \\ 0 & \\ 0 & \\ 0 & 1 \\ 0 & 1 \\ 0 & \\ 0 & 1 \\ 0 & 1 \\ 0 & 1 \\ 0 & 1 \\ & \end{array}$

№ Yes 
Q14. On average, how many minutes does this child spend each week walking, bicycling, or skating to and from school?

minutes per week

Q15. During the past week, how much time did your child spend outdoors:
A. On a typical weekday? minutes per day outdoors
B. On a typical weekend day? minutes per day outdoors

Q16. How do you rate this child's athletic coordination, compared to others of the same age and sex? (CIRCLE ONE NUMBER ONLY)

1. Much less coordinated

2. Somewhat less coordinated

3. About the same

4. Somewhat more coordinated

5. Much more coordinated

Q17. How much does this child enjoy physical activity? (CIRCLE ONE NUMBER ONLY)

1. Activity is very un-enjoyable

2. Activity is somewhat un-enjoyable

3. Neutral

4. Activity is somewhat enjoyable

5. Activity is very enjoyable

Q18. How much does this child enjoy physical education classes at school? (CIRCLE ONE NUMBER ONLY)

1. $P E$ is very unenjoyable

2. $\mathrm{PE}$ is somewhat un-enjoyable

3. Neutral

4. $\mathrm{PE}$ is somewhat enjoyable

5. $\mathrm{PE}$ is very enjoyable

6. Not enrolled in PE

Q19. What does this child usually do when she or he has a choice about how to spend recreational time? (CIRCLE ONE NUMBER ONLY)

1. Almost always chooses activities like TV, reading, listening to music, or computers

2. Usually chooses activities like TV, reading, listening to music, or computers

3. Just as likely to choose active as inactive recreation

4. Usually chooses activities like bicycling, dancing outdoor games, or active sports

5. Almost always chooses activities like bicycling, dancing, outdoor games, or active sports

\section{THIS CHILD'S ENVIRONMENT}

Q20 Please indicate which of the following apply to your neighborhood. (CIRCLE NO "O" OR YES "I" FOR EACH ITEM)

Sidewalks

Heavy traffic

Hills

Street lights

Dogs that are unattended

Enjoyable scenery

Frequently see people walking or exercising

High crime

$\begin{array}{cc}\text { No } & \text { Yes } \\ 0 & 1 \\ 0 & 1 \\ 0 & \\ 0 & \\ 0 & \\ 0 & \\ 0 & 1 \\ 0 & 1\end{array}$


Q21. How much do you agree with the following statements? (CIRCLE ONE NUMBER FOR EACH ITEM)

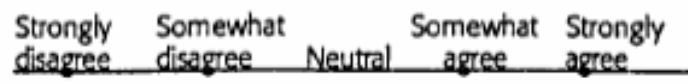

A. This child does enough physical activity to maintain good health and fitness.

$\begin{array}{lllll}1 & 2 & 3 & 4 & 5\end{array}$

B. It is safe for this child to play outdoors with other children in the neighborhood without adult supervision.

\section{2}

$3 \quad 4 \quad 5$

C. There are playgrounds, parks, or gyms close to home or that this child can get to easily.

Q22. How far from your home is the nearest public park where your child can be active or play sports?

$$
\text { miles }
$$

Q23. This park has a reputation of being: (CIRCLE ONE NUMBER ONLY)
1. Very unsafe
2. Somewhat unsafe
3. Neutral
4. Somewhat safe
5. Very safe

Q24. How often does this child go to this park? (CIRCLE ONE NUMBER ONLY)
0. None
1. Rarely
2. Sometimes
3. Often
4. Very often

Q25. At this child's school, are there supervised physical activity programs for all interested students? (CIRCLE ONE NUMBER FOR EACH ITEM)
A. After school
B. On weekends
C During the summer

$\begin{array}{ccc}\text { No } & \text { Yes } & \text { Don' Know } \\ 0 & 1 & 2 \\ 0 & 1 & 2 \\ 0 & 1 & 2\end{array}$

Q26. Yesterday, did this child eat the following: (CRCLE ONE NUMBER FOR EACH ITEM)

$$
\text { Nene Once More than once }
$$
A. Fresh fruit
B. Drank fruit juice
C. Green salad
D. Cooked vegetables
E. Hamburger, hot dog, or sausage
F. French fries or potato chips
G Cookies, doughnuts, pie, or cake

$\begin{array}{lll}0 & 1 & 2 \\ 0 & 1 & 2 \\ 0 & 1 & 2 \\ 0 & 1 & 2 \\ 0 & 1 & 2 \\ 0 & 1 & 2 \\ 0 & 1 & 2\end{array}$




\section{HOUSEHOLD INFLUENCES}

During a typical week how often has a member of your household: (CIRCLE ONE NUMBER FOR EACH TYPE OF PERSON)

Q27. Encouraged this child to do physical

None Once Sometimes daily Daily know applicable
activities or play sports?
A. Male adult(s)
B. Female adult(s)
C Other children

$\begin{array}{lllllll}0 & 1 & 2 & 3 & 4 & 5 & 6 \\ 0 & 1 & 2 & 3 & 4 & 5 & 6 \\ 0 & & 2 & 3 & 4 & 5 & 6\end{array}$

Q28. Done a physical activity or played sports with this child?
A. Male adult(s)
B. Female adult(s)
C Other children

$\begin{array}{lllllll}0 & 1 & 2 & 3 & 4 & 5 & 6 \\ 0 & 1 & 2 & 3 & 4 & 5 & 6 \\ 0 & 1 & 2 & 3 & 4 & 5 & 6\end{array}$

Q29. Provided transportation so this child can go to a place where he or she can do physical activities or play sports?
A. Male adult(s)
B. Female adult(s)
C. Other children

$\begin{array}{lllllll}0 & 1 & 2 & 3 & 4 & 5 & 6 \\ 0 & 1 & 2 & 3 & 4 & 5 & 6 \\ 0 & 1 & 2 & 3 & 4 & 5 & 6\end{array}$

Q30. Watched this child participate in physical activities or sports?
A. Male adult(s)
B. Female adult(s)
C. Other children

$\begin{array}{lllllll}0 & & 2 & 3 & 4 & 5 & 6 \\ 0 & 1 & 2 & 3 & 4 & 5 & 6 \\ 0 & 1 & 2 & 3 & 4 & 5 & 6\end{array}$

Q31. Told this child that physical activity is good for his or her health?
A. Male adult(s)
B. Female adult(s)
$\begin{array}{lllllll}0 & & 2 & 3 & 4 & 5 & 6 \\ 0 & & 2 & 3 & 4 & 5 & 6 \\ 0 & 1 & 2 & 3 & 4 & 5 & 6\end{array}$

Q32 How important is it to adults in your household that this child is good at sports and physical activities? (CIRCLE ONE NUMBER FOR EACH TYPE OF PERSON)

Very
Somewhat $\begin{gathered}\text { Somewhat Very Not } \\ \text { unimpertant__unimportant Neutral_important_important_Adolicable }\end{gathered}$
A. Male adult(s)
B. Female adult(s)

$\begin{array}{lll}1 & 2 & 3 \\ 1 & 2 & 3\end{array}$

$\begin{array}{lll}4 & 5 & 6 \\ 4 & 5 & 6\end{array}$

Q33. How much do the adults in your family enjoy physical activity or exercise? (CIRCLE ONE NUMBER FOR EACH TYPE OF PERSON)

$\begin{array}{cccccc}\begin{array}{c}\text { Not } \\ \text { eniorable }\end{array} & \begin{array}{c}\text { A little } \\ \text { eniovable }\end{array} & \begin{array}{c}\text { Not } \\ \text { sure }\end{array} & \begin{array}{c}\text { Somewhat } \\ \text { eniovable }\end{array} & \begin{array}{c}\text { Very } \\ \text { eniovable }\end{array} & \begin{array}{c}\text { Not } \\ \text { Applicable }\end{array} \\ 2 & 3 & 4 & 5 & 6 \\ 2 & 3 & 4 & 5 & 6\end{array}$




\section{THIS CHILD'S FRIENDS}

Q34. How many of this child's five closest friends are physically active on a regular basis? (CIRCLE ONE NUMBER ONLY)
Number of closest friends
01
2
$\begin{array}{lll}3 & 4 & 5\end{array}$

During a typical week how often: (CIRCLE ONE NUMBER FOR EACH ITEM)

None Once Sometimes Aaily Daily know

Q35. Does this child encourage his or her friends to do physical activities or sports?

$\begin{array}{llllll}0 & 1 & 2 & 3 & 4 & 5\end{array}$

Q36. Does this child's friends encourage him or her to do sports or physical activities?

0

$2 \quad 3 \quad 4 \quad 5$

Q37. Does this child's friends do physical activities or play sports with your child?

$\begin{array}{llllll}0 & 1 & 2 & 3 & 4 & 5\end{array}$

Q38. Do this child's friends or classmates tease him or her about not being good at physical activities or sports?

$\begin{array}{lllll}0 & 2 & 3 & 4 & 5\end{array}$

\section{PHYSICAL ACTIVITY OF ADULTS}

Q39. How many days in the past week did the adults in your household walk for exercise? (CIRCLE ONE NUMBER FOR EACH PERSON) Days in the past week Not applicable
A. Myself
B. Other adult female

$\begin{array}{ll}0 & 1 \\ 0 & 1 \\ 0 & 1\end{array}$
3

(3)

4
4
4

$\begin{array}{llll}5 & 6 & 7 & 8 \\ 5 & 6 & 7 & 8 \\ 5 & 6 & 7 & 8\end{array}$

Q40. On how many of the past 7 days did adults in your household do heavy house cleaning, gardening, or yard work for at least 20 minutes at a time?

(WRITE NUMBER FOR EACH PERSON OR LEAVE BLANK IF NOT APPLICABLE)
A. Myself days in past week
B. Other adult female days in past week
C. Other adult male days in past week

Q41. On how many of the past 7 days did adults in your household exercise or participate in sports acitvities for at least 20 minutes that made you sweat and breathe hard, such as basketball, jogging. swimming laps, tennis, fast bicyding or similar aerobic activities? WRITE NUMBER FOR EACH PERSON OR LEAVE BLANK IF NOT APPLICABLE)
A. Myself times per week
B. Other adult female times per week
C. Other adult male times per week 


\section{HOUSEHOLD DESCRIPTION}

Q42. Which of the following people live in the child's primary residence? (CIRCLE ALL THAT APPLY)

A. Mother

B. Other adult female

C. Father

D. Other adult male

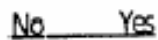

$\begin{array}{ll}0 & 1 \\ 0 & 1 \\ 0 & 1 \\ 0 & 1\end{array}$

Q43. Who is the main person completing this form? (CIRCLE ONE NUMBER ONLY)

1. Mother

2. Other adult female

3. Father

4. Other adult male

Answer the following questions for yourself and other adults in the household who help rear this child.

Q44. Which of the following categories includes the age of yourself and other adults in the household? (CIRCLE ONE NUMBER FOR EACH PERSON)

Under 25
$25-34$
$35-44$
$45-54$
$55-64$
$65-74$
75 or over
Not applicable

\section{A. Myself B. Other adult femaie 6 Other adult male}

Q45. For yourself and the other adults in the household, indicate the highest level of education completed. (CIRCLE ONE NUMBER FOR EACH PERSON)

High school or less

Some college but no degree

Associate degree in college-occupational program

A. Myself B. Other adult female C. Other adult male

Associate degree in college-academic program

Bachelors degree

Masters degree

Professional school degree

Doctorate degree

Not applicable

$\begin{array}{lll}1 & 1 & 1 \\ 2 & 2 & 2 \\ 3 & 3 & 3 \\ 4 & 4 & 4 \\ 5 & 5 & 5 \\ 6 & 6 & 6 \\ 7 & 7 & 7 \\ 8 & 8 & 8 \\ 9 & 9 & 9\end{array}$

Q46. How many children age 18 and younger live in this household most of the time (including child who is the subject of this survey)? children 18 and younger 


\section{Appendix B. Physical Activity Self-Efficacy Tool}

Please put a check by "Yes" or "No" for each of the following sentences. "Yes" means that you agree with the sentence. "No" means that you do not agree with the sentence. Remember that physical activity can be any play, game, sport, or exercise that gets you moving and breathing harder. There are no wrong answers.

1. I think that I can ask my parent or other adult to sign me up for a sport, dance, or other physical activity.

Yes No

2. I think I can ask my parent or other adult to take me to a physical activity or sport practice.

Yes No

3. I think I can ask my best friend to be physically active with me.

Yes No

4. I think I can ask my parents or other adult to do physically active things with me.

Yes No

5. I think I can ask my parent or other adult to get me the equipment I need to be physically active.

Yes No

6. I think I have the skills I need to be physically active.

Yes

No

7. I think I can be physically active most days after school.

Yes No

8. I think I can be physically active no matter how busy my day is.

Yes No

9. I think I can be physically active no matter how tired I may feel.

Yes No

10. I think I can be physically active even if it is hot or cold outside.

Yes No

11. I think I can be physically active, even if I have a lot of homework.

Yes No 
12. I think I can be physically active after school even if I could watch TV or play video games instead.

Yes No

13. I think I can be physically active even if I have to stay at home.

Yes No

14. I think I can be physically active even when I'd rather be doing something else.

Yes No

15. I think I can be physically active even if my friends don't want me to.

Yes No

16. I think I can be physically active after school even if my friends want me to do something else.

Yes

No

17. I think I can be physically active everyday for the next 12 weeks.

Yes No 


\section{Appendix C. Institutional Review Board Approval Letter}

\section{THE UNIVERSITY OF TENNESSEE}

Health Science Center

June 26, $2007 \quad, \quad \begin{array}{r}\text { Institutional Review Board } \\ 910 \text { Madison Avenue, Suite } 600 \\ \text { Memphis, TN } 38163 \\ \text { Tel: (901) } 448-4824\end{array}$
Dana Manley, MSN
c/o Patricia Cowan, Ph.D.
College of Nursing
Department of Nursing
920 Madison
Suite $507 N$
UTHSC
CAMPUS
RE: "Increasing Physical Activity in Middle School Students: A. Pedometer Study" [IRB 48700$]$
Dear Ms. Manley,

We are in receipt of your correspondence dated June 26,2007 in response our correspondence dated June $26_{\text {, }}$ 2007 concerning the above referenced Institutional Review Board Project.

The Administrative Section of the UTHSC Institutional Review Board (IRB) deternined your application to be consistent with the guidelines for expedited review under categories (5) and (7). Therefore, this application was approved in this regard as complying with proper consideration of the rights and welfare of human subjects, the risk involved, and the potential benefits of the study. This letter constitutes full approval of your application; invitation to informational meeting and phone script and consent form, stamped approved by the UTHSC IRB June 26, 2007 for the above referenced study. This project was approved for 12 months with an expiration date of June 25, 2008. The consent form dated June 26, 2007 is also approved from the date of this letter through June 25, 2008.

The IRB has also determined that the informed consent form, incorporating the authorization of subjects to use their protected health information in research, comply with the federal privacy regulations as specified in 45 CFR160 and 45 CFR 164

In the event that subjects are to be recruited using solicitation materials, such as brochures, posters, webbased advertisements, etc., these materials must receive prior approval of the IRB. Any revisions in the approved application must also be submitted to and approved by the IRB prior to implementation. In addition, you are responsible for reporting any unanticipated serious adverse events or other problems involving risks to subjects or others in the manner required by the local IRB policy.

Finally, re-approval of your project is required by the IRB in accord with the conditions specified above. You may not continue the research study beyond the time or other limits specified unless you obtain prior written approval of the IRB.

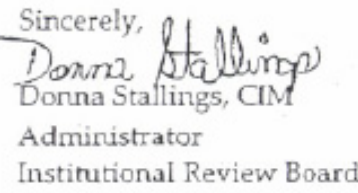

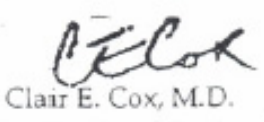

Institutional Review Board 


\title{
Appendix D. Informed Consent Form
}

\author{
Increasing Pbysical Activity in Middle School Students: A Pedometer Project
}

\author{
INFORMED CONSENT F,ORM
}

\author{
Principal Investigator: Dana Manley, MSN, ARNP \\ 920 Madison Avenue, Suite $507 \mathrm{~N}$ \\ Memphis, TN 38103 \\ 24-hour phone \# (270) 809-6225 \\ Collaborating Investigators: Patricia Cowan, $\mathrm{PhD}$, Carolyn Graff, $\mathrm{PhD}$, \\ Phyllis Richey, $\mathrm{PhD}$, and Zoila Sanchez, $\mathrm{PhD}$
}

\section{INTRODUCTION:}

Youlyour child,

(Please Print Child's Full Name) a student at

are being given the opportunity to participate in a research study to do

effectiveness of a developmentally appropriate, health related, physical activity program for middle school students. The study is being conducted by a graduate student in the College of Graduate Health Sciences at the University of Tennessee Health Science Center with the permission of the South Marshall and Benton Middle Schools administration.

\section{PROCEDURES TO BE FOLLOWED:}

Your child, along with all the students participating in the study, will engage in the physical activity program, led by his/her physical education teacher, during their regular school day throughout the school year. You hereby conseat to and authorized the University of Tennessee research personnel to assist your child's Physical Education teacher with the measurement of his/her height and weight, fitness test, and self-efficacy leveis. Your child will be asked to wear a pedometer for a one-week period with the number of steps being recorded on four separate occasions during the school year. This information will then be shared with the University's research personnel. You will be asked to complete an assessment of your attitudes regarding physical activity at the beginning and end of the study. Students in one of the schools (the school will be chosen by the flip of a coin) will wear a pedometer daily as a motivational tool to increase their physical activity. They will have an additional 10 minutes of physical activity each day, while wearing the pedometer, during the regularly scheduled school break time daily.

\section{RISKS ASSOCIATED WITH PARTICIPATION:}

The measurements and physical activity your child will participate in have no associated risks other than those normally associated with his/her participation in a regular sehool plysical education class. However, you will be informed if the study provides any new information that may affect your desire for your child to participate, so that you may decide whether or not to continue your child in the study.

\section{BENEFITS ASSOCIATED WITH PARTICIPATION:}

The information gathered by your child's participation in this program will help determine if the pbysical activity program improves the physical activity and physical fimess levels of the cbildren in the participating schools. The information will also help to develop strategies to be used in the prevention of childhood and adult obesity.

\section{ALTERNATIVES TO PARTICIPATION:}

You/your child will not have to undergo these procedures if they do not participate in the study.

IRB APPROVAL DATE 6-26. U2EXPIRATION DATE $6 \cdot 2.5 \cdot 08$

IRB \# 8700 APPROVED $\mathrm{BV}:$ ISf

Page 1 of 3 Subject or Parent/Legally Authorized Representative Initials 
Increasing Physical Activity in Middle-Sctool Students

Principal Investigator: Dana Manley

\section{CONFIDENTIALITY:}

Your child will not be personally identified in any presentation or publication based on the results of this study. Your child's individual information will be labeled with a code number. A master key that links your child's name and code number will be maintained in a separate and secure location. All individual data collectet on yout child will remain confidential and be available only to your child's Physical Education teacher, who nomally collects this information as part of his/her regular physical education class, and to the University of Tennessee investigators running the study

Under federal pnvacy regulations, you have the right to determine who has access to your personal health information (called "protected health information" or PHI). PHI collected in this study may include your child's height and weight, a physical fitness test score (one mile walk test score), number of daily steps using a pedometer, a self-efficacy score (questionnaire asking you child about their feelings about physical activity), as well as basic demographic information. By signing this consent form, you are authorizing the researchers at the University of Tennessee to have access to your PHI collected in this study. The Institutional Review Board (IRB) at the University of Tennessee Health Science Center may review your child's PHI as part of its responsibility to protect the rights and welfare of research subjects. Your child's PHI will not be used or disclosed to any other person or entity, except as required by law, or for authorized oversight of this research study by other regulatory agencies, or for other research for which the use anj disclosure of your child's PHI has been approved by the IRB. Your child's PHI will be used only for the research purposes described in the Introduction of this consent form. Your child's PHI will be used until the study is completed.

You may cancel this authorization in writing at any time by contacting the principal investigator listed on the first page of the consent form. If you cancel the authorization, continued use of your PHI is permitted if it was obtained before the cancellation and its use is necessary in completing the research However, PHI collected after your cancellation may not be used in the study. If you refuse to provide this authorization, you will not be able to participate in the research study. If you cancel the authorization, then you will be withdrawn from the study. Finally, the federal regulations allow you to obtain access to your child's PHl collected or used in this study.

\section{COMPENSATION AND TREATMENT FOR INJURY:}

I understand that I am not waiving any legal rights or releasing the University of Tennessee or its agents from liability for negligence. I understand that, in the event of physical injury resulting from research procedures, the University of Tennessee does not have funds budgeted for compensation either for lost wages or for medical treatment. Therefore, the University of Tennessee does not provide for treatment or reimbursement for such injuries. I or my insurance carrier will be billed for the costs associated with the medical treatment of a research related injury.

\section{QUESTIONS:}

If you have any questions regarding the study, the tests and measurements, or any discomfort or injury that may appear to be related to the physical activity, you may contact Dana Manley, MSN, ARNP at (270) 809-6225 or Patricia Cowan, Ph.D., R.N. at (901) 448-3318. If you have any questions about your rights as a participant in this study or your rights as a research subject, you may contact Dr. Terrence Ackerman, UTHSC IRB Chairman at (901) 448-4824.

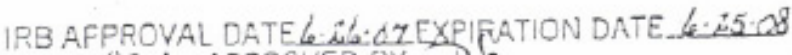

IRB $=$ STO0 APPROVED BY:Dh

Page 2 of 3

Version Date: 6/27/07
Subject or Parent/Legally Authorized Representative Initials 
Increasiug Physical Activity in Middle-School Students

Principal Investigator: Dana Manley

PAYMENT FOR PARTICIPATION:

You or your child will not receive payment for participating in this study.

COSTS OF PARTICIPATION:

You or your child will incur no costs for participating in this study.

\section{VOLUNTARY PARTICIPATION:}

You freely volunteer your child to participate in the study. You understand that your child does not have to take part in this study and that your refusal to participate will involve no penalty of loss of rights to which your child is entitled. You further understand that you are free to later withdraw your consent and discontinue your child in this study at any time. You understand that refusing to participate or later withdrawing from the stidy will not adversely affect your child's participation in any school programs to which he/she is entilled.

\section{CONSENT OF SUBJECT:}

1 have read or have had read to me the description of the research study as outlined above. The investigator has explained the study to me and has answered all of the questions I have at this time. I have been told of the potential risks and discomforts of the physical activity as well as possible benefits of the study.

I freely volunteer to participate in the study. I understand that I do not have to take part in this study and that my refusal to participate will involve no penalty or loss of rights to which I am entitled. I further understand that I am free to later withdraw my consent and discontinue participation in this study at any time. I understand that refusing to participate or later withdrawing from the study will not adversely affect my subsequent medical care. I understand that I will receive a copy of the consent form for my records.

Printed Name of Research Subject

Printed Name of Parent or Legally Authorized Representative Signature
Signature of Research Subject

Signature of Parent or Legally Authorized Representative $\overline{\text { Date }}$

Date

Relationship of Legally Authorized Representative

Printed Name of Person

Obtaining Consent

Printed Name of Witness

$\overline{\text { Printed Name of Principal Investigator }}$

Assent of Minor
Signature of Person Obtaining Consent

Signature of Witness

Signature of Principal Investigator
Date

Date

Date
Page 3 of 3

Version Date: 6/27/07

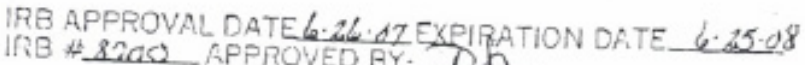

Date 


\section{VITA}

Dana Manley was born in 1969. After graduating from Crittenden County High School in Marion, Kentucky, she attended Murray State University in Murray, Kentucky and graduated with a BSN and MSN. As an advanced practice nurse, she worked in public health. In August 2001, she began teaching at Murray State University in the Nursing Program. During her career, she has been involved in several health promotion programs including a pedometer physical activity program and smoking cessation program. In 2005, she was accepted to The University of Tennessee Health Science Center-Memphis, Tennessee in order to pursue a PhD in Nursing. Her research advisor was Dr. Patricia Cowan. She has served as mentor through this dissertation process and has provided knowledge and expertise in completion of this adventure. 